\title{
SLEEP, EXERCISE, AND INSULIN SENSITIVITY
}

\author{
A Dissertation \\ presented to \\ the faculty of the Graduate School \\ at the University of Missouri - Columbia
}

In Partial Fulfillment

of the Requirements for the Degree

Doctor of Philosophy

\author{
by \\ JAY W. PORTER \\ Dr. Jill A. Kanaley, Dissertation Advisor \\ MAY 2020
}


The undersigned, appointed by the Dean of the Graduate School, have examined the dissertation entitled

\section{SLEEP, EXERCISE, AND INSULIN SENSITIVITY}

Presented by Jay W. Porter

a candidate for the degree of doctor of philosophy, and herby certify that, in their opinion, it is worthy of acceptance

Professor Jill A. Kanaley

Associate Professor Victoria J. Vieira-Potter

Professor Elizabeth J. Parks

Doctor of Medicine Guido Lastra-Gonzalez

Professor Christina McCrae 


\section{ACKNOWLEDGEMENTS}

I would like to thank Dr. Jill Kanaley for her guidance and support during my doctoral training at the University of Missouri. I have acquired a great deal of knowledge and skills working with Dr. Kanaley which has allowed me to pursue a career in science. I am thankful for Dr. Vieira-Potter for allowing me to learn laboratory skills and guidance for publishing my first first-author project while Dr. Kanaley was serving as a Jefferson Fellow during my first year at the University of Missouri. I thank my dissertation committee (Dr. Vieira-Potter, Dr. Parks, Dr. Lastra, and Dr. McCrae) for providing important feedback and critical thinking skills throughout my training. I also thank the fellow graduate students (Nathan Winn, Ryan Pettit-Mee, Jill Barnas, Travis Emerson), and lab technicians (Ying Liu, Rebecca Welly) for help with various aspects of my dissertation. Most importantly, I thank my family for their love and support throughout this journey. 


\section{TABLE OF CONTENTS}

ACKNOWLEDGEMENTS $\ldots \ldots \ldots \ldots \ldots \ldots \ldots \ldots \ldots \ldots \ldots$ ii

LIST OF FIGURES $\ldots \ldots \ldots \ldots \ldots \ldots \ldots \ldots \ldots \ldots \ldots \ldots \ldots \ldots$

LIST OF TABLES $\ldots \ldots \ldots \ldots \ldots \ldots \ldots \ldots \ldots \ldots \ldots \ldots \ldots$

ABBREVIATIONS ........................ vi

ABSTRACT $\ldots \ldots \ldots \ldots \ldots \ldots \ldots \ldots \ldots \ldots \ldots \ldots \ldots \ldots \ldots$ viii

CHAPTER:

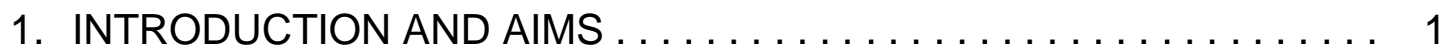

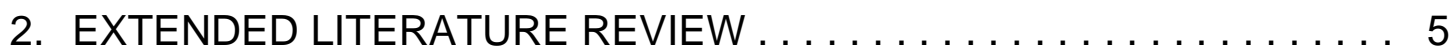

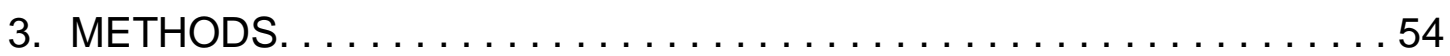

4. RESULTS . . . . . . . . . . . . . . . . . . . . . 64

5. DISCUSSION, LIMITATIONS, AND FUTURE DIRECTIONS . . . . . . 85

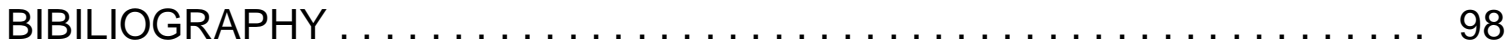

APPENDIX:

i. INFORMED CONSENT AND STUDY MATERIALS . . . . . . . . . . 115

ii. CURRICULUM VITAE . . . . . . . . . . . . . . . . . . . . . . 128

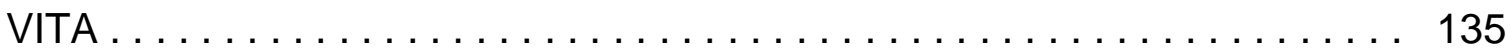




\section{LIST OF FIGURES}

\section{CHAPTER ONE}

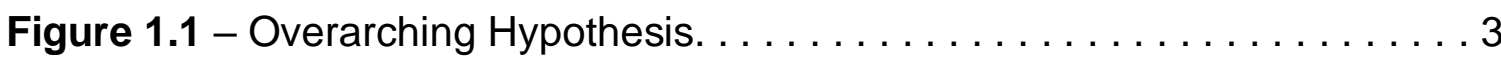

\section{CHAPTER THREE}

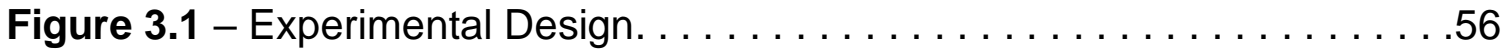

\section{CHAPTER FOUR}

Figure 4.1 - Effects of sleep restriction on glucose and insulin with and without exercise. ............................ 72

Figure 4.2 - Effects of sleep restriction on physical activity with and without

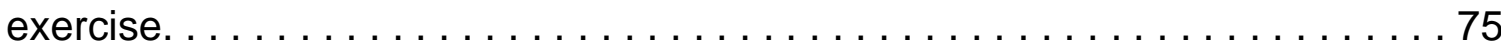

Figure 4.3 - Effects of sleep restriction on NEFA and adipose tissue insulin resistance with and without exercise $\ldots \ldots \ldots \ldots \ldots \ldots \ldots \ldots \ldots \ldots$ Figure 4.4 - Adipose tissue adrenergic stimulation after sleep restriction with and

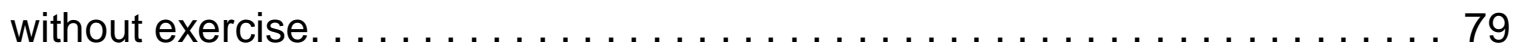

\section{CHAPTER FIVE}

Figure 5.1 - Ex vivo adipose tissue insulin stimulation curves. . . . . . . . . .95 


\section{LIST OF TABLES}

CHAPTER TWO

Table 2.1 - Sleep restriction and glucose metabolism . . . . . . . . . 24

Table 2.2 - Sleep restriction, physical activity, and glucose metabolism. . . . . . 52

CHAPTER FOUR

Table 4.1 - Baseline Characteristics . . . . . . . . . . . . . . . . . 65

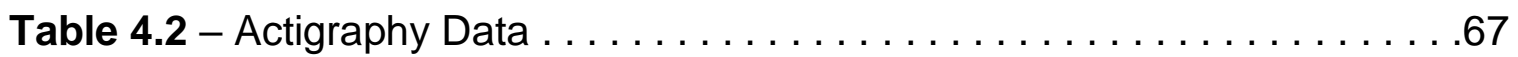

Table 4.3 - Energy Metabolism . . . . . . . . . . . . . . . . . 71

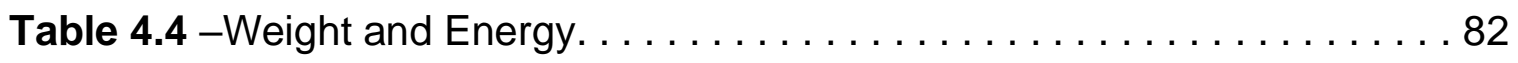

Table 4.5 - Stress and Cognitive Function ..................... 84 


\section{LIST OF ABBREVIATIONS}

Adipo-IR: Adipose tissue insulin resistance

Akt: Protein kinase B

AUC: Area under the curve

BMI: Body mass index

DASS: Depression anxiety stress scale

DLW: Doubly labeled water

DXA: Dual x-ray absorptiometry

ESS: Epworth sleepiness scale

FAS: Fatty acid synthase

GIP: Gastric inhibitory polypeptide

GLP-1: Glucagon like peptide-1

GLUT4: Glucose transporter type 4

HIIT: High-intensity interval training

HOMA-IR: Homeostatic Model Assessment of Insulin Resistance

HSL: Hormone sensitive lipase

IL: Interleukin

ISO: Isoproterenol

IVGTT: Intravenous glucose tolerance test

LTPA: Light physical activity

MEQ: Morningness - eveningness questionnaire

MMT: Mixed meal tolerance test

MVPA: Moderate-vigorous physical activity 
NEFA: Non-esterified fatty acids

NREM: Non-rapid eye movement

N1-4: NREM stages 1-4

OGTT: Oral glucose tolerance test

PSQI: Pittsburgh sleep quality index

REM: Rapid eye movement

RER: Respiratory exchange ratio

SCN: Suprachiasmatic nucleus

SR: Sleep restriction

$S R \pm E X$ : Sleep restriction with or without exercise

SREX: Sleep restriction + exercise

SWS: Slow-wave sleep

T2D: Type 2 Diabetes

TNFa: Tumor necrosis factor alpha

VOrmax: Maximal peak oxygen consumption

WASO: Wake after sleep onset 


\section{ABSTRACT}

Accumulating evidence supports short sleep duration as a novel risk factor for obesity and diabetes, but little work has been done outside of healthy men or with consideration to changes in physical activity. Thirteen overweight and obese adults were sleep restricted for five nights with a six-hour sleep opportunity each night, followed by a two-day recovery period. Sleep restriction had no impact on glucose tolerance in response to a mixed meal test despite an increased peak glucose response $(+7.3 \mathrm{mg} / \mathrm{dL})$ and elevated non-esterified free fatty acid concentration (NEFA, $+0.1 \mathrm{mmol} / \mathrm{L})$. Sleep restriction did not modify step counts or physical activity intensities. Recovery period restored glucose responses, NEFA concentrations, and improved homeostatic model assessment of insulin resistance (HOMA-IR), despite increased sedentary time and reduced step counts. Daily exercise increased step counts $(+4,700$ steps/day, $p<0.001)$, decreased sedentary time $(-2.6 \%, \mathrm{p}=0.02)$, and increased moderate-vigorous physical activity $(+3.7 \%, p<0.001)$. Exercise reduced the insulin response to a meal but was not effective at preventing the increased peak glucose response or elevated NEFA. Adipose tissue samples, obtained after baseline, sleep restriction, and exercise $(\mathrm{N}=8)$, showed no increase in lipolytic capacity following sleep restriction. Protein content of fatty acid synthase tended to increase following sleep restriction $(p=0.07)$, but not following exercise. Sleep restriction did not adversely affect glucose tolerance, but increased circulating NEFA are seen with no changes in adipose tissue lipolytic capacity. Recovery sleep showed a powerful effect of sleep on glucose metabolism. 


\section{CHAPTER 1 - SPECIFIC AIMS}

Over the past few decades, increases in the prevalence of obesity and insulin resistance have paralleled lifestyle changes such as insufficient sleep. Approximately $33-45 \%$ of American adults do not obtain the recommendation of seven to nine hours of sleep per night, and approximately $40 \%$ of adults choose to sleep longer on weekends to "catch up" for the shorter weekday sleep schedules (1-4). Sleep restriction strongly associates with systemic insulin resistance, and therefore obese and overweight adults may be particularly susceptible to its adverse effects (5-9). Interestingly, two days of "catch up" sleep normalizes insulin sensitivity in healthy men after five days of restricted sleep $(10,11)$. Despite extensive work in healthy adults, how reducing sleep duration during a workweek and a "catch up" weekend impacts glucose tolerance in overweight and obese adults is not well known. Assessment of glucose tolerance in overweight and obese adults who restrict sleep in a free-living setting provides clinically relevant insight into the metabolic consequences of short sleep duration in a population that has an increased risk for metabolic diseases.

While extending sleep opportunities has been shown to minimize the metabolic effects of sleep loss, the mechanisms by which sleep restriction induces insulin resistance are unclear. Elevated circulating non-esterified fatty acid (NEFA) concentrations seen in sleep-restricted adults suggests that disrupted adipose tissue insulin sensitivity may be a potential mechanism of sleep-restriction mediated insulin resistance (12-14). Indeed, one study in healthy adults showed a $30 \%$ reduction in adipose tissue insulin signaling 
capacity after five days of sleep restriction (15), and another study in healthy males showed a blunting of skeletal muscle insulin signaling after two days of sleep restriction (16). These limited findings suggest that NEFA released from adipose tissue inhibits insulin signaling. Additionally, physical activity is an extensively vetted strategy to mitigate insulin resistance and is known to induce adaptations in skeletal muscle and adipose tissue (17-19). Studies of at-home sleep restriction have yielded varying observations of free-living physical activity, from increased activity (20) to decreased activity (7). Healthy males that were sedentary or exercise-trained before or during a single night of sleep restriction/deprivation exhibited protection against sleep restriction-induced reduction in insulin sensitivity (21), blunted glycemic responses to glucose (22), and reduced fasting NEFA concentrations (22). Further, exercise is an effective strategy to improve adipose tissue insulin signaling and may confer functional benefits to overweight and obese adults who sleep restrict.

This study aimed to assess the effects of a modest workweek sleep restriction on glucose tolerance, physical activity, and adipose tissue of overweight and obese men and women. The overarching hypothesis (Figure 1.1) was that sleep restriction decreases physical activity, resulting in decreased glucose tolerance and adipose tissue insulin sensitivity. Additionally, regular exercise would ameliorate the detrimental impact of sleep restriction. 


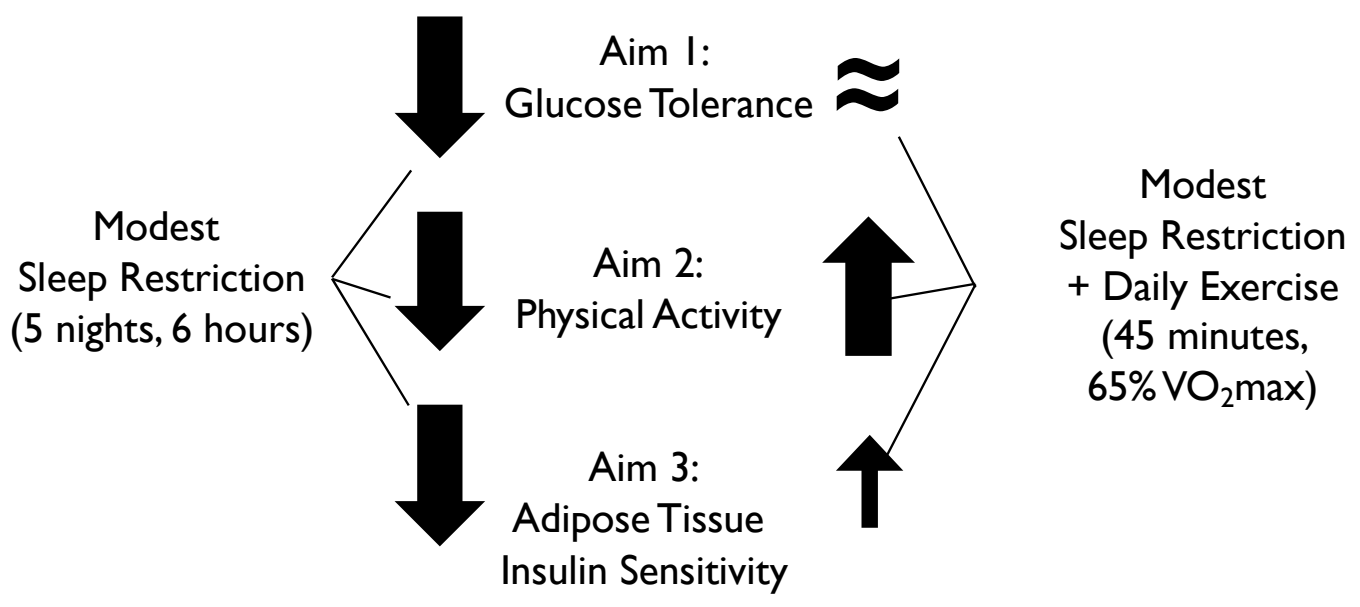

Figure 1.1. Overarching Hypothesis.

The following specific aims were addressed:

Aim 1: To determine 1) if six hours of sleep for five nights in overweight and obese adults, who typically achieve seven to nine hours per night, impairs glucose tolerance; 2) if two days of unrestricted sleep opportunity improves glucose tolerance following five days of restricted sleep; 3 ) if five days of moderate-intensity exercise ( $\left.65 \% \mathrm{VO}_{2} \mathrm{max}\right)$, throughout five days of restricted sleep, protects against decrements in glucose tolerance seen with sleep restriction alone.

Hypothesis: Restricting sleep during the workweek adversely affects glucose tolerance; however, a two-day, unrestricted sleep opportunity restores glucose tolerance. Regular exercise during sleep restriction attenuates the decrements in glucose tolerance and improves the restorative effects of recovery sleep on glucose tolerance. 
Aim 2: To determine 1) if overweight and obese adults increase sedentary time throughout the day when sleep is restricted to six hours in bed for five days; 2 ) if physical activity is affected during the weekend recovery following restricted sleep; 3) if regular moderate-intensity exercise during the restricted sleep workweek decreases the time spent sedentary.

Hypothesis: Reducing sleep duration during a workweek increases the sedentary time and reduces steps taken per day. Regular exercise prevents increases in sedentary time when sleep is restricted.

Aim 3: To determine 1) if restricted sleep causes adipose tissue insulin resistance, assessed via circulating NEFA and ex vivo tissue stimulation with insulin and beta-adrenergic agonist; 2) if regular moderate-intensity exercise will counteract the decrements in sleep restriction induced adipose tissue insulin sensitivity.

Hypothesis: Sleep restriction reduces adipose tissue insulin sensitivity as seen through increases in circulating NEFA, reduction of insulin signaling within adipose tissue, and increases in lipolysis when stimulated. Regular exercise ameliorates decrements in adipose tissue insulin sensitivity. 


\section{CHAPTER 2 - EXTENDED LITERATURE REVIEW}

\section{INTRODUCTION}

Obesity is a complex disease that is associated with increased mortality risks, and unfortunately, rates have steadily increased despite interventions aimed to prevent and remediate the disease. The etiology of obesity is generally accepted to be due to a chronic positive energy balance, resulting in excess energy stored primarily as fat (23). Management of obesity involves comprehensive lifestyle modifications, including dietary changes, physical activity, and, most recently, proper sleep habits. Sleep loss effects on hormones that regulate blood glucose is a critical link to increased risk of obesity $(3,24)$. Interestingly, mechanisms of blood glucose regulation overlap during sleep loss and exercise, in opposite manners, suggesting exercise may be a therapeutic strategy to mitigate the negative consequences of curtailed sleep. This literature review will detail the metabolic effects of restricted hours of sleep and the metabolic similarities to that of physical inactivity, along with the scarcity of research on the relationship of sleep and physical activity.

\section{PART 1 - SLEEP}

Traditional public health interventions have focused on lifestyle changes in physical activity, diet quality, tobacco use, and alcohol intake (25). Recently, the demands of modern $24 / 7$ society have contributed to a lifestyle of insufficient sleep in both adults and adolescents. Like physical inactivity, insufficient sleep is 
associated with numerous health disorders; in particular, a relationship between shortened sleep and the development of cardiovascular disease and other metabolic disorders.

The American National Sleep Foundation recommends that adults sleep 7-9 hours each night for optimal health, with even longer hours appropriate for younger age groups (4). Despite these recommended hours, sleep curtailment is a common practice. The Center for Disease Control's data indicate that one in three Americans report sleeping six or fewer hours per night. Other research suggests that nearly half of middle-aged adults obtain less than six hours of sleep per night $(1,2)$. The increased prevalence of reduced hours of sleep in adults has occurred in conjunction with an increase in obesity rates, suggesting poor sleep habits contributing to the risk of obesity and also possibly vice versa (3).

\section{SLEEP ARCHITECTURE}

Sleep is categorized by two major phases, rapid eye movement (REM) and non-REM (NREM). These two periods continuously cycle throughout sleep and complete four to six cycles per night with extended REM periods and shortened NREM periods as the sleep period progresses (26). NREM periods can be distinguished by four stages, starting with a brief stage one (N1) and progression to stage four (N4), and then subsequent progression to REM sleep.

Stage $\mathrm{N} 1$ is the transition from wake to sleep cycling, where awake is distinguished as a greater than $50 \%$ alpha wave and N1 as low-voltage, mixed- 
frequency waves (27). This stage encompasses a small percentage of sleep and is easily disrupted back to wake, and lasts for one to seven minutes. Stage N2 is the most common stage of sleep, and the cycle duration lengthens with each successive cycle, comprising $45-55 \%$ of total sleep. Low-voltage, mixedfrequency waves are again observed along with the presence of K-complexes (long delta waves), which are thought to be necessary for memory consolidation (28). The last stages of NREM, N3 and N4, are not easy to distinguish between and are indicated by high-voltage, slow-wave activity (>20\% delta waves) and together are referred to as slow-wave sleep (SWS). During this SWS sleep, deep sleep occurs and is the most restorative of the sleep stages (3). During SWS, heart rate slows, blood pressure drops, sympathetic nervous activity is reduced, and a variety of hormones are released (29). Aging decreases the time spent in SWS, and some metabolic consequences are a result of reduced SWS (30).

Following slow-wave sleep, the REM stage presents desynchronized brain wave activity (predominantly theta waves) and bursts of rapid eye movements $(27,31)$. As cycles of NREM and REM progress, REM duration increases from one to five minutes during the first cycle to up to an hour in the final cycle (32). Dreaming is most often associated with REM sleep.

Alterations in the typical architecture, such as sleep deprivation, fragmentation, or restriction, result in circadian misalignment. This misalignment alters neuroendocrine physiology and potentiates adverse health outcomes such as obesity and diabetes $(33,34)$. 


\section{CIRCADIAN RHYTHMS}

Circadian systems are becoming increasingly well documented for their fundamental importance in mammalian physiology and involvement in hormonal secretion, temperature regulation, and molecular regulation of gene transcription and translation (35). The suprachiasmatic nucleus (SCN) located within the hypothalamus is commonly referred to as the "master clock," where neurons determine the period of an organism's circadian rhythm (36). Cell-autonomous circadian oscillators are also found in peripheral tissues/cells, including skeletal myocytes, hepatocytes, adipocytes, and pancreatic islet cell subtypes (37). The circadian clock is composed of a transcription-translation feedback loop with transcription factors CLOCK and BMAL1, along with repressor genes that encode period (PER 1,2) and cryptochrome (CRY 1,2) proteins. Secondary regulators, Rev-erb $\alpha / \beta$ and $\mathrm{ROR} \alpha / \beta$, ensure molecular stability through transcriptional repression and activation of BMAL1. CLOCK-BMAL1 heterodimer activates transcription of target genes via DNA binding to conserved promoter regions, E-box, where up to $20 \%$ of the genome display some form of regulatory oversight by the circadian clock (38). Clock-controlled genes are involved in the regulation of cellular metabolism, both centrally at the SCN through light entrainment and within peripheral tissues through hormonal and nutritional influence (39).

Skeletal muscle, a key glucoregulatory tissue, contains a robust circadian clock. CLOCK-BMAL1 regulation within the skeletal muscle is involved with glucose transporter type 4 (GLUT4) expression and translocation, glucose 
uptake and oxidation, glycogen deposition, mitochondrial oxidative capacity, and protein and lipid metabolism (35). Animal models have shown that musclespecific BMAL1 knock-out reduces skeletal muscle mass, function, and mitochondrial density with reduced GLUT4 expression (40). Knock-out mice have a more significant reliance on lipid utilization and storage than glucose, recapitulating the phenotypical changes observed in skeletal muscle throughout the development of type 2 diabetes (T2D) $(40,41)$. Disrupted circadian rhythms also attenuated expression and enzymatic activity of hexokinase and pyruvate dehydrogenase (35). With muscle accounting for $80 \%$ of insulin-mediated glucose clearance, such dramatic changes with disruptions in circadian biology strongly suggest that skeletal muscle physiology is a critical player in the link of sleep deprivation and whole-body metabolic consequences.

Hepatocellular circadian rhythm is highly involved with glucose metabolism via gluconeogenic enzymes, glucose uptake and storage, and lipid oxidation and storage $(35,36)$. Studies of the SCN and liver-specific circadian rhythm have shown that disruptions can result in high blood glucose concentrations in both fasting and postprandial states $(42,43)$. Local rhythms seem to be influenced in clock-dependent and clock-independent (nutrient influenced) manners of determining diurnal oscillations. Work by Lamia et al. has shown that liver-specific deletion of BMAL1 resulted in dysregulated levels of circulating glucose and overall glucose intolerance (44). These liver-specific disruptions also disrupt peroxisome proliferator-activated receptor $\alpha$ (PPAR $\alpha$ ), a transcription factor that regulates genes critical for lipid metabolism (45). 
Additionally, Zhang et al. (46) have shown that expression of CRY1 inhibits activation of gluconeogenic enzymes through binding and inhibition of the glucagon receptor; whereas, genetic overexpression of CRY1 attenuated gluconeogenesis and lowered glycemia in diabetic mice. Collectively, liverspecific disruptions in circadian rhythms recapitulate hepatic pathology in T2D and are capable of disrupting whole-body glucose homeostasis, fatty acid metabolism, and insulin sensitivity.

Although skeletal muscle and liver primarily control glucose homeostasis, adipose tissue is also known for energy homeostasis and endocrine function. Circadian clocks have been shown to impact adipose tissue metabolic pathways such as lipolysis, adipogenesis, and inflammation (35). Adipocyte-specific BMAL1 knock-out animals develop obesity with elevated plasma concentrations of polyunsaturated fatty acids and reduced neurotransmitters responsible for appetite regulation (47). Whole-body PER1/2 genetic disrupted animals exhibit increases in the inflammatory status of adipose tissue via increased M1 macrophage polarization (pro-inflammatory), potentially contributing to disrupted insulin signaling within adipose tissue (48). Circadian clock dysregulation in both adipocytes and adipose tissue macrophages is a critical process in the development of inflammation and dyslipidemia, which are known disrupters of metabolic health.

Maintenance of blood glucose concentrations is highly dependent on the function of the pancreas, specifically the $\alpha$ and $\beta$-cells of the islets, where glucagon and insulin are secreted in response to energy availability. Marcheva 
et al. (49) have reported that pancreatic islets have a circadian clock that regulates insulin secretion. Disruptions in BMAL1 within the islets decreased insulin secretion by $60 \%$, while disruption in CLOCK reduced the size of islets by $20 \%$, with trends toward decreased total pancreatic insulin content.

Circadian clock proteins control energy homeostasis by regulating energy availability and utilization through a coordinated effort between the SCN and peripheral tissues. Disruptions of these circadian proteins contribute to obesity and metabolic disorders and can be induced genetically in animal models but also through disrupted sleep in humans.

\section{SLEEP MONITORING}

The development of methods to monitor sleep has been critically important to establish public health recommendations for proper sleep habits as it is now appreciated that sleep is a modifiable lifestyle factor alongside diet and exercise. Early studies frequently relied on self-reported hours of sleep, not always differentiating time asleep from time in bed (50). Data obtained from polysomnography, a recording of the biophysiological changes that occur during sleep, are utilized in many sleep investigations but are costly and timeconsuming, therefore not considered feasible to study large populations. Wristworn technologies have escalated over recent years and are allowing a less cumbersome and objective measurement of sleep. Wrist-worn actigraphy provides a reliable and valid measure of sleep duration and quality, recording movements in three directions with the capacity to capture multiple days of data 
(51-53). Opportunities to monitor sleeping behaviors less objectively outside of the laboratory setting are critical to research aimed to improve public health recommendations.

Several sleep questionnaires have been developed over the last few decades in an attempt to obtain a subjective assessment of an individual's sleep patterns and quality. The Pittsburgh Sleep Quality Index (PSQI) is a well-known and accepted questionnaire developed in 1989 to measure sleep quality in a variety of patient groups (54). Other questionnaires, such as the Sleep Quality Questionnaire (55), Medical Outcomes Study Sleep Scale (55), Epworth Sleepiness Scale (56), and Stanford Sleepiness Scale (57), are self-reported assessments of sleep and are moderately correlated with objectively measured sleeping patterns. These questionnaires are amenable to large scale surveys in that they are inexpensive and easily administered to relevant populations. Consequently, they rely on subjective measurements of sleep.

Polysomnography is considered the gold standard diagnostic reference tool for several sleep disorders where recordings from four channels (electroencephalography, electromyography, and two electro-oculography) define sleep stages (58). The use of electroencephalography (EEG), eye movement, muscle activity, heart physiology, and respiratory function provide a comprehensive assessment of sleep-wake states (53). Hans Berger was the first to publish with EEG, where a string galvanometer recorded brain waves on a light-sensitive plate and monitor alpha rhythms that disappear at the onset of sleep (59). The distinctions of REM and NREM sleep were later recognized and 
facilitated the development of sleep stages for universal terminology. The difficulties in practicality and cost of the laboratory-based polysomnography have led to the development of other objective measures to evaluate sleep.

Wrist-based actigraphy is currently the most appropriate alternative to polysomnography as it has been the most widely used and validated for nonlaboratory measures of sleep $(58,60)$. Marino et al. $(53)$ validated the actigraphy for detecting sleep and wakefulness against the polysomnography through simultaneous data collection in a variety of subject populations and settings and found participant-specific accuracy to be above $80 \%$. Algorithms calculate sleep/wake cycles based on limb movement activity with thresholds to estimate sleep and wakefulness with epochs above the threshold during sleep periods classified as "awake" $(58,61-63)$. Actigraphy provides estimates of sleep latency, total sleep time, wake after sleep onset, and sleep efficiency (total sleep time/time in bed), but does not provide sleep architecture or respiratory function that polysomnography measures. One limitation of actigraphy is the possibility of overestimating sleep time and underestimating wake time (64). This limitation is due to the differences in monitoring the onset of sleep where polysomnography assesses the changes in brain electrical activity; whereas, actigraphy assesses the lack of movement to indicate the onset of sleep (53). This difference allows for quiet wakefulness to be counted as sleep with actigraphy, but the differences are generally deemed minimal when used in conjunction with a sleep diary as corrections can be made to account for discrepancies between actigraphy and diary $(63,65,66)$. The use of a wrist-based monitor is advantageous to that of 
polysomnography because it is simple, noninvasive, unobtrusive, and can monitor activity for weeks without inconvenience to participants. The combination of actigraphy and sleep diaries allows for long-term monitoring of patterns in sleep/wake behavior in a home setting and is a useful research tool when information on stages of sleep are not necessary.

\section{SLEEP RESTRICTION AND METABOLIC HEALTH}

Circadian physiology regulates numerous biological functions throughout central and peripheral tissues. Deviations from normal rhythmicity are becoming increasingly more common in society as rhythms are altered by artificial light and feeding schedules, occurring at all hours of the day. This circadian misalignment results in metabolic dysfunction and is strongly associated with the pathophysiological development of obesity, T2D, and other cardiometabolic diseases. Sleep loss is now thought to be as influential as diet and physical inactivity in terms of relative contribution to the risk of developing T2D (67).

\section{Insulin Sensitivity}

The chronic curtailment of sleep is a common choice amongst adults as the average sleep duration for Americans has fallen by more than an hour per night over the last few decades (68). Shortened sleep is now associated with an increased risk of diabetes, and the mechanisms for this association are still under scrutiny as inconsistencies in glucose metabolism and insulin sensitivity are prevalent in the literature. 
Van Cauter and colleagues (6) were one of the first groups to report the regulation of glucose and insulin secretion throughout various times of the day/night and wake/sleep periods. They demonstrated through continuous glucose infusion that eight hours of sleep followed by 28 hours of continuous wake resulted in a $17 \%$ increase in glucose levels and a $49 \%$ rise in insulin secretion. These marked increases in glucose levels and insulin secretion reached a maximum at a time similar to that of the regular night of sleep and then returned to normal levels during daytime hours. The abrupt delay of bedtime by 12 hours demonstrated that glucose and insulin concentrations are negatively affected by sleep loss, possibly contributing to metabolic risks.

In addition to continuous wakefulness displaying similar characteristics as insulin resistance, Spiegel et al. (69) showed a similar effect with six nights of shortened sleep. Healthy adults were restricted to four hours of sleep opportunity per night to investigate the implications on insulin sensitivity. Using an intravenous glucose tolerance test (IVGTT), the accumulation of a sleep debt decreased the rate of glucose clearance by $40 \%$ with the acute insulin response to glucose being $\sim 30 \%$ lower. While insulin sensitivity was not different, these data demonstrated a possible mechanism for sleep restriction being associated with diabetes.

Extending the work of Spiegel and colleagues, Buxton et al. (70) utilized a similar sleep restriction protocol, where healthy men restricted sleep to five hours per night for seven nights. Here, IVGTT derived insulin sensitivity decreased by $20 \%$, contradicting that of Spiegel. Further, utilizing a euglycemic- 
hyperinsulinemic clamp on the same subjects, they demonstrated again that insulin sensitivity was decreased by $11 \%$. Likewise, others (11) report that IVGTT tests showed that four nights of 4.5 hours of sleep decreased insulin sensitivity by $23 \%$ and disposition index by $16 \%$ with no change in the acute insulin response during IVGTT.

While 4.5-5 hours of sleep per night for several days disrupts the normal axis of insulin-stimulated glucose uptake, Wang et al. (71) sought to determine if a less severe protocol would impact insulin sensitivity as well. Following three days of six hours of sleep, healthy young men had no change in fasting glucose levels, while fasting insulin concentrations and insulin area under the curve $(A U C)$ in response to an oral glucose tolerance test (OGTT) were elevated by $20 \%$. Three indexes of insulin resistance/sensitivity (homeostatic model assessment of insulin resistance (HOMA-IR), Matsuda, and QUICKI) were negatively impacted after three days, highlighting the profound effect of sleep loss on insulin sensitivity when sleep is curtailed for multiple days.

Further, Sweeney et al. (16) investigated the effects of acute sleep restriction (four-hour sleep opportunities on two nights) on insulin sensitivity. Healthy young males were allowed to sleep at home during the intervention, whereas the previous studies confined the subjects to laboratory settings. Here, fasting levels of insulin and glucose were not negatively affected by reduced sleep. However, in response to an OGTT, insulin responses were elevated and the Matsuda index of insulin sensitivity was significantly decreased by $19 \%$. 
To further explore the minimum nights of reduced sleep time needed to influence insulin sensitivity, Donga et al. (13) investigated a single night of four hours of sleep opportunity. Fasting concentrations of glucose, insulin, and endogenous glucose production were not negatively affected by sleep loss in healthy men, but during a hyperinsulinemic clamp, endogenous glucose production was increased $(P=0.017)$ and glucose disposal rate was notably diminished $(P<0.001)$. Thus, a single night of shortened sleep modifies hepatic insulin resistance.

While the majority of studies demonstrate insulin resistance, Spiegel (69) and others (72) have reported a lack of changes in insulin sensitivity. Healthy men undergoing five nights of four hours of sleep have been reported to have no change in HOMA-IR (72). Despite no changes in insulin resistance, fasting glucose and insulin concentrations were significantly elevated $(p<0.001)$, and glucose responses to meals throughout the day were also elevated. These changes were suggestive of decrements in peripheral insulin sensitivity. Despite some studies not directly observing decrements in insulin sensitivity, disturbances in glucose metabolism were present and provide evidence for an underlying mechanism to the associated risks between sleep restriction and metabolic complications.

The hormones that modulate glucose metabolism are regulated cyclically by circadian systems $(6,73)$. Clock disrupted animals are obesity-prone (74), providing evidence that the time and way in which sleep is disrupted may affect the development and progression of metabolic diseases. Recently, Wilms et al. 
(75) examined the timing of sleep loss on glucose homeostasis. Fifteen healthy males were studied with modifications in the time of sleep loss, either four hours of sleep occurring during the first or second half of their typical eight hours per night. They corroborate that a single night of four hours of sleep is sufficient to reduce insulin sensitivity $(P=0.031)$. Interestingly, this decrement was independent of timing in which sleep loss occurred. Despite compromised insulin sensitivity irrespective of the time in which sleep loss occurred, some hormonal discrepancies between the timing of sleep loss were present. When sleep was lost in the second half of the night (early awakening), reduced fasting glucagon levels were observed. This data supports the previous work by the same group that showed four and a half hours of sleep occurring in the first half of the night (76) and total sleep deprivation (77) reduced fasting glucagon levels at $\sim 0800$ hours. However, other work from this group (14) and other researchers (13) contrasted these data in healthy men where no changes in glucagon concentrations occurred after one and two nights of four hours of sleep, respectively, or reported elevated glucagon after three nights of six hours of sleep (71).

While studies have shown impairments in whole-body glucose metabolism with sleep restriction, mechanisms responsible for these derangements are still not well developed. Work from many studies employing OGTT, IVGTT, and clamps do not conclusively indicate that hepatic insulin resistance is solely responsible for these metabolic disruptions and tends to indicate that peripheral tissue insulin sensitivity is susceptible to restricted sleep opportunities. Although 
peripheral tissues, such as adipose tissue and skeletal muscle, are involved in glucose homeostasis with sleep restriction, they have been scarcely investigated.

\section{Adipose Tissue Insulin Sensitivity}

Insulin resistance in adipose tissue is characterized by an increase in lipolysis due to a lack of inhibition from insulin signaling within the adipocyte, increasing NEFA released into circulation when energy demands are not present (78). One of the first studies (13) demonstrating that an acute sleep restriction (one night of four hours of sleep) induces insulin resistance also found that glucose disposal rate was decreased by $20 \%(P=0.009)$. Additionally, circulating NEFA concentrations were elevated by $19 \%(P=0.005)$ during a clamp, indicating adipose tissue insulin resistance.

Subsequent work by Schmid et al. (14) investigated the glucoregulatory response to breakfast food intake in healthy men after two days of four hours of sleep. Following sleep restriction, pre-breakfast glucose and insulin concentrations were unchanged, but in response to a meal, insulin and glucose peak responses were elevated $(P<0.02)$. Additionally, fasting NEFA concentrations were elevated after sleep restriction, potentially disrupting insulin sensitivity during the breakfast meal.

While an acute period of sleep restriction is suggested to alter lipid metabolism and insulin sensitivity, work by Ness et al. $(10,79)$ further investigated the implications on insulin sensitivity and lipemic responses with an IVGTT. Healthy men, consuming a control diet or high-fat diet throughout five nights with five hours of sleep, were shown to have decreased whole-body 
insulin sensitivity $(P=0.003)$ independent of diet. The high-fat diet, in combination with sleep restriction, elevated postprandial insulin concentrations but not glucose concentrations, while the opposite was observed for the control diet. Further, fasting NEFA levels were not disturbed by either diet or sleep restriction, but a suppressed NEFA response and increased triglyceride clearance were observed when a high-fat diet was consumed during sleep restriction.

Further work by Broussard et al. (15) investigated how adipose tissue insulin signaling responded to sleep restriction. Healthy young adults undergoing four nights of four and a half hours of sleep had abdominal subcutaneous adipose tissue biopsies taken after sleep restriction. Samples were measured for insulin signaling through phosphorylation of protein kinase B (Akt), where sleep restriction reduced adipose tissue insulin signaling by $30 \%(P=0.01)$. This decrement in insulin sensitivity in adipocytes is similar to that observed between obese and lean individuals (80) and also between diabetic and nondiabetic individuals (81). Further, these same subjects showed increased circulating NEFA concentrations with sleep restriction (12). A strong correlation between decrements in insulin sensitivity and increases in nocturnal NEFA concentrations was observed, implying that sleep restriction reduced adipose tissue insulin sensitivity, affecting fatty acid metabolism and possibly contributing to systemic insulin resistance.

Adipose tissue insulin sensitivity has been shown to express intrinsic circadian rhythm in insulin sensitivity (82). In healthy males, subcutaneous adipose tissue insulin sensitivity peaks around noon and reaches a nadir around 
midnight, with a $54 \%$ difference between the two times of the day. Interestingly, this circadian rhythm of insulin sensitivity was not observed in visceral adipose tissue. Other work (83) has investigated the morning to evening difference in white adipose tissue transcriptome in healthy men. Under a normal sleep condition (four-hour sleep condition) and a total sleep deprivation condition, adipose tissue clock gene rhythms remained stable, but the pathways of carbohydrate metabolism were highly sensitive to sleep loss. Genes associated with carbohydrate catabolism lost rhythmicity after sleep deprivation, being primarily upregulated in the morning. Genes regulating lipolysis and betaoxidation were largely unaffected by sleep curtailment. Additionally, insulin secretion was decreased after total sleep deprivation, as seen through circulating insulin and c-peptide levels. These data suggest that carbohydrate oxidation is enhanced after sleep loss.

While adipose tissue insulin sensitivity is impaired after sleep restriction, the potential for other insulin-sensitive peripheral tissue, such as skeletal muscle, are also likely to be adversely affected. Sweeney et al. (16) investigated the effects of sleep restriction (two nights with four hours of sleep) in ten healthy males on Akt phosphorylation within skeletal muscle. During their control condition at 30- and 120-minute post glucose ingestion, a 2.7-fold and 1.9-fold increase in Akt activity were noted, whereas, during the sleep restriction condition, only a 1.5-fold and 1.4-fold increase in Akt activity were observed. While not significant, this reduced propensity to phosphorylate Akt and blunt insulin action within muscle parallel that seen in adipose tissue (15). Elevated 
levels of NEFAs from adipose tissue during sleep restriction may be a critical link between chronic metabolic consequences with sleep deprivation since elevated circulating levels of NEFAs are known to decrease skeletal muscle glucose uptake (84). A recent study by Saner et al. (85) sleep-restricted healthy men for five nights with four hours of sleep, and investigated muscle protein synthesis and degradation. Participants undergoing sleep restriction did not report any differences in the protein content of p-AKTsER473. Unfortunately, no metabolic data was provided concerning insulin sensitivity. To date, no other studies have explicitly investigated skeletal muscle insulin sensitivity with regard to sleep restriction.

While a single day and even modest sleep restriction influence insulin sensitivity negatively $(13,70)$, little work has been conducted to minimize these negative consequences. Since diet-based interventions are common to ameliorate metabolic risks, Nedeltcheva and colleagues $(86,87)$ investigated a hypocaloric diet throughout 14 days of five and a half hours of sleep to ameliorate insulin resistance. Overweight men and women were prescribed a dietary restriction of $90 \%$ of caloric needs based on resting metabolic rate and allowed either eight and a half or five and a half hours of sleep. Interestingly, sleep restriction with caloric deficit reduced fasting glucose $(-2 \mathrm{mg} / \mathrm{dL})$ and insulin $(-2 \mathrm{mU} / \mathrm{dL})$ concentrations $(\mathrm{P}<0.05)$. While there was not a condition with a maintenance diet, the caloric deficit was effective at mitigating decrements in oral glucose tolerance that is frequently shown in healthy adults. Interestingly, during an IVGTT the following day, estimates of insulin resistance were higher in sleep- 
restricted dieters, but the data was inconclusive as insulin secretion rates changed during testing and did not allow for the assessment of non-insulinmediated glucose disposal. Fasting NEFA concentrations were elevated with sleep restriction, but substrate utilization favored carbohydrate oxidation rather than fatty acid oxidation. Restricted caloric intake induced weight loss $(\sim 1$ body mass index (BMI) units) but sleep curtailment decreased the amount of weight lost as fat by $55 \%(1.4 \mathrm{vs} .0 .9 \mathrm{~kg})$ and increased the amount of weight lost as fatfree body mass by $60 \%$ ( $1.5 \mathrm{vs} .2 .4 \mathrm{~kg}$ ). Discrepancies in the composition of weight loss imply that short sleep may compromise the effectiveness of dietary interventions to reduce fat mass.

Severe and modest sleep restriction in healthy males has been frequently shown to disrupt insulin sensitivity and glucose metabolism, Table 2.1. Unfortunately, overweight and obese adults, who represent the majority of western culture, have only been studied once, albeit only under dietary restriction. Future work needs to address how insulin sensitivity changes in overweight and obese adults when sleep is restricted. 
Table. 2.1. Sleep restriction and glucose metabolism.

\begin{tabular}{|c|c|c|c|c|}
\hline $\begin{array}{l}\text { First Author } \\
\text { (Ref.) }\end{array}$ & Subjects & Sleep Protocol & Technique & Result \\
\hline Van Cauter (6) & 8 Healthy men & 28 hours TSD & $\begin{array}{l}\text { Continuous } \\
\text { blood draw }\end{array}$ & Glucose $+17 \%$, Insulin secretion $+49 \%$ \\
\hline Spiegel (69) & 11 Healthy men & 6 night, 4 hours & IVGTT & $\begin{array}{l}\text { Glucose clearance }-40 \% \text {, acute insulin response - } \\
30 \% \text {, insulin sensitivity } \Leftrightarrow\end{array}$ \\
\hline Buxton (70) & 20 Healthy men & 7 night, 5 hours & IVGTT; Clamp & Insulin sensitivity $-20 \%$; insulin sensitivity $-11 \%$ \\
\hline Broussard $(11,12)$ & 19 Healthy men & $\begin{array}{l}4 \text { night, } 4.5 \\
\text { hours }\end{array}$ & IVGTT & $\begin{array}{l}\text { Insulin sensitivity }-23 \% \text {, disposition index }-16 \% \text {, } \\
\text { acute insulin response } \Leftrightarrow, \text { NEFA }+30 \%\end{array}$ \\
\hline Wang (71) & 15 Healthy men & 3 night, 6 hours & OGTT & $\begin{array}{l}\text { Insulin AUC +20\%, HOMA-IR +22\%, QUICKI -5\%, } \\
\text { Matsuda }-20 \%\end{array}$ \\
\hline Sweeney (16) & 10 Healthy men & 2 night, 4 hours & OGTT & Insulin AUC +14\%, Matsuda $-19 \%$ \\
\hline Donga (13) & $\begin{array}{l}9 \text { Healthy adults } \\
(5 \mathrm{M}, 4 \mathrm{~F})\end{array}$ & 1 night, 4 hours & Clamp & $\begin{array}{l}\text { Endogenous glucose production }+22 \% \text {, glucose } \\
\text { disposal rate }-20 \% \text {, NEFA }+19 \%\end{array}$ \\
\hline Reynolds (72) & 14 Healthy men & 5 night, 4 hours & Breakfast & Glucose $+11.4 \%$, insulin $+28.8 \%$, HOMA-IR $\Leftrightarrow$ \\
\hline Wilms (75) & 15 Healthy men & 1 night, 4 hours & IVGTT, Clamp & Insulin sensitivity $-12.5-15 \%$ (early vs late-night loss) \\
\hline Schmid (14) & 15 Healthy men & 2 night, 4 hours & Breakfast & $\begin{array}{l}\text { peak insulin }+40 \% \text {, insulin AUC }+52 \% \text {, peak glucose } \\
\text { response }+11 \% \text {, glucose AUC }+7.4 \%\end{array}$ \\
\hline Nedeltcheva (86) & $\begin{array}{l}10 \text { Overweight } \\
\text { adults }(7 \mathrm{M}, 3 \mathrm{~F})\end{array}$ & $\begin{array}{l}14 \text { night, } 5.5 \\
\text { hours }\end{array}$ & IVGTT & $\begin{array}{l}\text { Fasting glucose }-2 \mathrm{mg} / \mathrm{dL} \text {, fasting insulin }-2 \mathrm{mU} / \mathrm{dL} \text {, } \\
\text { NEFA }+58 \% \text {, disposition index }-23 \%\end{array}$ \\
\hline Rao (88) & $\begin{array}{l}14 \text { Healthy } \\
\text { adults }(8 \mathrm{M}, 6 \mathrm{~F})\end{array}$ & 5 night, 4 hours & OGTT; Clamp & $\begin{array}{l}\text { Increased NEFA +62\%, insulin AUC +20\%; insulin } \\
\text { sensitivity }-25 \% \text {, peripheral insulin sensitivity }-29 \% \text {, }\end{array}$ \\
\hline Ness (10) & 15 Healthy men & 5 night, 5 hours & IVGTT & $\begin{array}{l}\text { Insulin sensitivity }-38 \% \text {, fasting insulin } \Leftrightarrow \text {, fasting } \\
\text { glucose } \Leftrightarrow\end{array}$ \\
\hline
\end{tabular}

Details of studies investigating glucose metabolism with subject population, sleep protocol, investigative techniques, and results. TSD, total sleep deprivation, IVGTT, intravenous glucose tolerance test; Clamp, hyperinsulinemic-euglycemic clamp; OGTT, oral glucose tolerance test; QUICKI, quantitative insulin sensitivity index) M, males; F, females; $\Leftrightarrow$, no change. 


\section{Inflammation}

Inflammatory mechanisms contribute to the risk of many medical conditions and are predictive of cardiovascular events, hypertension, weight gain, and T2D (89). Early work (1970s) by Palmblad showed that sleep deprivation enhances the ability of leukocytes to produce interferon (90). More recent research has investigated total and partial sleep loss on cytokines, such as tumor necrosis factor-alpha (TNF $\alpha)$ and interleukin 6 (IL-6) $(91,92)$. Despite the associations between inflammation and metabolic disease, research has yet to outline a consistent story of how sleep loss affects immune responses.

Traditionally IL-6 is known for its pro-inflammatory profile, mediating the acute phase response, but recently IL-6 has also been shown to have a diurnal rhythm with peak values during sleep and nadir values during wakefulness (93). Vgontzas et al. (94) reported that total sleep deprivation of healthy young males for one day changed the temporal pattern of circadian IL-6 secretion the next day, with elevated daytime secretion, reduced nighttime secretion, but no change in total secretion. Subsequently, they investigated a modest sleep restriction protocol with six hours of sleep for seven nights and observed that twenty-fourhour IL-6 secretion was elevated with the modest sleep restriction, similar to the total sleep deprivation (95).

While a modest sleep restriction period elevated IL-6 secretion, Redwine et al. (96) investigated the acute response to sleep restriction with a single night of four hours of sleep. Healthy men that delayed sleep till the early morning had a delayed and blunted increase in circulating IL-6 levels. Additionally, after sleep 
restriction, there was a negative correlation between IL-6 release and slow-wave sleep, consistent with previous reports (94). These data suggest that the amount and depth of sleep impact the nocturnal secretion of IL-6 and may be necessary for the metabolically beneficial aspects of sleep.

Like IL-6, TNF $\alpha$ is an acute phase response cytokine, involved in activating many inflammatory cellular pathways mediating inflammation, apoptosis, neuroprotection/neurotoxicity, appetite, and sleep (97). TNF $\alpha$ is a potent inhibitor of the insulin signaling cascade through disruptions in the tyrosine phosphorylation on the beta chain of the insulin receptor substrate-1, strongly suggesting that elevated circulating TNF $\alpha$ concentrations contribute to the progression of systemic insulin resistance $(98,99)$. TNF $\alpha$ also disrupts the circadian rhythm within the liver and sleep homeostasis through inhibition of clock genes by interfering with CLOCK-BMAL1 induced activation of E-box regulatory elements (100). Mice lacking the receptors for TNF $\alpha$ have shown attenuated NREM and longer REM stages of sleep (101). Other work (102) has shown that exogenous administration of TNF $\alpha$ induced increases in NREM sleep and decreases in REM sleep, demonstrating a clear impact on sleep architecture. Indeed, healthy men who were sleep-deprived for 34 hours had elevated circulating TNF $\alpha$ (103). A more modest sleep restriction investigated by Vgontzas (95) elevated TNF $\alpha$ secretion in men but not women. In contrast, others $(104,105)$ have shown that healthy men undergoing partial sleep deprivation (four days of four-hour fragmented sleep) and total sleep deprivation had no changes in circulatory TNF $\alpha$ levels. Inconsistencies in TNF $\alpha$ responses 
to partial and total sleep deprivation highlight the complexity of immune responses under stressful conditions but may be a mechanistic link between sleep and glucose metabolism.

\section{Appetite Regulation}

Short sleep duration is a novel risk factor for weight gain and obesity due to the alterations in hormonal signaling. Rodent models have shown that total sleep deprivation leads to a hyperphagic response with similar evidence emerging in human sleep research $(20,106-108)$. The drive to eat is positively influenced by the hormone ghrelin and negatively by insulin and leptin $(109,110)$. Disruptions in these hormonal signals that balance hunger and energy balance may be one of the critical internal regulatory components linking sleep curtailment and obesity.

Hunger has been shown to have a robust circadian rhythm, independent of wakefulness/sleep cycle with the highest subjective hunger during the evening hours and least hungry in the early mornings, coinciding with levels of ghrelin

(111, 112). Additionally, a population-based longitudinal study of sleep disorders (113) found that shorter sleep time was negatively associated with ghrelin levels. During a night of total sleep deprivation, Hogenkamp et al. (106) found that men chose larger portion sizes, reported increased hunger rating, ate more snacks, and had elevated levels of fasting plasma ghrelin. Other experimental evidence in healthy men during a night of total sleep deprivation found neural activation 
correlated positively with subjective appetite ratings, indicating that sleep loss increased the drive to consume more food (114).

While a single night of total sleep deprivation increased hunger and ghrelin levels, Schmid et al. (115) investigated the difference between total sleep loss and a night of four and a half hours of sleep on ghrelin and hunger levels. Total and partial sleep loss resulted in elevated fasting levels of ghrelin, but hunger was markedly elevated with total sleep deprivation. Extending from a single night of sleep restriction, research investigating two nights of four hours of sleep further showed that circulating ghrelin concentrations were elevated, and that hunger ratings were also increased, and appetite for calorie-dense, highcarbohydrate foods were more common (116).

Similar to ghrelin, leptin also has a diurnal rhythm with the lowest concentrations in the early morning, but the highest concentrations of leptin occur during sleep at night $(33,117)$. A population-based longitudinal study of sleep disorders has observed that self-reported sleep duration was positively associated with levels of leptin (113). While obesity is linked with high leptin levels, sleep restriction data is inconclusive but likely to contribute to the risks of obesity.

Under a circadian misalignment protocol, healthy men were placed in either a 24.0 or 24.6 hours of wakefulness-sleep schedule to monitor circadian changes in leptin concentrations (33). Circadian misalignment reduced the circulating leptin concentrations. These data corroborate Scheer and colleague's 
report that leptin levels were reduced when rapid changes in environmental time were induced, such as flying four time zones westward each day (34).

In an extreme model of disrupted sleep, healthy men were deprived of sleep for 88 hours to investigate the effects on the diurnal rhythm of circulating leptin concentrations (118). Leptin amplitude was rapidly reduced during the sustained wake period and remained low throughout the deprivation. Interestingly, the amplitude was reversed during the first night of sleep. Thus, sleep may play an important role in the control of the nocturnal rise of leptin and balance of the drive to eat.

In a less extreme model of sleep restriction, Schmid et al. (115) investigated the difference between a single night of total sleep loss and a night of four and a half hours of sleep. Healthy males did not experience any changes in fasting concentrations of leptin in either condition. In contrast, other studies $(116,119)$ have demonstrated that sleep restriction over two and six nights with four hours of sleep reduced fasting leptin levels, maximal levels, and rhythm amplitude in 24-hour leptin profiles.

While data of total sleep loss show reductions in leptin, Reynolds et al. (72) investigated healthy men under strict dietary control during five nights of four hours of sleep. Leptin levels across the day were elevated by $13.7 \%(P=0.001)$. The authors suggested that under adequate dietary intake, leptin increases were likely due to adequate caloric intake and a sedentary lifestyle in the subjects while in the laboratory. Further, the authors noted that a reduction in leptin levels 
is likely due to caloric restriction during sleep loss rather than disruption of leptin metabolism.

Collectively, circadian misalignment and sleep loss significantly affect hunger and satiety, although not in a consistent manner. Increased awake time and subtle changes in hormonal regulation of appetite may promote increased food intake but are not solely responsible for the relationship between reduced sleep and obesity.

\section{Energy Expenditure}

Energy expenditure is lower following the onset of sleep and during the scheduled sleep period compared to wakefulness (120-122). The energy cost of staying awake for extended periods was reported by Jung et al. (122), where eight hours of nighttime sleep was compared to total sleep deprivation (40 hours) in seven healthy men. Here, 24-hour energy expenditure was increased by approximately $7 \%$ ( 135 kcals) during sleep deprivation as compared to 8 hours of sleep. Similarly, Markwald et al. (123) investigated the energy costs of prolonged wake time by utilizing five days of five hours of sleep restriction rather than total sleep deprivation. Healthy men were kept in a whole room calorimeter and were found to have increased total daily energy expenditure by $\sim 5 \%(\sim 111$ kcals). Notably, food intake was also increased as the food was readily available to these participants while sleep was curtailed. The increase in food intake was primarily consumed after dinner and accounted for nearly a kilogram of increased weight over the five days. 
While a modest increase in daily expenditure has been shown with added wakeful hours, Nedeltcheva et al. (124) utilized deuterated water to monitor changes in energy expenditure over 14 days. Healthy adults slept five and a half hours per night with ad libitum food access throughout the study. Energy expenditure and resting metabolic rates were not altered with this modest sleep restriction over an extended period, but increased total energy intake due to snacks and a higher percentage of carbohydrates were recorded. Both variables were predictive of weight gain during the 14 days of the study. Similarly, other studies in healthy adults utilizing deuterated water over five nights of four hours of sleep found no changes in resting metabolic rate or energy expenditure (125). Energy intake was increased again in this shorter duration ( 300 kcals/day) but was related to calories from fat rather than carbohydrates.

Minimal changes in energy expenditure are present with curtailed sleep. These slight increases in caloric needs are often thought to be exceeded by the consumption of late-night snacks, contributing to the relationship between reduced sleep time and obesity.

\section{“CATCH UP” SLEEP}

Despite many Americans not obtaining adequate sleep throughout a workweek, it is commonly believed that compensatory sleep during non-work days allows for "catch up" by extending sleep opportunities. The National Sleep Foundation has reported that approximately $40 \%$ of adults sleep longer on weekends to "catch up" for the shorter weekday sleep schedule (4). The extent 
and veracity of the prospect of weekend catch up has not been clearly elucidated.

While some studies suggest that catch up sleep may provide some health benefits, population-based studies report conflicting assessments. A populationbased study by Im et al. (126) suggested that sleep extension improves sleeprestriction induced issues such as obesity. Korean adults who utilized catch up sleep had a dose-dependent relationship with BMI, where every additional hour of weekend sleep was associated with a decrease of $0.12 \mathrm{~kg} / \mathrm{m} 2$ in BMI. Additional work in children from Asian countries has demonstrated that weekend or holiday sleep extension is associated with lower risks of being overweight, also in a dose-dependent manner, particularly with children who slept fewer hours during weekdays (127).

Since the majority of sleep studies restrict hours from healthy adults obtaining adequate hours of sleep, Killick et al. (128) investigated healthy men who chronically experience lifestyle-driven sleep restriction (six hours sleep per night) and also regularly use the weekend to "catch-up" on sleep. They reported that three nights of catch up sleep effectively improved insulin sensitivity in men who were chronically sleep restricted. Similarly, Leproult et al. (129) examined how adding an hour of sleep for six weeks influenced insulin sensitivity in chronically sleep-restricted men. Fasting levels of glucose and insulin did not change with added sleep, but a positive correlation was observed between extending sleep time and indices of insulin sensitivity. Additionally, work by Eckel et al. (130) reported conflicting data between the use of OGTT and IVGTT 
measurements during recovery sleep periods. While three days of nine hours of sleep was effective at restoring oral glucose tolerance, two additional nights of nine hours of sleep opportunity did not improve IVGTT insulin sensitivity. These data reveal that a better understanding of the time course for recovery from insufficient sleep is needed and what physiological factors are mediating the differences in oral and intravenous measures of glucose tolerance.

A weekend "catch up" model was investigated by Ness et al. $(10,79)$ in which one and two recovery nights, respectively, (10 hours of sleep) were used to establish if the weekend period was capable of restoring the adverse effects of five nights of five hours of sleep with and without a high-fat meal. Under normal dietary control and a single night of recovery sleep, insulin sensitivity and disposition index were not recovered despite improvements in the glucose response. During the OGTT, NEFA responses were normalized after a single recovery night. When sleep restriction was accompanied by a high-fat meal test, fasting insulin concentrations and responses were elevated and then normalized with two nights of recovery sleep; glucose was not different throughout the study. Fatty acid concentrations during a high-fat meal test following sleep restriction were suppressed and not recovered after two nights of recovery.

Using an IVGTT, Broussard et al. (11) also investigated a weekend catch up period where sleep was restricted for four days with four and a half hours of sleep and followed up with two consecutive nights with 12 and 10 hours of sleep, respectively. Recovery sleep was effective in restoring insulin sensitivity 
$(P=0.02)$ and the disposition index $(P=0.03)$ and effectively reduced the risks of diabetes imposed by sleep restriction.

While weekend "catch up" data on insulin sensitivity is exciting as an effective strategy to workweek sleep loss, recent work by Depner et al. (8) reported that a weekend recovery period did not protect against recurrent sleep restriction the following weekdays. In this study, sleep was restricted for five nights of five hours of sleep, two days of weekend recovery (ad libitum), and then two days of insufficient sleep. During recurrent insufficient sleep following the weekend recovery, the circadian phase was delayed, and whole-body, hepatic, and muscle insulin sensitivity were decreased $\sim 9-27 \%$. These data suggest that weekend recovery sleep is not an effective strategy to prevent metabolic dysregulation associated with recurrent insufficient sleep. The studies investigating the capacity of recovery periods after sleep restriction are limited; future research needs to explore the impact of workweek patterns on insulin sensitivity.

\section{STRESS AND COGNITIVE FUNCTION}

Research on the impact of sleep loss has strongly suggested that there is a broad impact on cognitive abilities. While the effects of sleep loss on cognitive abilities can be challenging to quantify and compare, there have been several objective testing methods developed (131). Currently, the "gold standard" for measuring sleepiness in both the clinical and research settings is the multiple sleep latency test where the time from lights off to the time of sleep onset is 
measured by polysomnography (132). Unfortunately, polysomnography is cumbersome and complex and does not address cognitive function.

Alternative objective measures of executive functions such as taskswitching, provides insight into the vulnerabilities of mental processes that enable planning, attention, memory, and task switching, when sleep is curtailed (133135). Performance on task-switching sessions was tested in a large scale trial of college students who either skipped a night of sleep or slept normally (133). Sleep-deprived students had a higher proportion of errors and reduced performance speed compared to students with a normal night of sleep. Students were less capable of adjusting behavior rapidly or flexibly to the changing environment, suggesting practical implications when shifts between different cognitive tasks are needed following sleep loss. However, total sleep deprivation is not necessarily comparable to a single night of partial sleep loss. Ballesio et al. (136) compared insomnia patients against university students who were good sleepers but only allowed five hours of sleep. Interestingly, task-switching improved in partially sleep-deprived university students compared to students who experience insomnia that had no change in task-switching ability.

The Stroop task is generally regarded as an executive function test due to the use of inhibition of response, activating the dorsolateral prefrontal cortex and anterior cingulate cortex $(137,138)$. To establish the effect of 40 hours of being awake, Cain et al. (137) had participants perform Stroop tasks every two hours. Performance degraded as a function of time awake such that after 14-16 hours of awake time, reaction time and error rates increased $(P<0.001)$ over the next 10 - 
12 hours, then stabilized after 24 hours and slightly rebounded between 28-36 hours awake. Interestingly, the difference between congruent and incongruent tasks was not different. In contrast, Tassi et al. (139) reported that 17 male undergraduate students who were partial sleep deprivation (two hours of total sleep) displayed a distinct time course to performance. During the first half-hour of being awake, the subjects' reaction time was high but progressively decreased after 30 minutes, which coincided with an increase in percent error.

Working memory, a component of executive function, is commonly tested via N-Back testing, where responses are paired to previous stimuli. Healthy young males, who self-reported sleep duration of six to eight hours, were found to have a positive correlation in total sleep time with correctly recalling stimuli (140). These data suggest that even within the recommended sleep duration, longer sleep time has a positive influence on working memory.

Inconsistencies in various tasks to evaluate executive function is prevalent within total and partial sleep deprivation protocols. Inadequate sleep and sleep disturbance can negatively impact mood and perceived stress, potentially adversely impacting performance (141). Interestingly, perceived stress has not been evaluated by the many investigations reporting impaired glucose metabolism. Cross-sectional data have shown that perceived psychological stress is positively associated with the prevalence of T2D (142). Prospective work should include the stress associated with sleep loss to understand if the severity of sleep loss affects glucose metabolism in a dependent or independent manner. 


\section{PART 2 - PHYSICAL ACTIVITY}

Increased physical activity and exercise training are common lifestyle interventions to combat obesity as they are inversely related to the consequences of obesity. Improvements in cardiorespiratory fitness, muscular strength and endurance, and body composition have the potential to influence various aspects of health (143). Decreased physical activity in occupational and leisure settings increases the risk for the development of obesity rates.

Unfortunately, over the last few decades, physical activity levels have substantially decreased despite the wealth of knowledge to support a physically active lifestyle (144-146). The physical activity guidelines for adults have been recommended as (147):

- Moderate-intensity cardiorespiratory exercise training $\geq 30$ minutes/day, greater than five days/week, totaling 150-300 minutes/week

- Or, vigorous-intensity cardiorespiratory exercise training $\geq 20$ minutes/day, greater than three days/week, totaling 75-150 minutes/week

- Preferably, aerobic activity should be spread throughout the week

- Moderate or higher intensity muscle-strengthening activities

- involve all major muscle groups: Legs, hips, back, chest, abdomen, shoulders, and arms.

- Two or more days a week 
These physical activity recommendations are known to improve fitness over time and lower the risk of all-cause and cardiovascular disease-related mortality and morbidity $(143,148)$. Increases in the minimum exercise volume are recommended to maximize health benefits (146).

\section{PHYSICAL ACTIVITY MONITORS}

The estimation of energy expenditure is of extreme importance when monitoring physical activity and implementing public health policies. Advances in technology since the 1980s (149) have accelerated the capacity of wearable devices to provide detailed, objective, and continuous measurements of physical activity. With the rapid expansion of activity monitors available, a consensus and understanding of what is being measured and translated are critical to the proper characterization of physical activity.

Early approaches to energy expenditure were assessed through a diarybased approach, seven-day recall, and questionnaires. These strategies to monitor habitual physical activity levels for research are limited by reporting errors $(150,151)$, and likely fail to represent sedentary behavior and light intensity physical activities, which typically comprise the majority of the day (152, 153). Studies also show significant variations in the measurement of physical activity and sedentary time when comparing self-report and objective measures, with more substantial differences seen with higher volume and intensity (154).

The difficulty in accurately measuring energy expenditure is due to the complex nature of physical activity, so the gold standard for estimation remains 
with the use of doubly labeled water (DLW), $2 \mathrm{H}_{218} \mathrm{O}_{2}(155,156)$. The use of heavy hydrogen $(2 \mathrm{H})$ and heavy oxygen $(18 \mathrm{O})$ allows the monitoring of the isotope fractionization and elimination to determine metabolic demand. This analysis allows for accurate measures of energy expenditure in daily life for extended periods. The use of DLW is costly and labor-intensive, thus other methods to predict energy expenditure have been developed. Accelerometry is one method that has received considerable attention.

Accelerometry based monitors for physical activity have been widely used for energy expenditure via algorithms shown to provide excellent reliability and validity with indirect calorimetry and DLW. Many of these validations require a minimum of 10 hours per day of wear time and use activity counts per minute for cut-points of sedentary, light, moderate, and vigorous activity (157-159). Discrepancies exist between the placement of these monitors, which can be worn at the wrist, hip, and ankle (160-162). Some reports (163) suggest greater accuracy with wrist-worn Actigraph devices as opposed to hip placement, but hip-worn monitors are generally accepted to provide the most accurate assessment of normal ambulation (164-168). The discrepancies between placement and devices used for monitoring must continue to improve in consistency to provide insight into healthy lifestyle recommendations accurately. 


\section{PHYSICAL INACTIVITY}

Epidemiological studies have found that sedentary behaviors are strongly related to the risks of obesity, T2D, hypertension, cardiovascular disease, cancer, and ultimately, mortality rates $(169,170)$. Approximately $80 \%$ of adults do not meet the physical activity recommendation, with only $26 \%$ of men and $19 \%$ of women meeting the recommendations $(147,171)$. While the terms physically inactive (insufficient physical activity) and sedentary (sitting or reclining) are different (172), both have similar potential influences on the risk of disease development (173).

\section{Physical Activity and Insulin Sensitivity}

In an extreme model of inactivity, bedrest studies were initially used to report the adverse effects of sedentary time on insulin sensitivity (174). Despite these studies eliciting adverse metabolic effects, more recent work has been focused on reduced physical activity rather than the total elimination of ambulatory activity. Olsen et al. (175) examined the effects of reducing steps from non-exercising men from 6203 steps/day to 1394 steps/day. An OGTT revealed a 53\% increase in insulin response after one week of reduced steps, increased $61 \%$ after two weeks, and increased $79 \%$ after three weeks.

To further explore changes in physical activity, Krogh-Madsen and colleagues $(175,176)$ restricted healthy subjects from $>10,000$ steps/day to 1,500 steps/day and examined insulin sensitivity for two weeks. After two weeks of restricted steps, insulin responses to an OGTT were elevated by $57 \%$, as well 
as elevated intra-abdominal fat mass, and reduced maximal peak oxygen consumption ( $\mathrm{VO}_{2 m a x}$ ). All of these measurements are associated with morbidity and mortality rates (173).

In a less severe restriction model of inactivity, Mikus et al. (177) decreased the physical activity of healthy adults from $>10,000$ steps/day to $<5,000$ steps/day to represent a sedentary adult's daily step count. During three days of physical inactivity, plasma glucose excursions, insulin and c-peptide responses were significantly elevated during an OGTT. These data demonstrated that an acute short-term loss of physical activity negatively affects glycemic control and is an essential factor in the development of insulin resistance.

Recent work by Winn et al. (178) investigated the implications of diet and energy intake on metabolism during physical inactivity in healthy adults. Subjects were restricted from $\sim 12,000$ steps/day to $<5,000$ steps/day for ten days and tested with a control diet and a higher protein diet (+14\% protein, $-14 \%$ carbohydrate) with a 400-kcal deficit to offset the reduced energy expenditure. Reduced steps decreased $\mathrm{VO}_{2}$ max independent of diet, but no disruption in fasting or postprandial glucose, insulin, or fatty acid concentrations were observed in response to an OGTT. However, when a subset of subjects was subjected to a hypercaloric diet (+35\%) and inactivity, body weight, body fat percentage, and HOMA-IR all significantly increased. This indicates that if caloric intake is not modified with inactivity, negative ramifications can occur. 
While multiple days of inactivity and non-restricted caloric intake are detrimental to insulin sensitivity, Stephens et al. (179) investigated a single day of inactivity on whole-body insulin action. The acute effect of sitting was particularly detrimental for insulin action when caloric intake was in surplus $(-39 \%, \mathrm{P}<0.001)$, a modest restriction of caloric intake to account for the decreased energy expenditure minimized but did not prevent the reductions in insulin action $(-18 \%$, $\mathrm{P}=0.07)$.

To counter the adverse effects of prolonged sitting, frequent interruptions to sedentary time has been postulated as an effective strategy to mitigate the effects of sedentary activity (180-183). One study (180) investigated the capacity of two-minute bouts of walking every 20 minutes to mitigate the effects of continuous sitting in obese adults. Accumulation of 28 minutes of light or moderate walking sessions was effective at reducing the glucose and insulin responses to an OGTT. Other work $(182,183)$ has also shown that interrupting sedentary time with light walking is effective at improving insulin sensitivity, but standing without ambulation was not protective in healthy adults. Other data $(184,185)$ suggest that individuals with T2D may see metabolic benefits from standing compared to prolonged sitting. Collectively, these data suggest that metabolism is adversely affected by inactivity, but carefully accounting for the change in energy expenditure, energy intake, and duration of the sitting period can partially mitigate these adverse effects of inactivity. 


\section{EXERCISE}

Performing regular physical activity contributes to a $20-30 \%$ reduction in risks for premature mortality and chronic conditions, including cardiovascular disease, cancer, diabetes, and hypertension $(146,186,187)$. The benefits of exercise that contribute to these changes in risks are primarily due to factors extending beyond cardiovascular fitness, such as enhanced glycemic control, increased insulin signaling, improved blood lipid profile, and reduced chronic inflammation. The impact of exercise on each tissue and organ system play individual and coordinated roles in these overall improvements to health and provide potential targeted mechanisms for their contributions to improved health status.

During insulin resistance, insulin fails to induce GLUT4 protein translocation to the sarcolemma in skeletal muscle, in part due to less tyrosine phosphorylation of insulin receptor-1 (188-190). Acute bouts of exercise are capable of increasing circulating glucose clearance through insulin-independent mechanisms, resulting in GLUT4 translocation to the plasma membrane during muscle contraction and uptake of glucose to the skeletal muscle, independent of insulin resistance (191). Thus, exercise provides an effective strategy for the prevention and treatment of insulin resistance.

A single bout of exercise has been shown to improve insulin sensitivity in healthy, obese, and insulin-resistant adults and persist up to 72 hours postexercise (192-194). To test the effect of exercise intensity on insulin sensitivity in obese adults, Rynders et al. (195) investigated a similar exercise intensity 
experiment where exercising at the lactate threshold was compared against a higher exercise intensity. Insulin sensitivity was improved $85 \%$ one hour after high-intensity exercise, whereas the moderate-intensity exercise only improved insulin sensitivity by $51 \%$. Glucose, insulin, and c-peptide concentrations were all reduced during an OGTT with the higher intensity exercise. In contrast, Newsom et al. (196) utilized a single exercise bout at 50\% VO2peak and 65\% VO2peak. The day following the exercise session, the lower intensity bout improved insulin sensitivity by $35 \%$, whereas the slightly higher intensity bout only improved sensitivity by $20 \%$. While the time frame between these studies and exercise intensities were not matched, both showed improvements in insulin sensitivity at moderate and higher intensities after a single bout.

To further explore the benefits of exercise on obese, sedentary adults, Houmard et al. (197) utilized various exercise intensities and durations to determine the effectiveness of exercise to improve insulin sensitivity. Subjects were prescribed an exercise regimen for six months consisting of a lowvolume/moderate-intensity group ( 12 miles walking/week at $40-55 \%$ $\dot{\mathrm{V} O}$ 2max), low-volume/high-intensity group ( 12 miles jogging/week at $65-80 \%$ $\dot{\mathrm{V}}$ 2max), or high-volume/high-intensity group ( 20 miles jogging/week at 65$80 \% \dot{V}_{2}$ max). Training volume (miles/week) was achieved by exercising $\sim 115$ $\mathrm{min} /$ week (low-volume/high-intensity group) or $\sim 170 \mathrm{~min} /$ week (lowvolume/moderate-intensity and high-volume/high-intensity groups). Subjects that remained sedentary had a decrease in insulin sensitivity $(P<0.05)$, while subjects that were performing exercise, independent of volume or intensity, had 
improvements in insulin sensitivity $(P<0.05)$. Exercising for a greater duration throughout the week resulted in a substantially greater improvement in insulin sensitivity, regardless of exercise intensity.

While exercise and weight loss are capable of improving insulin sensitivity, it is important to distinguish if weight loss from the caloric deficit created by exercise is responsible for the improvements observed or if exercise alone is sufficient. To explore the differential effect of exercise vs. caloric restriction, Ross et al. (198) investigated the effect of a negative energy balance (700 $\mathrm{kcal} /$ day) for 14 weeks through either exercise or diet and compared these treatments to adults exercising without a caloric deficit. A negative caloric balance was effective at improving glucose disposal, independent of the intervention (diet, $+43 \%$; exercise,$+64 \%$ ). Exercise without weight loss did not statistically improve glucose disposal (+30\%) but reduced abdominal fat and prevented weight gain. These data suggest that weight loss is important for the improvements in insulin sensitivity, but exercise is effective at preventing weight gain and decreasing abdominal fat.

Skeletal muscle coordinates with other organs such as adipose tissue to communicate energy needs during exercise, i.e., increasing adipose tissue lipolysis to provide fatty acids for energy (199). Adipose tissue is also a highly insulin sensitive depot. When insulin resistance occurs, lipolysis is not adequately regulated, and fatty acids are released into circulation under conditions that do not require an abundance of available energy. This abundance of circulating free fatty acids contributes to accumulation within the 
skeletal muscle, which has been shown to disrupt insulin signaling and is suggested to precede complications of diabetes such as hyperglycemia (193, 200).

In rodents, exercise training (e.g., swimming, wheel running) has been shown to decrease the size of adipocytes and increase insulin sensitivity (17, 201). Exercise training mice for eight weeks improved adipose tissue lipolysis and increased activation of enzymes that improved fat oxidation (202). Exercise training in mouse models also improved inflammatory profiles in adipose tissue, in part mediated through mitochondrial adaptations and reduced reactive oxygen species $(17,18,203)$. Additionally, work in sedentary mice receiving transplanted subcutaneous adipose tissue from mice trained for 11 days decreased fasting blood glucose and insulin levels (204). Collectively, animal models have shown that exercise training improves adipose tissue fatty acid metabolism and inflammation.

Exercise-trained humans have also shown beneficial adaptations in adipose tissue. A study of a 20 -week training program in healthy adults investigated adipose tissue adaptations through morphology and fatty acid metabolism (205). Four to five days a week of 40 minutes at $80 \%$ maximal heart rate was effective at lowering the adiposity of men but not women; however, both sexes were observed to have improved epinephrine stimulated lipolysis. Similar work in postmenopausal women also reported exercise-induced reductions in abdominal adipocyte size, which was not induced by dietary restriction alone (206). 
Since exercise decreases adipose tissue size in adults, healthy, sedentary men undergoing a six-month mild exercise intervention, three hours per week, were assessed for genome-wide mRNA expression changes in subcutaneous adipose tissue (207). Transcriptional pathways involved in oxidative phosphorylation and many metabolic pathways within adipose tissue were upregulated by exercise training. Interestingly, these changes in the transcriptome were independent of a familial history of T2D and also occurred without changes in body weight.

While six months of training induces transcription changes in adipose tissue, a single bout of exercise in healthy males has also been shown to have similar effects (208). Adipocytes responded to an exercise session by modulating the transcriptomic response of pro-inflammatory genes; this was even more pronounced in untrained men than trained men. Interestingly, training for six weeks resulted in a blunted gene expression response to exercise compared to a single session of exercise.

In summary, insulin resistance and obesity are increasingly common amongst adults, yet exercise is an effective therapy against the onset and progression of these diseases. While exercise training primarily involves skeletal muscle, it is well accepted that adipose tissue accrues exercise-induced adaptations as well. More work in human adipose tissue adaptations to exercise are needed as the majority of the work is done in animal models. 


\section{PHYSICAL ACTIVITY AND SLEEP RESTRICTION}

Recent evidence suggests that restricting sleep time induces insulin resistance; however, little work has been done to explain these disruptions through other modifiable lifestyle factors. Since physical inactivity is an independent risk factor for obesity, Schmid et al. (7) investigated changes in spontaneous physical activity during a night of sleep restriction. Healthy adults reduced free-living, spontaneous physical activity after one night of sleep four hours of sleep, specifically with a shift to lower physical activity intensities. Tajiri et al. (209) have also reported increased sedentary time in healthy women restricted sleep for three nights, although this was attenuated when accounting for time awake. Additional work in healthy participants with a familial history of T2D, sleep reduced by slightly more than two hours per night for seven nights resulted in $31 \%$ fewer daily activity counts and $24 \%$ less time engaged in moderate-vigorous physical activity, increasing overall sedentary time (210).

The question that arises is if activity behaviors are affected by the timing of sleep loss. Wilms et al. (211) examined the changes in activity behavior when sleep loss was either early or late in the night. When sleep was restricted during the late-night, physical activity was substantially decreased compared to regular sleep and early night sleep loss. This discrepancy in the timing of sleep loss is important and may influence physical activity, and ultimately contribute to less energy expenditure and overall positive energy balance. This decrease in physical activity is suggestive that short sleep may contribute to a decrease in 
energy expenditure through changes in physical activity, contributing to the overall positive energy balance and obesity.

In contrast to studies reporting decreases in physical activity, Brondel et al. (20) have reported increased free-living physical activity of healthy men that were sleep-restricted for two nights with four hours of sleep. Specifically, physical activity during the evening hours was elevated compared to a day of eight hours of sleep, despite increased perceived sleepiness. The discrepancies in behavioral responses to sleep restriction emphasize the need for more research to assess how adults who sleep restrict alter other lifestyle behaviors.

Interestingly, exercise and sleep restriction overlap in many metabolic pathways, suggesting increases in physical activity to mitigate the negative consequences of sleep loss. The first report of exercise to mitigate the effects of sleep deprivation was conducted by VanHelder et al. (21). Healthy males were sleep deprived for 60 hours while remaining sedentary or activity. Total sleep deprivation did not change oral glucose tolerance, but insulin responses were negatively affected by sleep deprivation and exercise partially mitigated this response. Thus, the development of insulin resistance can be partially reversed by physical activity.

Following the work by VanHelder, de Souza et al. (22) investigated the effectiveness of a high-intensity interval training (HIIT) strategy to mitigate the adverse effects of 24 hours of total sleep deprivation. Healthy, normal sleeping men participated in six training sessions (8-12 x 60 -second intervals at $100 \%$ of peak power output) over two weeks prior to a sleep deprivation period. Fasting 
glucose and insulin concentrations were not elevated by sleep deprivation, but AUCs during the OGTT were elevated. These changes in glucose and insulin responses were effectively mitigated by performing HIIT prior to the loss of sleep. Exercise restored NEFA levels that were elevated with sleep loss, potentially due to training adaptations that allowed for skeletal muscle to better utilize fatty acids for energy.

While these previous studies have investigated extreme acute sleep loss (Table 2.2), Saner et al. (85) recently utilized HIIT to counteract the metabolic consequences of sleep restriction on skeletal muscle mass. Healthy, young men were sleep restricted to four hours of sleep for five nights and randomized into normal sleep, restricted sleep, and restricted sleep with HIIT. Training sessions consisted of $10 \times 60$-s intervals performed on a cycle ergometer at $90 \%$ of peak power on days two through four of the five days sleep restriction period. While no blood parameters were reported in this publication, skeletal muscle biopsies were collected and assessed for protein changes in muscle protein synthesis and degradation pathways. Decreases in myofibrillar protein synthesis were induced only by sleep restriction, which was mitigated by performing HIIT $(\mathrm{P}<0.05)$, i.e., preserved muscle mass. This process of preserving muscle mass may be critically important for glucose homeostasis during sleep restriction and provides evidence that exercise can offset sleep restriction induced metabolic derangements.

While exercise prior to sleep loss has shown some protective effects on glucose metabolism, Sweeney et al. investigated the use of sprint interval 
training after sleep loss. Nineteen health men had one night of four hours of sleep and then either performed sprints the next day or remained sedentary. An OGTT was tested 30 minutes after the training session. Insulin concentrations were elevated with sleep restriction alone, but when exercise was performed after sleep restriction, the late-phase insulin AUC was reduced. Glucose AUC was not different between conditions. This is the only study to date that has investigated exercise after sleep restriction as a therapeutic strategy to mitigate the adverse effects of sleep restriction. 
Table 2.2. Sleep restriction, physical activity, and glucose metabolism.

\begin{tabular}{|c|c|c|c|c|}
\hline First Author (Ref.) & Subjects & $\begin{array}{l}\text { Sleep and } \\
\text { Exercise } \\
\text { Protocol }\end{array}$ & Technique & Results \\
\hline Schmid (7) & 15 Healthy men & 2 night, 4 hours & Breakfast buffet & $\begin{array}{l}+5 \% \text { low intensity activity, }-3 \% \text { high intensity } \\
\text { activity. }\end{array}$ \\
\hline Bromley (210) & $\begin{array}{l}18 \text { Healthy adults } \\
(9 F, 9 M) \text { familial } \\
\text { history of T2D }\end{array}$ & $\begin{array}{l}14 \text { day, } 5.5 \\
\text { hours }\end{array}$ & & $\begin{array}{l}-31 \% \text { activity counts, }-24 \% \text { MVPA, }+21 \mathrm{~min} / \text { day } \\
\text { of sedentary time }\end{array}$ \\
\hline Wilms (211) & 11 Healthy men & $\begin{array}{l}1 \text { night, } 4 \text { hours } \\
\text { Early- vs. late- } \\
\text { night sleep loss }\end{array}$ & & $\begin{array}{l}\text { Lower physical activity after late-night loss vs. } \\
\text { early-night loss }\end{array}$ \\
\hline Brondel (20) & 12 Healthy men & 1 night, 4 hours & Ad lib food & $+27 \%$ activity counts during the evening hours \\
\hline Tajiri (209) & 16 Healthy women & 3 night, 4 hours & Ad lib buffet & $\begin{array}{l}\text { Step count } \Leftrightarrow \text {, sedentary time }+20 \% \text {, sedentary- } \\
\text { light activity }+20 \%\end{array}$ \\
\hline VanHelder (21) & 10 Healthy men & $\begin{array}{l}60 \text { hours TSD, } \\
\text { sedentary vs. } \\
\text { daily PA }\end{array}$ & OGTT & $\begin{array}{l}\text { Insulin response increased in both conditions } \\
\text { (Sedentary > daily PA), }\end{array}$ \\
\hline de Souza (22) & 11 Health men & $\begin{array}{l}24 \text { hours TSD, } \\
\text { HIIT ( } 2 \text { weeks } 8- \\
12 \times 60 \text { s at } \\
100 \%)\end{array}$ & OGTT & $\begin{array}{l}\text { Elevated glucose and insulin AUC, HIIT+TSD } \\
\text { lowered glucose and insulin AUC to baseline, } \\
\text { TSD increased NEFA, Matsuda or HOMA-IR } \Leftrightarrow \\
\text { after baseline, TSD, or HIIT+SD }\end{array}$ \\
\hline Sweeney (212) & 19 Healthy men & $\begin{array}{l}1 \text { night, } 4 \text { hours, } \\
\text { at home, sprint } \\
\text { interval exercise }\end{array}$ & OGTT & Late phase insulin AUC lower in exercise $-32 \%$, \\
\hline Saner (85) & 24 Healthy men & $\begin{array}{l}5 \text { night, } 4 \text { hours, } \\
\text { HIIT ( } 3 \text { sessions) }\end{array}$ & $\begin{array}{l}\text { Skeletal muscle } \\
\text { biopsies, no } \\
\text { blood }\end{array}$ & $\begin{array}{l}\text { Reduced myofibrillar protein synthesis lower, } \\
\text { preserved with HIIT, }\end{array}$ \\
\hline
\end{tabular}

Details of studies investigating sleep restriction and physical activity effects on glucose metabolism with subject population, sleep and exercise protocols, investigative techniques, and results. TSD, total sleep deprivation; $F$, female; $M$, male; OGTT, oral glucose tolerance test; HIIT, high-intensity interval training; MVPA, moderate-vigorous physical activity, NEFA, non-esterified fatty acids; HOMA-IR, homeostatic model of assessment of insulin resistance; AUC, area under curve; $\Leftrightarrow$, no change. 


\section{Summary}

Collectively, two common lifestyles, sleep curtailment and physical inactivity, have profound metabolic implications and are increasingly associated with the increased incidence of obesity, T2D, cardiovascular disease, and total mortality. These lifestyles seemingly are involved individually and synergistically to contribute to health risks, highlighting how similar the potential mechanisms driving these associations are between the two lifestyles. Further investigation into the relationship between restricted sleep and physical activity habits in freeliving scenarios is needed. Furthermore, the inclusion of overweight and obese adults, who make up the majority of our population, need to be studied with sleep restriction to establish if health status is influential in the susceptibility to decrements in insulin sensitivity. Additionally, disruptions in adipose tissue insulin sensitivity and fatty acid metabolism have been indicated as a potential mechanism sleep restriction induced dysfunction, yet lipolysis within adipose tissue has not been investigated. This review has summarized the independent areas of relevant research and the paucity of work done in combination with these two prominent lifestyle factors that have important implications in public health. 


\section{CHAPTER 3 - EXPERIMENTAL DESIGN AND METHODS}

\section{Participants}

This study was approved by the University of Missouri's Health Science Institutional Review Board and all participants provided written informed consent. All participants (seven male and six female) were regular sleepers (seven to nine hours per weeknight), overweight or obese (BMI $25-40 \mathrm{~kg} / \mathrm{m} 2)$, between the ages of $21-40$ years, and non-smokers (Table 4.1). For female participants, testing was initiated the Monday following the start of menstruation, with the exception of one participant who had a hysterectomy and was started at a similar date for the second condition.

\section{Screening}

Questionnaires: The health inventory form addressed demographic information, health history, smoking habits, menstrual history, physical activity, body weight control, and food habits. Sleeping habits were assessed through the Epworth Sleepiness Scale (ESS), Pittsburg Sleep Quality Index (PSQI), Berlin Questionnaire, and Morningness-Eveningness Questionnaire (MEQ). Excessive tiredness, poor sleep quality and patterns, and high risks for sleep disordered breathing were used for exclusion from the study.

Body Composition: Dual x-ray absorptiometry (DXA) was used to determine percentages of lean and fat mass, and bone density. 
Aerobic Capacity: Participants performed a VOrmax test on a treadmill for calculations during exercise regimen, $65 \% \mathrm{VO}_{2}$ max. A mask was securely fitted to the participant's face, covering the nose and mouth, and connected to the Parvo Medics TrueOne 2400 (Parvo Medics, Sandy, UT) metabolic cart via a flexible hose to monitor carbon dioxide expulsion and oxygen consumption. A modified Bruce protocol began with a two-minute walk at $3 \mathrm{mph}$, from there the speed and incline of the treadmill increased every two minutes until volitional exhaustion. An active cool down was utilized to ensure the participant's heart rate and blood pressure return to near baseline values, following ACSM guidelines.

Sleep Apnea Screening: Participants wore a wrist-based pulse oximeter (WristOX2, Model 3150, Nonin Medical, Inc. Plymouth, MN), for one night to assess pulse and oxygen throughout the night for sleep apnea screening. An adjusted index (one event per hour) cutoff of 15 events per hour was used for exclusion from the study.

\section{Experimental design}

Two experimental sleep restriction protocols, with a crossover, randomized design, were used to test 13 overweight and obese adults for two weeks. A baseline week preceded both conditions and sleep was restricted during the second week (Monday - Friday) to six hours of time in bed (Condition 1 - SR) and repeated with a daily exercise regimen (Condition 2 - SREX) (Figure 3.1). Mixed meal tests (MMT) were administered prior to sleep restriction period 
(following a week of baseline monitoring), following five nights of sleep restriction with normal physical activity and with daily exercise (SR $\pm E X)$, and following two days of weekend recovery sleep. Adipose tissue biopsies were collected on one baseline study day and after both condition's five sleep restricted weeknights $(n=8)$. Blood samples were collected at fasting and throughout the three-hour MMT.

Following the screening visit, participants performed 2 conditions with a counterbalanced design (Figure 3.1).

\begin{tabular}{|cccc|}
$\begin{array}{c}\text { Baseline } \\
\text { 5 Weekdays }\end{array}$ & $\begin{array}{c}\text { Weekend } \\
\text { 2 days }\end{array}$ & $\begin{array}{c}\text { Intervention } \\
\mathbf{5} \text { days }\end{array}$ & $\begin{array}{c}\text { Recovery } \\
\text { 2 days }\end{array}$ \\
\hline Condition $\mathbf{1}$ & & SR & \\
\hline Regular Sleep and Physical Activity & $\begin{array}{c}\text { Sleep Restriction (6 hours sleep) } \\
\text { Regular Physical Activity }\end{array}$ & $\begin{array}{c}\text { Ad Lib } \\
\text { Sleep }\end{array}$ \\
\hline
\end{tabular}

\section{Condition 2}

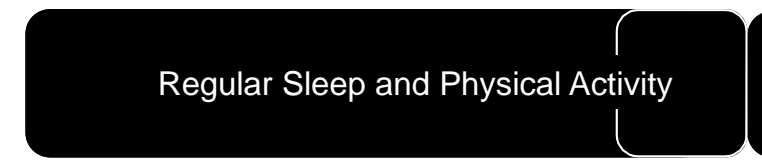

SREX

Figure 3.1. Experimental Design.

Sleep Restriction and Monitoring: Both conditions of the experimental design incorporated sleep restriction periods. Participants who habitually slept seven to nine hours per night restricted sleep to six hours for five successive days. Shortened sleep was accomplished by subjects staying up late and waking at their habitual wake time. Adherence to the sleep protocol was monitored through use of the Actiwatch Spectrum Plus (Philips Respironics, Murrysville, PA). Actiwatch data was collected for the entirety of the two weeks 
for both conditions (v. 6.0.9, Philips Respironics, Murrysville, PA) and analyzed for sleep and wake intervals. Additionally, a sleep log with quality and duration of sleep were completed for each night of the study protocols and used to validate analyzed actigraphy data.

Physical Activity Monitoring: An Actigraph (ActiGraph Corp., Pensacola, FL) was worn on the dominant hip for the two-week period of both conditions. Additional comments about exercises performed were detailed within the sleep diary, logging time, type, and additional description of exercise.

Exercise Regimen: During the SREX condition, participants completed 45 minutes of supervised walking at $65 \% \mathrm{VO}_{2}$ max each day of sleep restriction (Figure 3.1). Oxygen consumption was monitored via Parvo Medic's metabolic cart for the first 10-15 minutes of the first exercise session to ensure subject were working at $65 \%$ of $\mathrm{VO}_{2}$ max. Speed and grade were matched on the following exercise sessions to ensure consistent workload.

Dietary Records: Participants were instructed to write down all food and beverage consumed for four days of each baseline and intervention weeks, Thursday - Sunday. An informational sheet was provided with the record sheets to provide education on examples of food description and quantities with space for participants to provide as much information as possible. Caffeine was not limited throughout the conditions other than abstaining for 10 hours prior to mixed meal test. Diet diaries were analyzed with Nutritionist Pro (Axxya Systems LLC, Stafford, Texas, USA). 
Mixed Meal Test: A MMT was conducted after baseline week measurements (Figure 3.1). A second MMT was conducted the morning after the fifth night of sleep restriction with and without exercise, and a third the morning after the two-day recovery period, for both study conditions, thus participants completed six MMT. The MMT consisted of $440 \mathrm{kcals}$ of a nutrition shake (two, eight-ounce bottles; Ensure Original Vanilla, Abbott Laboratories, Columbus, $\mathrm{OH}$ ), providing 64 grams carbohydrates, 18 grams protein, and 12 grams fat. The MMT was consumed within 10 minutes, and blood samples were collected for three hours from the start of the MMT ingestion.

Blood Samples: Samples collected in EDTA tubes with a DDP-IV inhibitor and aprotinin during the MMT and were immediately tested for glucose concentrations, YSI 2300 STAT PLUS glucose analyzer (YSI Incorporated, Yellow Springs, $\mathrm{OH}$ ). Tubes were held on ice until centrifuged at $10,000 \mathrm{G}$ for 10 minutes at $4^{\circ} \mathrm{C}$ to obtain the blood plasma. Plasma was then aliquoted into two tubes and frozen at $-80^{\circ} \mathrm{C}$ for future analyses.

Task performance and stress evaluation: Participants completed computer-based brain games (Stroop, Task Switching, and N-Back) in a random order through psytoolkit.org $(213,214)$. Each game had two practice games and a final recorded game. Additionally, participants completed the Depression Anxiety Stress Scale (DASS) questionnaire. Computer games and questionnaire were initiated after the one-hour blood draw of MMT.

Adipose Tissue Biopsy: Participants had the option to participate in an additional aim of the study involving adipose tissue biopsies. Three biopsy 
collections were conducted after baseline, SR, and SREX. Sterile procedures were used to prep the biopsy site. A mix of lactate ringer and $1 \%$ lidocaine were injected into biopsy site. An incision was made with a sterile surgical scalpel, roughly $1 \mathrm{~cm}$ wide, on the left or right anterior axillary line slightly above or below the umbilicus. A biopsy needle was then inserted through the incision. After tissue was collected, the needle was expressed onto a weigh dish and separated from blood, lidocaine-lactate ringer solution, and connective tissue. Further collection of adipose tissue occurred if there was not adequate amount of adipose tissue with collected, with no more than 3 collections per procedure. Adipose tissue was aliquoted into tubes prepped for ex vivo adrenergic stimulation. An ice pack was applied to the biopsy site for periods of 20 minutes over next three hours of MMT. Instructions and care package were given to participant to tend to the wound at home.

Adipose Tissue Insulin-Signaling Assay: Collected tissue aliquot was immediately held in Dulbecco's Modified Eagle Medium (DMEM, Gibco \#31053028 ) and $0.1 \%$ fetal bovine serum (FBS, Sigma, F0926) on ice in a $50 \mathrm{~mL}$ conical until fresh media and incubations. Contents of $50 \mathrm{~mL}$ conical were dispensed onto a weigh dish lined with towel and tissue organized into 12 equal portions for duplicate tissue incubations (8-10 if insufficient tissue collected) in fresh DMEM/0.1\% FBS solution. A 96-well plate was used for incubations, containing $270 \mathrm{~mL}$ DMEM/0.1\% FBS for control (0nM) and $265.5 \mathrm{~mL}$ DMEM/0.1\% FBS for insulin (Humulin R) treatments $(0.25 \mathrm{nM}, 0.5 \mathrm{nM}, 1 \mathrm{nM}, 5 \mathrm{nM}, 10 \mathrm{nM}$ insulin treatment). Samples were incubated with DMEM/0.1\% FBS at $37^{\circ} \mathrm{C}$ for three 
hours on shaker plate before addition of $4.5 \mu \mathrm{L}$ of appropriate insulin treatments and incubated for an additional 30 minutes. After final incubation, duplicate tissues were collected and rinsed with $1 \times$ PBS before freezing and held at $-80^{\circ} \mathrm{C}$ until analysis.

Adipose Tissue Lipolysis Assay: The tissue aliquot was immediately held in low glucose DMEM (Gibco \#11054-020; (+) 1g/L D-Glucose, (+) 110 mg/L Sodium Pyruvate, (-) L-Glutamine, (-) Phenol Red) and 2\% bovine serum albumin (BSA; Sigma, A8806-5G) on ice in a $50 \mathrm{~mL}$ conical until fresh media and incubations. Contents of $50 \mathrm{~mL}$ conical were dispensed onto a weigh dish and tissue separated into 2 aliquots for incubations with/without an adrenergic agonist, isoproterenol (ISO). Flip top tubes were filled with $742.5 \mu \mathrm{L}$ fresh DMEM $/ 2 \%$ BSA and incubated with tissue for $10-45$ minutes at $37^{\circ} \mathrm{C}$ on a shaker plate. $7.5 \mu \mathrm{L}$ of $1 \mathrm{mM}$ ISO was added to the treated flip top tube (media concentration of $10 \mu \mathrm{M}$ ISO). Both 0 and $10 \mu \mathrm{M}$ ISO were then incubated for $2 \mathrm{~h}$ at $37^{\circ} \mathrm{C}$ on a shaker plate. Media and tissue were then collected and stored separately and held at $-80^{\circ} \mathrm{C}$ until analysis. Tissue was rinsed with $1 \times$ PBS before freezing.

Histology: Formalin-fixed samples of subcutaneous adipose tissue will be processed through paraffin embedment, sectioned at $4 \mu \mathrm{m}$, and stained with hematoxylin and eosin for adipocyte morphometric determinations. Crosssectional areas of the adipocytes will be obtained from perimeter tracings using ImageJ software (National Institutes of Health, Bethesda, Maryland). 
Western Blots: Triton XS-100 tissue lysates were used to produce Western blot ready Laemmli samples from ISO stimulated adipose tissue, similar to previously completed work (17). Protein samples (6 $\mu \mathrm{g} / \mathrm{lane})$ were separated by SDS-PAGE, transferred to polyvinylidene difluoride membranes, and probed with primary antibodies (Akt; Cell Signaling Technology, 2920S), phospho-Akt (Serine473; Cell Signaling Technology, 4060S), hormone sensitive lipase (HSL; Cell Signaling Technology, 4107S), phospho- (p) HSL(Serine 660, Invitrogen, PA5-64494), and fatty acid synthase (FAS, C2065, Cell Signaling Technology, 4107S)). Images were obtained with chemiluminescence on ChemiDoc MP Imaging System (Bio-Rad) and analyzed for protein quantification through Image Lab (Bio-Rad) with total protein normalization.

Calculations:

Homeostatic model assessment of insulin resistance (HOMA-IR) (215):

$$
\frac{G_{0} * I_{0}}{405}
$$

Matsuda index of insulin sensitivity (215):

$$
\frac{10,000}{\sqrt{G_{0} * I_{0} * \bar{G} * \bar{I}}}
$$

Adipose tissue insulin resistance (Adipo-IR) (216):

$$
I_{p} * F F A_{m}
$$


Area under the curve (AUC):

$$
\text { Area }=\int_{a}^{b} f(x) d x
$$

$G_{0}$ is fasting glucose (mg/dL), $I_{0}$ is fasting insulin $(\mu \mathrm{U} / \mathrm{mL}), \bar{G}$ is the average glucose at time points $30,60,90$, and $120, \bar{I}$ is the average insulin at time points $30,60,90,120, I_{p}$ is fasting insulin (pmol/L; $\mu \mathrm{U} / \mathrm{mL} * 6.9444$ ), and $F F A_{m}$ is free fatty acids (mmol/L). AUC was calculated by trapezoidal rule on GraphPad Prism version 8.3 (GraphPad Software, LLC) with values at time points 0, 5, 10, 15, 20, $30,45,60,90,120,150$, and 180.

Statistical Analysis

The statistical analysis was performed using SPSS statistical software, version 26 (IBM, Inc.) with a linear mixed model created for a 2x2 ANOVA with repeated measures (fixed effects conditions (1 - SR, 2 - SREX) and study days (baseline, SR $\pm E X$, recovery)). Additionally, glucose and insulin curves during the MMT were modeled by conditions, study days, and time (11 time points, $0-180$ minutes). To statistically evaluate if insulin resistance and physical activity were negatively influenced by $S R \pm E X, 2 \times 2$ ANOVA models of baseline vs. $S R \pm E X$, $\mathrm{SR} \pm \mathrm{EX}$ vs. recovery, and baseline vs. recovery were assessed. Intensity of physical activity was analyzed with the same repeated measures, with the addition of baseline weekdays vs. baseline weekend, and weekend vs. recovery. To evaluate the adipose tissue response to insulin and adrenergic stimulation 
after $\mathrm{SR} \pm \mathrm{EX}$, repeated measures ANOVA tested baseline vs. SR vs. SREX.

Statistical significance was $p \leq 0.05$. All data are shown as mean \pm SEM. 


\section{CHAPTER 4 - RESULTS}

\section{Subject characteristics}

Thirteen overweight and obese adults (seven males, six females) completed both study conditions, and eight subjects (four males, four females) completed three adipose tissue biopsies. Baseline circulating concentrations of cholesterol, triglycerides, low-density lipoproteins, and high-density lipoproteins were all in normal ranges (Table 4.1.). Body composition determined by DXA was comprised of $57.4 \pm 2.2 \mathrm{~kg}$ of lean mass, $32.8 \pm 1.0 \mathrm{~kg}$ of fat mass, $0.5 \pm 0.4$ bone mineral density, and $35.3 \pm 1.6 \%$ body fat.

Prior to enrollment, subjects were screened for sleeping habits with questionnaires. A global PSQI score of $2.8 \pm 0.3$ (range of 1-4) was indicative that all subjects were considered "good" sleepers. The ESS score of 5.7 \pm 1.2 (range of $0-14$ ) indicated that two subjects had "excessive" daytime sleepiness. Berlin questionnaire screening revealed that one subject was at "high risk" for sleep apnea, but pulse oximetry screening for sleep apnea showed a mean apneahypopnea index of $2.7 \pm 0.6$ events/hour (range of $0-6.6$ events/hour), which is indicative of no subjects exemplifying sleep apnea. The MEQ classified four subjects as moderately morning type, one as moderately evening type, and eight as neither morning or evening types. Subjects had normal blood pressure (BP) of $119 \pm 2 \mathrm{mmHg} / 69 \pm 2 \mathrm{mmHg}$ and mean arterial pressure (MAP) of $85.8 \pm 1.2$ mmHg. Six subjects had slightly elevated systolic BP $(>120 \mathrm{mmHg}$, four males and two females), but MAP was within normal ranges for all subjects. 
Table. 4.1. Baseline Characteristics

\begin{tabular}{|l|c|}
\hline Baseline Characteristics & \\
\hline Age (years) & $28.8 \pm 1.2$ \\
\hline BMI (kg/m2) & $31.5 \pm 1.0$ \\
\hline Body Fat (\%) & $35.3 \pm 1.6$ \\
\hline Lean mass (kg) & $57.4 \pm 2.2$ \\
\hline Fat mass (kg) & $32.8 \pm 2.2$ \\
\hline Bone Mineral Density & $0.5 \pm 0.4$ \\
\hline Waist (cm) & $102 \pm 3$ \\
\hline Hip (cm) & $115 \pm 2$ \\
\hline VO2max (mL/kg/min) & $34.3 \pm 1.9$ \\
\hline Blood Pressure (mmHg) & $119 \pm 2 / 69 \pm 2$ \\
\hline Global PSQl score & $2.8 \pm 0.3$ \\
\hline ESS score & $5.7 \pm 1.2$ \\
\hline Berlin Score & $0.7 \pm 0.2$ \\
\hline O2 Adjusted Index (events/hour) & $2.7 \pm 0.6$ \\
\hline MEQ Score & $53.8 \pm 2.5$ \\
\hline Fasting Circulatory Markers & \\
\hline Triglycerides (mg/dL) & $115.1 \pm 20.6$ \\
\hline Cholesterol (mg/dL) & $164.2 \pm 7.0$ \\
\hline LDL (mg/dL) & $108.8 \pm 7.5$ \\
\hline HDL (mg/dL) & $43.3 \pm 4.0$ \\
\hline
\end{tabular}

Data are present as mean \pm SEM. BMI, body mass index; PSQI, Pittsburg sleep quality index, ESS, Epworth sleepiness scale; LDL, low-density lipoproteins; HDL, high-density lipoproteins. 
Sleep

Habitual sleep duration at home during the baseline weekdays was 8.0 \pm 0.1 hours/night and was not different between Condition 1 and 2 (Table 4.2.). Mean bedtime during baseline weekdays was 2308 hours with wake time at 0733 hours. During sleep restriction, subjects adhered to the six hours of sleep, as shown by $5.9 \pm 0.1$ and $5.9 \pm 0.0$ hours/night during SR and SREX, respectively, which is significantly lower than baseline sleep duration $(p<0.001)$. Although sleep time was reduced during SR $\pm E X$, sleep efficiency was increased by $2.2 \pm 0.9 \%$ compared to baseline weekdays ( $p<0.001$; Table 4.2.). This increase in efficiency was reflected in the time spent awake after sleep onset (WASO), where subjects spent 15.6 \pm 3.4 fewer minutes awake each night during $S R \pm E X$ compared to baseline weekdays $(p<0.001)$.

Sleep duration on the baseline weekend was 0.6 hours less $(p=0.01)$ than baseline weekdays. Specifically, sleep duration on the weekend preceding SREX was 1.0 hours less than during baseline weekdays (Table 4.2, $p=0.03$ ). Following five days of restricted sleep, independent of exercise, subjects extended sleep during the recovery period $(7.8 \pm 0.2$ hours), similar to baseline weekdays and weekend. During the recovery weekend, subjects spent more time awake (+14 minutes) during the night (WASO) compared to SR $\pm E X$ $(p<0.001)$, similar to that of baseline weekdays and weekend (Table 4.2.). 
Table 4.2. Actigraphy data for the study conditions.

\begin{tabular}{|l|c|c|c|c|c|}
\hline & & Baseline & $\begin{array}{c}\text { Baseline } \\
\text { Weekend }\end{array}$ & SR \pm EX & Recovery \\
\hline $\begin{array}{l}\text { Duration } \\
\text { (hours) }\end{array}$ & Condition 1 & $7.9 \pm 0.2$ & $7.7 \pm 0.2$ & $5.9 \pm 0.1^{*} \dagger$ & $7.4 \pm 0.3$ \\
\hline $\begin{array}{l}\text { Efficiency } \\
\text { (\%) }\end{array}$ & Condition 1 & $88.5 \pm 1.6$ & $88.2 \pm 1.5$ & $91.1 \pm 1.3^{*}$ & $89.7 \pm 1.3$ \\
& Condition 2 & $89.4 \pm 1.0$ & $89 \pm 1.4$ & $91.8 \pm 0.6^{*}$ & $90.2 \pm 1.3$ \\
\hline $\begin{array}{l}\text { WASO } \\
\text { (min.) }\end{array}$ & Condition 1 & $41 \pm 5.6$ & $39.2 \pm 4.4$ & $24.6 \pm 3.8^{*} \dagger$ & $35.7 \pm 3.1$ \\
\hline $\begin{array}{l}\text { Bed Time } \\
\text { (hh:mm) }\end{array}$ & Condition 2 & $37.2 \pm 3.1$ & $28.1 \pm 2.4$ & $22.5 \pm 2.4^{*} \dagger$ & $39.3 \pm 5.9$ \\
\hline $\begin{array}{l}\text { Wake } \\
\text { Time } \\
\text { (hh:mm) }\end{array}$ & Condition 1 & $23: 19$ & $22: 58$ & $0: 36{ }^{*}$ & $23: 43$ \\
& Condition 2 & $23: 23$ & $23: 44$ & $0: 21^{*}$ & $23: 08$ \\
\hline
\end{tabular}

Data are mean \pm SEM. Condition $1-S R$; Condition 2 - SREX; WASO, wake after sleep onset.

Main effect of study day: * $p<0.05$ vs. baseline; $\dagger p<0.05$ vs. recovery

Post hoc: a $p<0.05$ vs. baseline (within condition); $d p<0.05$ vs. recovery (within condition); \# $p<0.05$ vs. condition 1 (within study day) 


\section{Energy metabolism}

Glucose: Fasting glucose concentrations were not different at the beginning of the MMT for the baseline periods and SR EXX (Table 4.3.). The pattern of glucose responses to the MMT was not similar between baseline and

$\mathrm{SR} \pm \mathrm{EX}$ (condition by study day interaction, $\mathrm{p}<0.01$; Figure 4.1 . A,B). Independent of exercise, sleep restriction caused higher glucose concentrations throughout the first hour and lower glucose concentrations in the third hour, but overall glucose AUC was similar (Figure 4.1. C). Peak glucose concentration following $\mathrm{SR} \pm \mathrm{EX}$ was higher compared to baseline $(\mathrm{p}=0.04$; Figure 4.1. A, B).

The recovery period slightly decreased fasting glucose concentrations compared to baseline $(81.5 \pm 1.2$ vs $84.4 \pm 1.6 \mathrm{mg} / \mathrm{dL}$, respectively; $p=0.02$; Table 4.3.). The pattern of glucose responses to the MMT during the recovery weekend was different compared to $\mathrm{SR} \pm \mathrm{EX}$ (study day by time interaction, $\mathrm{p}=0.05$; Figure 4.1. A, B) but similar to baseline.

Insulin: Fasting insulin concentrations were not different between baseline and SR \pm EX (Table 4.3.). The insulin patterns in response to MMT were not affected by sleep restriction with or without exercise (Figure 4.1. D, E), but insulin AUC was lower during SREX compared to SR alone $(p=0.01)$.

Following the recovery period, fasting insulin concentrations were lower than baseline $(p=0.02)$. Peak insulin response to MMT was lower following SR recovery compared to $S R(p=0.05)$, and SREX recovery was higher than SREX $(p<0.01)$ (condition by study day interaction, $p=0.001$; Figure 4.1. D, E). 
Additionally, insulin AUC after SR was elevated compared to the subsequent recovery $(p=0.05)$ (condition by study day interaction, $p=0.01$; Figure 4.1. $F$ ). Homeostatic model assessment of insulin resistance (HOMA-IR) and Matsuda index of insulin sensitivity were similar at baseline and not affected by sleep restriction with or without exercise (Table. 4.3.). Compared to baseline, HOMA-IR was attenuated following recovery $(p<0.01)$. Insulin sensitivity, Matsuda index, was improved after recovery following SR compared to SR $(p=0.02)$ (condition by study day interaction, $p=0.04$; Table 4.3.).

C-peptide: In contrast to insulin, fasting c-peptide concentrations tended to be decreased after $S R \pm E X$ compared to baseline $(p=0.06)$. Fasting concentrations were normalized after the recovery period. No differences were observed in AUC between any study day periods.

Glucagon: A study day by condition interaction was observed for fasting concentrations of glucagon, where glucagon was significantly decreased after SREX compared to baseline $(p=0.01)$. Glucagon AUC was decreased during $\mathrm{SR} \pm$ EX compared to baseline $(\mathrm{p}=0.01)$. Recovery period restored glucagon AUC compared to $S R \pm E X(p=0.05)$. Fasting concentrations of glucagon were decreased at recovery compared to baseline $(p=0.03)$, but AUC was not different between study days. 
Incretin Hormones: Fasting GIP and GLP-1 concentrations were not different between baseline and SR EXX (Table 4.3.). GIP AUC was elevated after $S R \pm E X$ compared to baseline $(p=0.02)$. Fasting GLP-1 concentrations were decreased after recovery compared to baseline $(p=0.02)$.

Inflammation: Fasting TNF $\alpha$ and IL-6 did not change throughout either condition (Table 4.3). 
Table 4.3. Energy Metabolism

\begin{tabular}{|c|c|c|c|c|}
\hline & & Baseline & SR土EX & Recovery \\
\hline \multicolumn{5}{|c|}{ Fasting Blood Markers } \\
\hline $\begin{array}{l}\text { Glucose } \\
\text { (mg/dL) }\end{array}$ & $\begin{array}{l}\text { Condition } 1 \\
\text { Condition } 2\end{array}$ & $\begin{array}{l}84.8 \pm 1.9 \\
84.1 \pm 2.2 \\
\end{array}$ & $\begin{array}{l}82.5 \pm 2.3 \\
83.0 \pm 2.1\end{array}$ & $\begin{array}{l}82.2 \pm 1.6^{*} \\
80.9 \pm 1.4 \text { * }\end{array}$ \\
\hline $\begin{array}{l}\text { Insulin } \\
(\mu \mathrm{lU} / \mathrm{mL})\end{array}$ & $\begin{array}{l}\text { Condition } 1 \\
\text { Condition } 2\end{array}$ & $\begin{array}{l}12.7 \pm 1.7 \\
13.4 \pm 2.0\end{array}$ & $\begin{array}{c}14.4 \pm 3.5 \\
9.9 \pm 1.3\end{array}$ & $\begin{array}{l}11.2 \pm 1.8^{*} \\
10.9 \pm 1.5 \text { * }\end{array}$ \\
\hline $\begin{array}{l}\text { C-peptide } \\
\text { (mg/dL) }\end{array}$ & $\begin{array}{l}\text { Condition } 1 \\
\text { Condition } 2\end{array}$ & $\begin{array}{c}1,175 \pm 71 \\
1,338 \pm 177\end{array}$ & $\begin{array}{c}1,194 \pm 140 \\
952 \pm 82\end{array}$ & $\begin{array}{c}1,237 \pm 168 \\
991 \pm 83\end{array}$ \\
\hline $\begin{array}{l}\text { Glucagon } \\
\text { (mg/dL) }\end{array}$ & $\begin{array}{l}\text { Condition } 1 \\
\text { Condition } 2\end{array}$ & $\begin{array}{c}38.4 \pm .2 \\
34.5 \pm 4.7\end{array}$ & $\begin{array}{l}31.2 \pm 4.8 \\
25.1 \pm 4.1\end{array}$ & $\begin{array}{l}25.3 \pm 2.8 \text { * } \\
27.6 \pm 3.3 \text { * }\end{array}$ \\
\hline $\begin{array}{l}\text { GLP-1 } \\
\text { (mg/dL) }\end{array}$ & $\begin{array}{l}\text { Condition } 1 \\
\text { Condition } 2\end{array}$ & $\begin{array}{l}22.1 \pm 10.0 \\
19.4 \pm 11.1\end{array}$ & $\begin{array}{l}20.2 \pm 11.0 \\
13.6 \pm 8.1\end{array}$ & $\begin{array}{l}16.3 \pm 11.2^{*} \\
16.9 \pm 10.4 \text { * }\end{array}$ \\
\hline $\begin{array}{c}\text { GIP } \\
(\mathrm{mg} / \mathrm{dL})\end{array}$ & $\begin{array}{l}\text { Condition } 1 \\
\text { Condition } 2\end{array}$ & $\begin{array}{l}82.3 \pm 14.4 \\
83.1 \pm 23.9\end{array}$ & $\begin{array}{c}111.5 \pm 45.8 \\
45.1 \pm 7.5\end{array}$ & $\begin{array}{l}70.8 \pm 23.1 \\
62.3 \pm 17.6\end{array}$ \\
\hline $\begin{array}{c}\text { NEFA } \\
(\mathrm{mmol} / \mathrm{L})\end{array}$ & $\begin{array}{l}\text { Condition } 1 \\
\text { Condition } 2\end{array}$ & $\begin{array}{l}0.29 \pm 0.03 \\
0.33 \pm 0.05\end{array}$ & $\begin{array}{l}0.42 \pm 0.05^{*} \dagger \\
0.40 \pm 0.05 *\end{array}$ & $\begin{array}{l}0.28 \pm 0.03 \\
0.30 \pm 0.03\end{array}$ \\
\hline $\begin{array}{l}\text { TNFa } \\
\text { (pg/mL) }\end{array}$ & $\begin{array}{l}\text { Condition } 1 \\
\text { Condition } 2\end{array}$ & $\begin{array}{l}2.9 \pm 0.3 \\
2.5 \pm 0.2\end{array}$ & $\begin{array}{l}2.8 \pm 0.4 \\
2.6 \pm 0.2\end{array}$ & $\begin{array}{l}2.9 \pm 0.3 \\
2.3 \pm 0.3\end{array}$ \\
\hline $\begin{array}{c}\mathrm{IL}-6 \\
(\mathrm{pg} / \mathrm{mL})\end{array}$ & $\begin{array}{l}\text { Condition } 1 \\
\text { Condition } 2\end{array}$ & $\begin{array}{l}3.1 \pm 0.5 \\
2.6 \pm 0.7\end{array}$ & $\begin{array}{l}3.6 \pm 0.9 \\
3.0 \pm 0.8\end{array}$ & $\begin{array}{l}4.0 \pm 1.1 \\
2.7 \pm 0.8\end{array}$ \\
\hline \multicolumn{5}{|c|}{ Mixed Meal Test AUCs } \\
\hline C-peptide & $\begin{array}{l}\text { Condition } 1 \\
\text { Condition } 2\end{array}$ & $\begin{array}{l}485,242 \pm 32,811 \\
511,595 \pm 38,647\end{array}$ & $\begin{array}{l}511,181 \pm 37,813 \\
475,664 \pm 35,990\end{array}$ & $\begin{array}{l}469,063 \pm 27,041 \\
483,768 \pm 33,819\end{array}$ \\
\hline Glucagon & $\begin{array}{l}\text { Condition } 1 \\
\text { Condition } 2\end{array}$ & $\begin{array}{l}5,712 \pm 603 \\
7,005 \pm 812 \\
\end{array}$ & $\begin{array}{c}5,283 \pm 465^{*} \\
5,291 \pm 660\end{array}$ & $\begin{array}{l}5,809 \pm 770 \\
6,031 \pm 757 \\
\end{array}$ \\
\hline GLP-1 & $\begin{array}{l}\text { Condition } 1 \\
\text { Condition } 2\end{array}$ & $\begin{array}{l}6,102 \pm 1,931 \\
5,089 \pm 1,866\end{array}$ & $\begin{array}{l}4,873 \pm 1,721 \\
4,643 \pm 1,815\end{array}$ & $\begin{array}{l}4,750 \pm 1,866 \\
4,718 \pm 1,590\end{array}$ \\
\hline GIP & $\begin{array}{l}\text { Condition } 1 \\
\text { Condition } 2\end{array}$ & $\begin{array}{l}41,420 \pm 4,214 \\
45,057 \pm 2,375\end{array}$ & $\begin{array}{l}49,935 \pm 5,999 \text { * } \\
47,447 \pm 3,242 \text { * }\end{array}$ & $\begin{array}{l}45,077 \pm 2,375 \\
45,060 \pm 3,629\end{array}$ \\
\hline \multicolumn{5}{|c|}{ Insulin Sensitivity Indexes } \\
\hline HOMA-IR & $\begin{array}{l}\text { Condition } 1 \\
\text { Condition } 2\end{array}$ & $\begin{array}{l}2.7 \pm 0.4 \\
2.8 \pm 0.5\end{array}$ & $\begin{array}{l}3.0 \pm 0.7 \\
2.0 \pm 0.3\end{array}$ & $\begin{array}{l}2.3 \pm 0.4 \text { * } \\
2.2 \pm 0.3 \text { * }\end{array}$ \\
\hline Matsuda & $\begin{array}{l}\text { Condition } 1 \\
\text { Condition } 2\end{array}$ & $\begin{array}{l}5.3 \pm 0.9 \\
5.3 \pm 1.1\end{array}$ & $\begin{array}{c}5.2 \pm 0.9 d \\
5.8 \pm 0.9\end{array}$ & $\begin{array}{l}6.2 \pm 1.0 \\
5.6 \pm 0.8\end{array}$ \\
\hline
\end{tabular}

Data are mean \pm SEM. GLP-1, glucagon like peptide-1; GIP, gastric inhibitory polypeptide; NEFA, non-esterified fatty acid; TNF $\alpha$, tumor necrosis factor alpha; IL-6, interleukin 6; HOMA-IR; homeostatic model of assessment of insulin resistance Main effect of study day: ${ }^{*}<<0.05$ vs. baseline; $\dagger p<0.05$ vs. recovery Post hoc: a $p<0.05$ vs. recovery (within condition); $d p<0.05$ vs. recovery (within condition) 

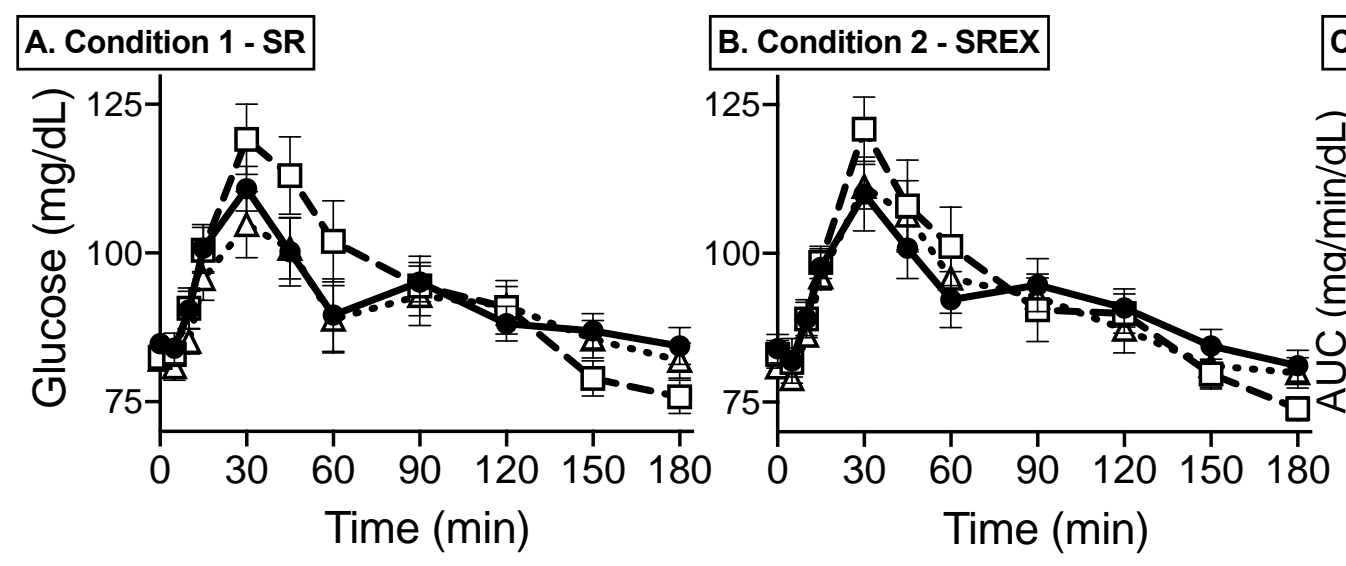

C

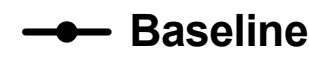

- $\square-$ - SR+EX
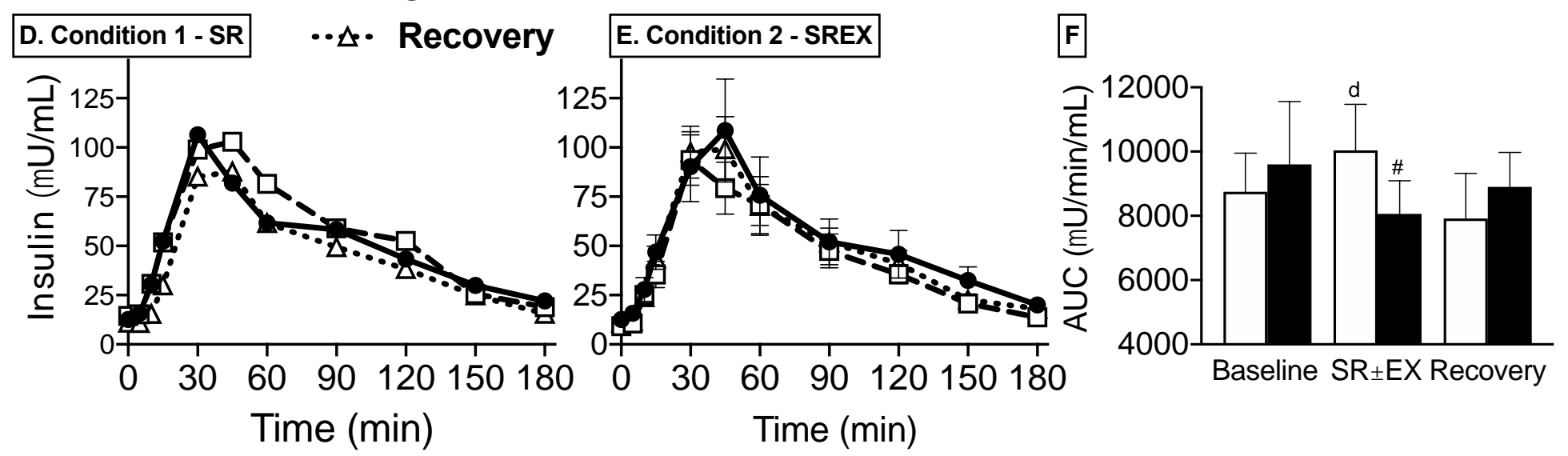

Figure 4.1. Effects of sleep restriction on glucose and insulin with and without exercise. Glucose curves in response to a MMT for (A) Condition 1 and (B) Condition 2, and (C) glucose AUC. Insulin curves in response to a MMT for (D) Condition 1 and $(E)$ Condition 2, and $(F)$ insulin AUC. Data are mean \pm SEM. Post hoc: ap<0.05 vs. recovery (within condition); $\# p<0.05$ vs. Condition 1 (within study day). 


\section{Physical Activity}

Subjects' step counts during baseline weekdays were similar between conditions (Baseline SR, 7,945 \pm 579 steps; Baseline SREX, 8,137 \pm 709 steps)

(Figure 4.2. A). Interestingly, step counts were maintained during SR $(7,466 \pm 653$ steps, $p>0.05$ ), and steps increased as expected with regular exercise (SREX, $12,877 \pm 670$ steps, $p<0.001$ compared to both baseline period and $S R$ ).

Sedentary physical activity decreased during SREX compared to both baseline ($2.6 \%, p=0.02)$ and SR $(-4.8 \% p<0.001$; Figure 4.2. B). Light physical activity (LTPA) during SR $\pm E X$, was similar to physical activity during baseline weekdays. A condition by study day interaction was found for moderate to vigorous physical activity (MVPA) between baseline and SR EEX. Daily exercise increased MVPA compared to SR $(+4.4 \%, p<0.001)$ and BsREx $(+3.7 \%, p<0.001)$, while MVPA did not change with SR alone (Figure 4.2. D).

Step counts during the baseline weekend were reduced $~ 23 \%$ compared to weekdays (Baseline, $8,040 \pm 471$ steps; weekend, $6,164 \pm 494$ steps; $p<0.01$; Figure 4.2. A). Although steps were reduced during the weekend, subjects decreased sedentary time $(p=0.02$; Figure 4.2. B) and MVPA $(p=0.01$; Figure 4.2. D), therefore, LTPA increased compared to baseline weekdays ( $<<0.001$; Figure 4.2. C).

During the recovery period, step counts decreased dramatically compared to the weekend (recovery, $4,639 \pm 412$ steps; weekend, $6164 \pm 494$ steps; $p<0.01$; Figure 4.3. A). The recovery period had higher sedentary time compared to the weekend $(+3.9 \%, \mathrm{p}<0.01$; Figure 4.2. B). The increased LTPA observed during 
the weekend compared to baseline weekdays tended to be diminished following sleep restriction, independent of exercise ( $S R \pm E X$ vs. recovery, $p=0.07$; weekend vs. recovery, $p<0.01)$. The decreased MVPA during the weekend compared to baseline weekdays was further exacerbated following $S R \pm E X$ with subjects performing $1.2 \%$ less MVPA during recovery than baseline weekend days $(p=0.03)$. 

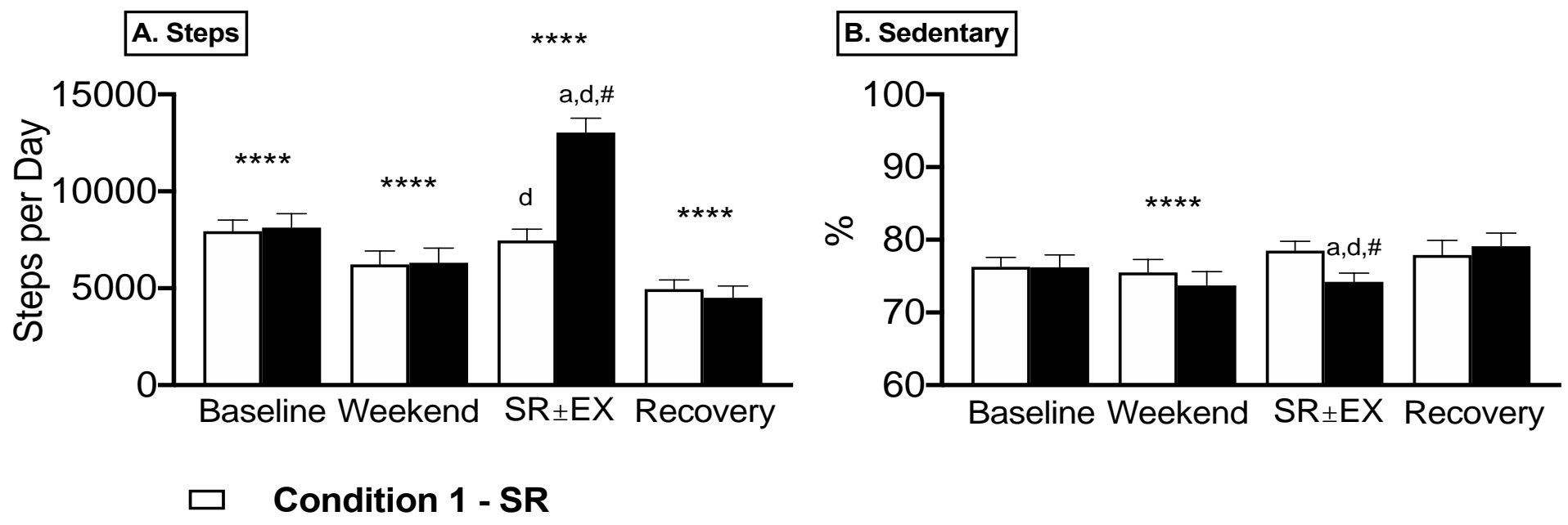
- Condition 2 - SREX
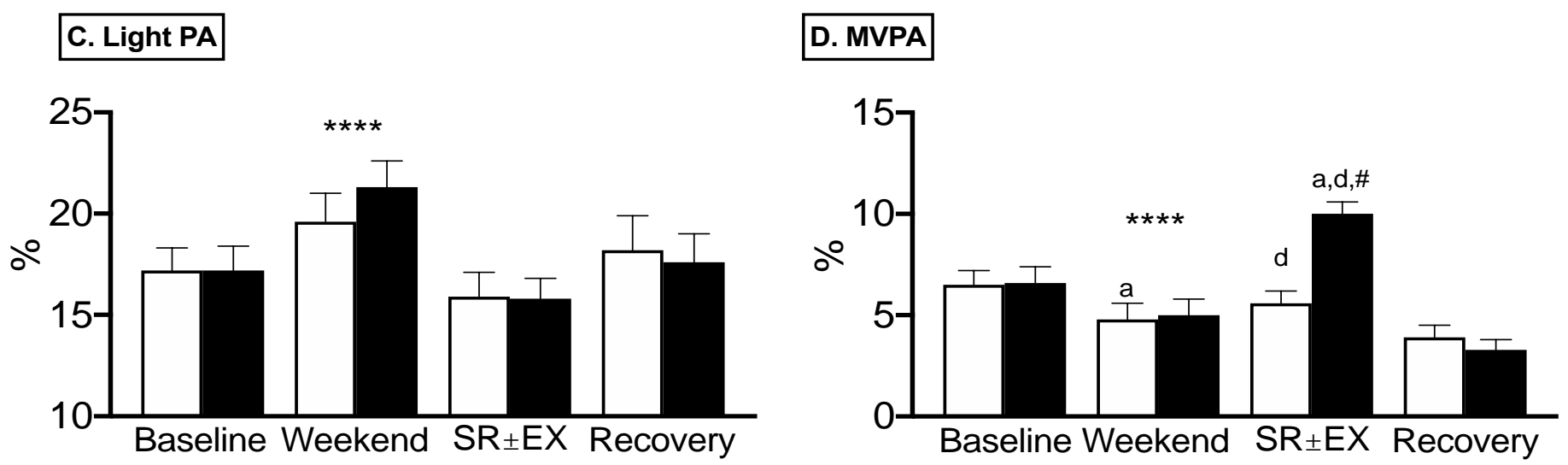

Figure 4.2. Effects of sleep restriction on physical activity with and without exercise. Condition 1 and 2 (A) steps, (B) sedentary, (C) Light physical activity, (D) moderate-vigorous physical activity. Data are mean \pm SEM. ${ }^{* * * *} p<0.05$ compared to all other study days. Post hoc: $a p<0.05$ vs. baseline (within condition); $a p<0.05$ vs. recovery (within condition); $\# p<0.05$ vs. Condition 1 (within study day). 
Fatty Acids: Since one of the primary functions of insulin is to inhibit lipolysis, circulating NEFA and adipose tissue-specific insulin sensitivity (AdipoIR) were measured. Fasting NEFA concentrations were elevated prior to starting the MMT during SR \pm EX $(0.41 \pm 0.04 \mathrm{mmol} / \mathrm{L})$ compared to baseline $(0.31 \pm 0.03$ $\mathrm{mmol} / \mathrm{L}, \mathrm{p}=0.001)$ and compared to recovery $(0.29 \pm 0.02 \mathrm{mmol} / \mathrm{L}, \mathrm{p}=0.001$; Table 4.2). The NEFA curves in response to MMT were not similar between $S R \pm E X$ and recovery (study day by time interaction, $p=0.02$; Figure 4.3. A, B), seemingly due to the elevated fasting NEFA. During SR \pm EX, NEFA AUC was elevated compared to baseline $(p<0.05)$ and recovery $(p<0.01$; Figure 4.3. $C)$.

The recovery period was effective at reducing fasting circulating NEFA concentrations to levels similar to the baseline. Consistent with HOMA-IR and the Matsuda calculation for whole-body insulin resistance/sensitivity, the recovery period tended to reduce Adipo-IR compared to $S R \pm E X(p=0.06$; Figure 4.3. D). Adipose tissue cell size $(n=6)$ did not differ between baseline, SR, and SREX ( $p=0.4)$. Adipose tissue samples stimulated with a beta-adrenergic agonist were assessed for protein differences of key enzymes of fatty acid oxidation. No differences were observed for the ratio of phospho-HSL to total HSL content in any condition or unstimulated/stimulated scenarios (Figure 4.4 A). Adrenergic stimulation of adipose tissue did not affect FAS protein content in either unstimulated or stimulated samples. However, the exploratory analysis revealed a trend of increased stimulated samples' protein content of fatty acid synthase (FAS) after SR compared to baseline $(p=0.07)$, this trend was not observed during SREX (Figure 4.4. B). Stimulated and unstimulated adipose 
tissue did not differ in lipolysis stimulated release of NEFA or glycerol (Figure 4.4.

$D, E)$, although the change in fatty acids released from unstimulated to stimulated was increased by 1.58 -fold with exercise compared to baseline $(p=0.04)$ and 1.75 -fold compared to sleep restriction $(p=0.03)$. 


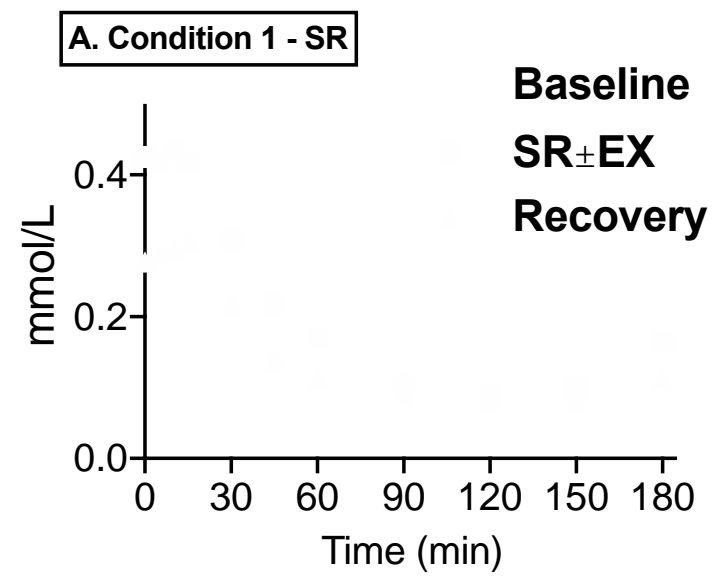

B. Condition 2 - SREX

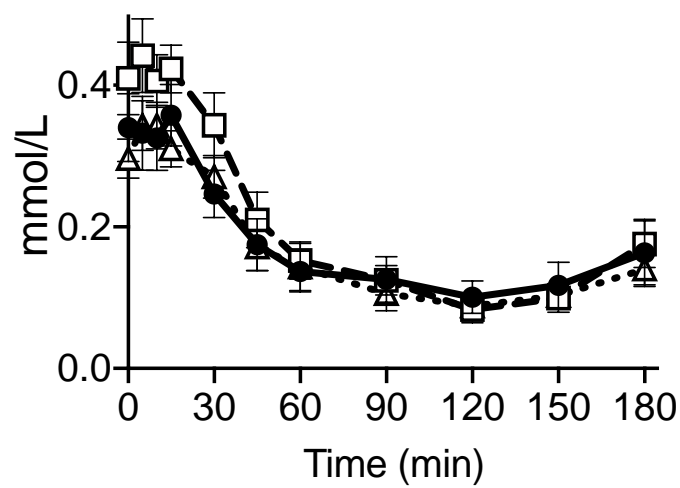

C

D

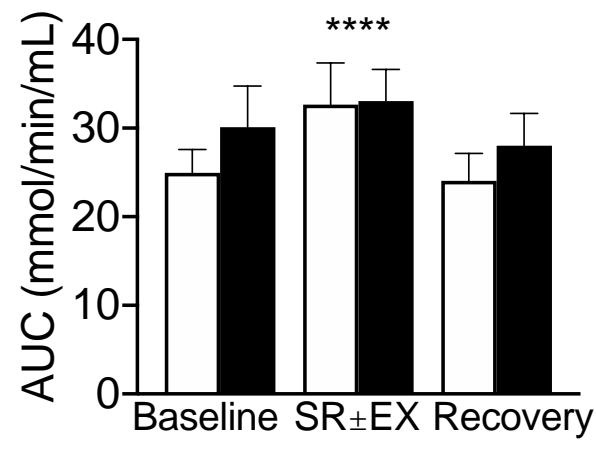

\section{Condition 1 - SR} $\square$ Condition 2 - SREX

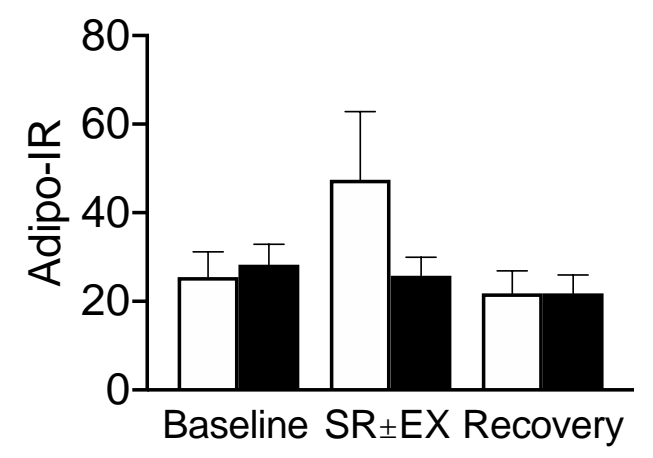

Figure 4.3. Effects of sleep restriction on NEFA and adipose tissue insulin resistance with and without exercise. NEFA responses to MMT in (A) Condition 1 - SR and (B) Condition 2 - SREX, with (C) AUC. Calculations for (D) Adipo-IR based on fasting concentrations of insulin and NEFA. Data are mean \pm SEM. AUC, area under the curve. ${ }^{* * *} p<0.05$ compared to all other study days. 

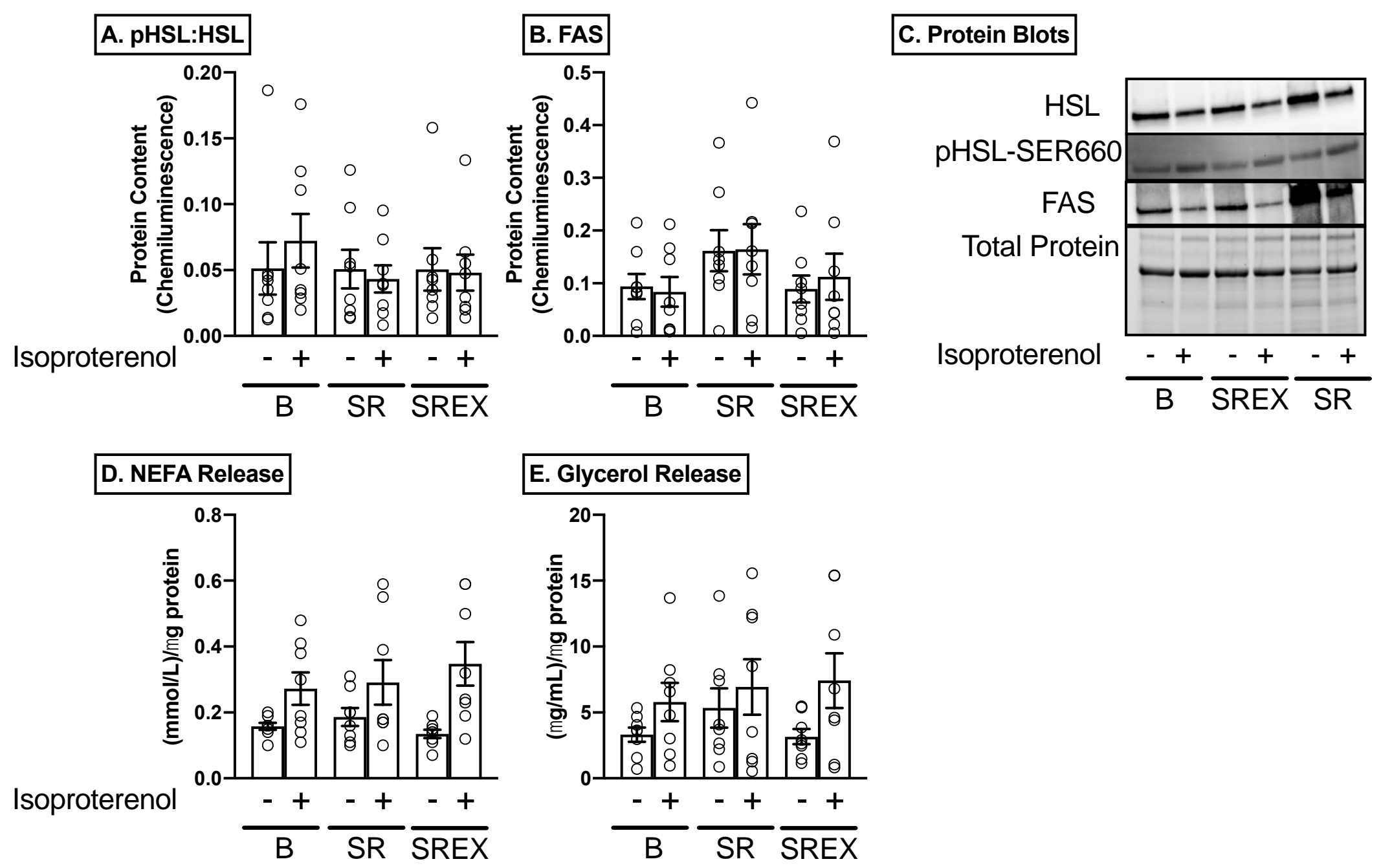

Figure 4.4. Adipose tissue adrenergic stimulation with sleep restriction with and without exercise. Baseline, Condition $1-$ SR, and Condition 2 - SREX (A) ratio of phosphorylated HSL to total HSL and (B) FAS, with representative protein blots. Unstimulated and stimulated secretion of (D) NEFA and (E) glycerol. 


\section{Diet and energy}

Subjects' weight and resting energy expenditure did not change over the course of the study (Table 4.4.). Energy consumption did not differ throughout the weekdays, but energy consumption was increased during baseline weekend preceding SREX compared to the baseline weekend prior to SR $(p=0.03)$ and also compared to the recovery following SREX $p<0.05)$. Energy expenditure (kcal/hour) from the accelerometer (Table 4.4.) was reflective of the step counts throughout the study (Figure 4.2. A).

Macronutrient composition was analyzed to determine changes in dietary composition that occurred with sleep restriction (Table 4.4.). Protein content did not differ throughout either condition. Subjects ate more carbohydrates during $S R \pm E X$ than during baseline weekdays $(43.3 \pm 1.3 \%$ vs. $46.4 \pm 1.9 \% ; p=0.01)$ as well as more carbohydrates during recovery compared to baseline weekend $(p<0.01)$. Macronutrient composition of fat was not different between baseline and $S R \pm E X$ but was decreased during recovery compared to baseline weekend period $(p=0.04)$. Alcohol consumption tended to be higher during baseline compare to $S R \pm E X(p=0.06)$. This difference in alcohol consumption is likely due to the required abstinence from alcohol on the Friday of $S R \pm E X$ due to testing on the following Saturday morning.

Caffeine consumption did not differ between baseline and SR \pm EX nor between weekend and recovery. Subjects tended to consume more caffeine during the weekdays than weekend/recovery $(p=0.06)$. 
Substrate Utilization: The respiratory exchange ratio (RER) shifted toward fatty acid metabolism in response to sleep restriction, independent of exercise $(p<0.001$; Table 4.4.). The RER for recovery following SR tended to be higher than following SREX ( $p=0.06)$ (condition by study day interaction, baseline vs. recovery, $\mathrm{p}=0.04)$. 
Table 4.4. Weight and energy

\begin{tabular}{|c|l|c|c|c|c|}
\hline & & Baseline & $\begin{array}{c}\text { Baseline } \\
\text { weekend }\end{array}$ & $\begin{array}{c}\text { Sleep } \\
\text { Restriction }\end{array}$ & $\begin{array}{c}\text { Weekend } \\
\text { recovery }\end{array}$ \\
\hline Weight (kg) & Condition 1 & $92.5 \pm 3.1$ & & $92.2 \pm 3.1$ & $92.4 \pm 3.2$ \\
& Condition 2 & $92.3 \pm 3.5$ & & $92.4 \pm 3.3$ & $92.5 \pm 3.3$ \\
\hline REE (kcal) & Condition 1 & $1740 \pm 66$ & & $1777 \pm 87$ & $1726 \pm 57$ \\
& Condition 2 & $1727 \pm 70$ & & $1756 \pm 63$ & $1705 \pm 50$ \\
\hline RER & Condition 1 & $0.89 \pm 0.01$ & & $0.87 \pm 0.02{ }^{*} \dagger$ & $0.91 \pm 0.02$ \\
& Condition 2 & $0.90 \pm 0.01$ & & $0.85 \pm 0.01{ }^{*} \dagger$ & $0.88 \pm 0.01$ \\
\hline Energy & Condition 1 & $27.2 \pm 2.5$ & $21.1 \pm 2.5^{*} \dagger$ & $26.2 \pm 2.5 \mathrm{~d}$ & $18.4 \pm 1.9$ \\
$\begin{array}{c}\text { Expenditure } \\
\text { (kcal/hour) }\end{array}$ & Condition 2 & $28.0 \pm 2.8$ & $23.6 \pm 3.0{ }^{*} \dagger$ & $47.3 \pm 4.0$ ad & $15.5 \pm 1.9$ \\
\hline Energy & Condition 1 & $2264 \pm 1.87$ & $2025 \pm 172$ & $2182 \pm 172$ & $2320 \pm 238$ \\
Consumed \\
(kcal/day) & Condition 2 & $2542 \pm 420$ & $2512 \pm 246 \#$ & $2153 \pm 214$ & $2024 \pm 156 \mathrm{~b}$ \\
\hline \%Protein & Condition 1 & $15.96 \pm 1.06$ & $18.36 \pm 1.50$ & $16.78 \pm 1.41$ & $17.02 \pm 1.32$ \\
& Condition 2 & $17.48 \pm 1.50$ & $17.27 \pm 1.38$ & $17.05 \pm 1.00$ & $16.85 \pm 0.77$ \\
\%CHO & Condition 1 & $43.49 \pm 1.44$ & $39.98 \pm 1.33 \dagger$ & $44.34 \pm 2.54 *$ & $45.57 \pm 1.79$ \\
& Condition 2 & $43.06 \pm 1.96$ & $42.86 \pm 2.67 \dagger$ & $48.42 \pm 1.86 *$ & $45.44 \pm 2.25$ \\
\%Fat & Condition 1 & $36.37 \pm 1.73$ & $39.45 \pm 1.61 \dagger$ & $37.33 \pm 2.58$ & $34.43 \pm 1.34$ \\
& Condition 2 & $35.38 \pm 2.57$ & $36.27 \pm 2.56 \dagger$ & $34.31 \pm 2.03$ & $33.97 \pm 2.58$ \\
\%Alcohol & Condition 1 & $3.70 \pm 1.77$ & $2.07 \pm 1.10$ & $1.14 \pm 0.57$ & $3.60 \pm 1.43$ \\
Caffeine & Condition 2 & $3.19 \pm 1.53$ & $4.24 \pm 1.97$ & $0.43 \pm 0.40$ & $2.57 \pm 1.34$ \\
(mg) & Condition 1 & $122.4 \pm 42.3$ & $114.9 \pm 41.1$ & $112.1 \pm 38.3$ & $92.9 \pm 25.0$ \\
& Condition 2 & $127.5 \pm 35.0$ & $107.4 \pm 31.9$ & $125.7 \pm 37.1$ & $71.6 \pm 28.1$ \\
\hline
\end{tabular}

Data are mean \pm SEM. Condition 1 - SR; Condition 2 - SREX; REE, resting energy expenditure; RER, respiratory exchange ratio; $\mathrm{CHO}$, carbohydrate. Main effect of study day: ${ }^{*} p<0.05$ vs. baseline; $\uparrow p<0.05$ vs. recovery Post hoc: $a p<0.05$ vs baseline, $b p<0.05$ vs. baseline weekend, $d p<0.05$ vs. recovery (within condition), \#p<0.05 vs Condition 1 (within study day) 


\section{Stress and Task Performance}

Depression anxiety and stress scale (DASS): Subjects reported higher scores on DASS42 during sleep restriction, independent of exercise, compared to baseline $(p=0.02)$, and compared to recovery $(p=0.01)$. Exercise did not alleviate the perceived stress of sleep restriction (Table 4.5.).

Stroop: Scores, response time, and error rate were not affected by sleep restriction, independent of exercise. The incongruent response time was decreased during recovery following SREX compared to SREX ( $p=0.03)$, and responses during recovery were faster following SREX compared to recovery following $S R(p=0.04)$.

$N$-Back: Mean response time and error rate were not affected by sleep restriction, independent of exercise. The recovery period improved response time and error rate compared to baseline ( $p=0.04, p<0.01$, respectively). Recovery following SREX significantly improved error rates compared to SREX $(p=0.02)$.

Task-Switching: Performance on task-switching was not affected by sleep restriction, independent of exercise. The recovery period improved mean response time compared to both baseline $(p=0.001)$ and $S R \pm E X(p=0.03)$. Additionally, recovery improved task switch costs compared to baseline $(p=0.04)$. 
Table 4.5. Stress and Cognitive Function

\begin{tabular}{|c|c|c|c|c|}
\hline & & Baseline & SR \pm EX & Recovery \\
\hline DASS42 & $\begin{array}{l}\text { Condition } 1 \\
\text { Condition } 2\end{array}$ & $\begin{array}{l}4.6 \pm 1.0 \\
4.6 \pm 2.1\end{array}$ & $\begin{array}{l}12.9 \pm 4.6{ }^{*} \dagger \\
8.1 \pm 1.5{ }^{*} \dagger\end{array}$ & $\begin{array}{l}3.2 \pm 1.4 \\
2.5 \pm 0.9\end{array}$ \\
\hline \multicolumn{5}{|l|}{ Stroop } \\
\hline $\begin{array}{c}\text { Stoop Effect } \\
(I-C)\end{array}$ & $\begin{array}{l}\text { Condition } 1 \\
\text { Condition } 2 \\
\end{array}$ & $\begin{array}{c}91 \pm 30 \\
106 \pm 24 \\
\end{array}$ & $\begin{array}{c}88 \pm 24 \\
107 \pm 23 \\
\end{array}$ & $\begin{array}{l}125 \pm 15 \\
72 \pm 16\end{array}$ \\
\hline Congruent & $\begin{array}{l}\text { Condition } 1 \\
\text { Condition } 2\end{array}$ & $\begin{array}{l}686 \pm 41 \\
701 \pm 34\end{array}$ & $\begin{array}{l}688 \pm 32 \\
696 \pm 24\end{array}$ & $\begin{array}{l}660 \pm 23 \\
672 \pm 36\end{array}$ \\
\hline Incongruent & $\begin{array}{l}\text { Condition } 1 \\
\text { Condition } 2\end{array}$ & $\begin{array}{l}777 \pm 34 \\
807 \pm 30\end{array}$ & $\begin{array}{c}776 \pm 34 \\
803 \pm 24 d\end{array}$ & $\begin{array}{c}784 \pm 25 \\
744 \pm 31 \#\end{array}$ \\
\hline $\begin{array}{c}\text { Mean } \\
\text { Response Time }\end{array}$ & $\begin{array}{l}\text { Condition } 1 \\
\text { Condition } 2\end{array}$ & $\begin{array}{l}751 \pm 32 \\
799 \pm 32\end{array}$ & $\begin{array}{l}769 \pm 37 \\
782 \pm 32\end{array}$ & $\begin{array}{l}742 \pm 27 \\
735 \pm 37\end{array}$ \\
\hline Error (\%) & $\begin{array}{l}\text { Condition } 1 \\
\text { Condition } 2\end{array}$ & $\begin{array}{l}3.3 \pm 0.9 \\
3.5 \pm 1.4 \\
\end{array}$ & $\begin{array}{l}5.4 \pm 1.6 \\
3.8 \pm 0.9 \\
\end{array}$ & $\begin{array}{l}5.8 \pm 1.2 \\
4.4 \pm 1.1 \\
\end{array}$ \\
\hline \multicolumn{5}{|l|}{ N-Back } \\
\hline $\begin{array}{c}\text { Mean } \\
\text { Response Time }\end{array}$ & $\begin{array}{l}\text { Condition } 1 \\
\text { Condition } 2 \\
\end{array}$ & $\begin{array}{l}826 \pm 60 \\
783 \pm 58 \\
\end{array}$ & $\begin{array}{l}803 \pm 49 \\
847 \pm 40\end{array}$ & $\begin{array}{l}777 \pm 58 \text { * } \\
735 \pm 47 \text { * }\end{array}$ \\
\hline Error (\%) & $\begin{array}{l}\text { Condition } 1 \\
\text { Condition } 2\end{array}$ & $\begin{array}{l}14.2 \pm 3.7 \\
13.7 \pm 2.5\end{array}$ & $\begin{array}{c}13.3 \pm 3.2 \\
19.2 \pm 4.0 \mathrm{~d}\end{array}$ & $\begin{array}{l}12.3 \pm 3.8 \text { * } \\
10.4 \pm 3.3 \text { * }\end{array}$ \\
\hline \multicolumn{5}{|l|}{ Task-Switching } \\
\hline $\begin{array}{l}\text { Task switch } \\
\text { cost in RTs }\end{array}$ & $\begin{array}{l}\text { Condition } 1 \\
\text { Condition } 2\end{array}$ & $\begin{array}{l}336 \pm 73 \\
383 \pm 82\end{array}$ & $\begin{array}{l}279 \pm 70 \\
270 \pm 68\end{array}$ & $\begin{array}{l}224 \pm 61 \text { * } \\
216 \pm 61 \text { * }\end{array}$ \\
\hline $\begin{array}{c}\text { Mean } \\
\text { Response Time }\end{array}$ & $\begin{array}{l}\text { Condition } 1 \\
\text { Condition } 2\end{array}$ & $\begin{array}{l}803 \pm 43 \\
816 \pm 43\end{array}$ & $\begin{array}{l}754 \pm 42 \dagger \\
756 \pm 35 \dagger\end{array}$ & $\begin{array}{l}645 \pm 25 \text { * } \\
728 \pm 37 \text { * }\end{array}$ \\
\hline Error (\%) & $\begin{array}{l}\text { Condition } 1 \\
\text { Condition } 2\end{array}$ & $\begin{array}{l}4.1 \pm 0.8 \\
3.8 \pm 0.8\end{array}$ & $\begin{array}{l}4.1 \pm 0.8 \\
4.9 \pm 1.2\end{array}$ & $\begin{array}{l}4.4 \pm 0.7 \\
5.4 \pm 1.0\end{array}$ \\
\hline
\end{tabular}

Data are mean \pm SEM. Condition 1 - SR; Condition 2 - SREX; DASS42, depression anxiety stress scale; I-C, incongruent - congruent; RTs, reaction time in milliseconds;

Main effect of study day: ${ }^{*}<<0.05$ vs. baseline; $\dagger p<0.05$ vs. recovery Post hoc: $\mathrm{d} p<0.05$ vs. recovery (within condition), $\# p<0.05$ vs Condition 1 (within study day) 


\section{CHAPTER 5 - DISCUSSION, LIMITATIONS, AND FUTURE DIRECTIONS}

\section{Discussion}

This study is the first to report the effects of modest sleep loss on glucose tolerance and physical activity patterns in overweight men and women. Five days of modest sleep restriction did not negatively affect glucose tolerance, insulin sensitivity (Matsuda), or insulin resistance (HOMA-IR), contrary to the hypothesis that overweight and obese adults would recapitulate the data in healthy men $(70,71)$. Further, two fewer hours of sleep did not reduce step counts, nor shift physical activity intensity throughout the workweek, again contrary to the hypothesis that sleep loss would negatively affect free-living physical activity. A regular exercise pattern during sleep restriction increased steps per day, replaced sedentary time with MVPA, and decreased insulin AUC during MMT. Sleep restriction, independent of exercise, elevated peak glucose responses to MMT, increased fasting NEFA concentrations, and influenced substrate utilization. Finally, the ad libitum sleep opportunity during the weekend following sleep restriction, independent of exercise, improved fasting glucose, insulin, and NEFA concentrations, along with indexes of insulin resistance, despite reduced steps and increased sedentary time. These data show that the effects of sleep restriction are profound enough not to be affected by exercise.

Most sleep restriction studies have implicated insulin resistance as the major negative health outcome $(8,9,69-72)$. Contrary to healthy populations, these data show that modest sleep restriction in overweight adults did not 
increase HOMA-IR, fasting insulin or fasting glucose concentrations; although, peak glucose concentrations were elevated $(+7.3 \mathrm{mg} / \mathrm{dL})$ by sleep restriction, independent of exercise. Matsuda calculations revealed a similar lack of change with sleep restriction, although the use of MMT as opposed to a glucose challenge may have made it more difficult to detect small changes in insulin sensitivity (217). More free-living studies in healthy and overweight adults would provide better insight into the consequences of shortened sleep on other behavioral aspects that affect insulin sensitivity, such as physical activity and dietary choices.

Healthy men have been shown to reduce their spontaneous physical activity when sleep was restricted (four hours of sleep), as seen through shifts toward less intense activity (7). In this previous study, subjects were instructed to avoid intense physical activity when outside the lab and also restricted activity to sitting while in the laboratory delaying bedtime. Work by Wilms et al. (211) demonstrated similar effects after one night of late-night sleep loss in free-living healthy men. In healthy adults with a familial risk factor for diabetes, subjects reallocated 30 minutes of their daily MVPA with less intense and sedentary activities when sleep-restricted (five and a half hours sleep), while in a laboratory setting where indoor leisure activity was allowed (210). In contrast to these studies, Tajiri et al. (209) reported that healthy free-living Japanese women increased step counts during sleep restriction, but when the extra hours awake were accounted for, significance was lost. This study is the first to report activity in overweight and obese individuals and found that step counts were maintained 
in a free-living setting without changes in physical activity intensity during the sleep-restricted workweek. The overweight and obese adults in this study were relatively active ( 8,000 steps per day during baseline weekdays), which may not accurately represent the average overweight/sedentary population. Interestingly, overweight and obese adults in this study were less active during the baseline weekend compared to the weekdays, and even more so during the recovery from the sleep-restricted workweek. This low level of activity on the weekend was surprising and prospective work should consider the days following sleep restriction if this compensatory activity behavior occurs in healthy and more severely sleep-restricted adults.

Increased sedentary activity is linked to adverse health outcomes through increased body mass index and body fat percentage (218-221). Bosy-Westphal et al. (222) and Markwald et al. (123) showed that healthy adults experiencing insufficient sleep (four nights at home gradually decreasing hours of sleep; five nights in the lab with five hours of sleep, respectively) increased energy intake and gained weight with ad libitum food access. In contrast, this study of five days of modest sleep restriction had no impact on the subject's weight. Despite being free-living and having unrestricted food access, caloric consumption was not increased during sleep restriction, and exercising throughout the sleep-restricted workweek did not influence energy consumption. Dietary records showed that participants chose to eat a higher percentage of carbohydrates $(+3.1 \%)$ during the sleep-restricted workweek compared to baseline weekday, in agreement with Markwald et al. (123). In contrast, fat consumption during sleep restriction has 
been shown to be increased $(7,20,223)$, but this was not observed in the present study. During the subsequent recovery weekend, subjects consumed a higher percentage of carbohydrates and lower fat compared to baseline weekend. Similar to activity behaviors, dietary choices may be influenced in the days after sleep restriction and be a critical component of the risks for obesity and insulin resistance.

Exercise is a well-accepted tool for the prevention and treatment of obesity and T2D through improved glucose tolerance and insulin sensitivity (224, 225). To date, few studies have monitored physical activity during periods of sleep restriction, and only one study has investigated exercise during a multinight sleep restriction protocol, although no hormone data were presented (85). VanHelder et al. (21) reported that 60 hours of total sleep deprivation, with concurrent exercise, was only partially protective against the increased insulin responses seen during total sleep deprivation. More recently, another study noted that high-intensity interval training for two weeks prior to 24-hour sleep deprivation attenuated increases of glucose, insulin, and free fatty acid concentrations (22). While these studies examined extreme sleep loss, this study showed that in overweight adults performing moderate-intensity exercise while undergoing modest sleep restriction did not alter fasting glucose or insulin concentrations, but the exercise was effective at reducing the insulin AUC in response to MMT.

The mechanisms for whole-body insulin resistance observed with sleep restriction are still unknown. Only a few investigators have explored the 
mechanisms directly in peripheral tissues $(15,16)$. Broussard and colleagues (15) have shown reduced phosphorylation of Akt in adipocytes after sleep restriction, indicating a lack of inhibition on lipolysis, and later reported sleep restriction increased circulating free fatty acids (12). Paralleling the work of Broussard, Sweeney et al. (16) indicated a propensity to decrease Akt activity within the skeletal muscle after a period of sleep restriction, demonstrating a reduction in insulin signaling capacity. While it appears that insulin signaling in peripheral tissues is disrupted, fatty acid metabolism has not been well explored.

Previous studies have reported that free fatty acids are elevated with sleep restriction $(12,14,22,88)$. As circulating glucose is not commonly elevated at fasting states in response to sleep restriction $(70-72,75,128)$, it is plausible that adipose tissue is utilizing circulating glucose for de novo lipogenesis in order to maintain glucose homeostasis as opposed to increased lipolysis of stored triglycerides within adipose tissue contributing to the circulating pool of NEFA. In the present study, adipose tissue FAS protein content tended to be upregulated with sleep restriction, despite no adverse effects of sleep restriction on Adipo-IR. The increased FAS protein may be a contributing mechanism to the development of insulin resistance as an excessive accumulation of fatty acids within a tissue is known to disrupt insulin signaling (226). Exercise mitigated this slight increase in FAS despite not effectively reducing the circulating free fatty acids. Increased NEFA concentrations and decreased RER data suggest a whole-body switch towards fatty acid metabolism, and the metabolic flexibility to switch after a weekend sleep recovery 
period restored fasting levels of free fatty acids. This shift to increased fat oxidation during sleep restriction has also been observed by others $(88,227$, 228). Sleep restriction did not increase adipose tissue lipolysis compared to baseline as pHSL:HSL protein content was not different and adrenergic stimulation did not produce an elevated secretion of NEFA or glycerol. Adipose tissue samples collected after sleep restriction with concurrent exercise had a larger response to adrenergic stimulation, i.e., elevated NEFA secretion. These data do not conclusively implicate adipose tissue lipolysis or fatty acid synthesis as the mechanisms for adipose dysfunction with sleep restriction. Both adipose tissue and skeletal muscle need mechanistic studies to determine the individual and combined roles each tissue contributes to sleep-restriction induced insulin resistance.

With the sedentary lifestyles and reduced sleep hours becoming an increasingly common lifestyle, few studies have pursued the lasting effects from the workweek on the subsequent weekend $(10,11)$. Previously, Broussard et al. (11) showed that two nights of recovery sleep following four nights of four and a half hours sleep restored insulin sensitivity; whereas others (10) have noted that two nights of recovery sleep from five nights of five hours of sleep did not restore the loss in insulin sensitivity, but was effective in restoring lipemic responses. In this study, the weekend recovery from a modest workweek sleep restriction improved HOMA-IR compared to baseline, due to the reduced fasting glucose and insulin concentrations. Interestingly, the improvements in insulin resistance seen in the current study are independent of performing regular exercise during 
sleep restriction and surprisingly occurred while the subjects simultaneously reduced step counts and increased sedentary time during the weekend. This shows for the first time that weekend recovery sleep was beneficial at restoring fasting free fatty acid concentrations. Adipose tissue insulin resistance index was not affected by sleep restriction, but the weekend recovery period tended to decrease adipose insulin resistance. While these improvements suggest a strong influence of recovery sleep independent of exercise and activity during the weekend, Depner et al. (8) recently demonstrated that the improvements during the weekend in insulin sensitivity are not protective against a recurrent lifestyle of sleep loss the following week. This highlights the profound impact of sleep on glucose metabolism, as well as the need to explore the long-term consequences of restricting sleep.

Metabolic health and immune responses are highly integrated, and since immune factors contribute to the natural sleep process (229), inflammation may provide some underlying mechanisms to insulin resistance during sleep restriction. Several studies have found that reduced/fragmented sleep increases circulating pro-inflammatory cytokines, but discrepancies exist between the responses reported in interleukins, TNF $\alpha$, and c-reactive protein $(95,230,231)$. Some studies $(230,231)$ have reported that four to five nights of four hours of sleep increased IL-6 concentrations, but not TNF $\alpha$, and that two nights of recovery sleep were not sufficient to normalize IL-6. Likewise, others (95) have also observed that six hours of sleep for one-week not only increased IL-6 in men and women but also TNF $\alpha$ in men. Additionally, circadian misalignment may 
implicate the timing of sleep loss on inflammatory profiles. Wright et al. (229) demonstrated that circadian misalignment disrupts inflammatory profiles as compared to a synchronized group. In the current study, no differences in fasting concentrations of TNF $\alpha$ or IL- 6 concentrations were found throughout either study condition, as well as no correlation with indices of insulin sensitivity/resistance. This lack of inflammatory change may be due to the modest sleep restriction and duration being unable to induce insulin resistance within an overweight adult population. Chronic and more severe curtailment of sleep may be needed to influence inflammatory profiles and contribute to metabolic complications.

Aside from metabolic implications to sleep restriction, cognitive task performance is frequently observed to be negatively affected by sleep restriction $(133,137)$. Interestingly, modest sleep restriction throughout the workweek in the current study was insufficient to support this common view of executive function vulnerability. Overweight and obese adults' performance in Stroop testing, N-Back, and task-switching was not affected by sleep restriction. Measures of depression, anxiety, and stress were elevated during sleep restriction and despite physical activity being known to have positive effects on psychological health (232), but in a modestly sleep-restricted workweek, exercise was not effective at reducing the stress related to sleep loss. Weekend ad libitum sleep effects on cognitive performance are unclear as the longer duration and severity of sleep restriction seem to determine the time necessary to restore the performance of various tasks (233). Here, the weekend period with ad 
libitum sleep opportunity reduced stress related to sleep loss and also showed improvements in executive function performances. Stress scores were not correlated with any circulating markers or indexes of insulin sensitivity, suggesting the emotional state of the subjects was not influencing insulin sensitivity.

\section{Summary}

For the first time, we demonstrate that a modest sleep restriction during a workweek does not overtly metabolically disrupt overweight and obese adults. Furthermore, a moderate-intensity exercise intervention was successful at reducing insulin responses and reducing sedentary time, although insulin sensitivity and fasting NEFA concentrations were not improved. Ad libitum sleep on the weekend following sleep restriction effectively restored, and in some cases improved, the metabolic fluctuations induced by sleep restriction. This occurred despite increased sedentary time and reduced steps, highlighting that sleep has substantial effects on metabolic health. More research needs to be conducted on sleep restriction in overweight populations to better understand changes in free-living behaviors and implications on metabolic health. 


\section{Limitations}

There are various strengths and limitations of this dissertation study. A strength of this study is the inclusion of overweight men and women, as much of the previous literature only includes healthy, lean, young males; thus, this project expands the population. Prospective studies should aim to include a healthy control group compared to an overweight group to explore the implications of athome sleep restriction thoroughly. Additionally, the menstrual cycle may impact sleep (234) but has been scantly explored, and research would benefit from the inclusion of female participants while also controlling for menstrual phases in which they studied. Female participants in this study were started within seven days of menstruation to keep consistent time frames for the two conditions, but because of study duration, testing was conducted in various phases of the menstrual cycle.

Sleep and physical activity data were captured in a free-living setting while the majority of previous studies occurred on research units that confine and restrict the activity of participants, potentially disrupting normal behaviors. Few studies $(7,20)$ have implemented a combination of free-living and in laboratory settings to assess behavioral changes outside of the laboratory, but limitations still exist with new sleeping environments. Additionally, oral glucose tolerance tests, intravenous glucose tolerance tests, and insulin clamps are the most commonly used techniques to assess insulin sensitivity in the literature pertaining to metabolic consequences of sleep restriction, but the use of a mixed meal test provides valid and sensitive measures of insulin sensitivity. 
Dietary records were collected from Thursday through Sunday in order to minimize the effect of recording on dietary choice and accuracy of reporting. This time frame may not accurately represent dietary habits for the week. Future work could consider the use of a phone-based application for records of food choices to minimize reporting error.

Importantly, adipose tissue samples were collected to investigate ex vivo insulin stimulation for changes in phosphorylation of Akt, a key marker of insulin signaling induction, in order to replicate work done by Broussard et al. (15). Unfortunately, tissue collections were limited and separated into a gradient of concentrations of insulin (Figure 5.1), resulting in a large proportion of tissue preparations that did not provide enough protein per sample to investigate the protein content of Akt effectively. Available data are shown in Figure 5.1 to compare what samples were measured for Akt (Cell Signaling Technology, 2920S) and phosphorylation of Akt at Serine 473 (Cell Signaling, 4060S).
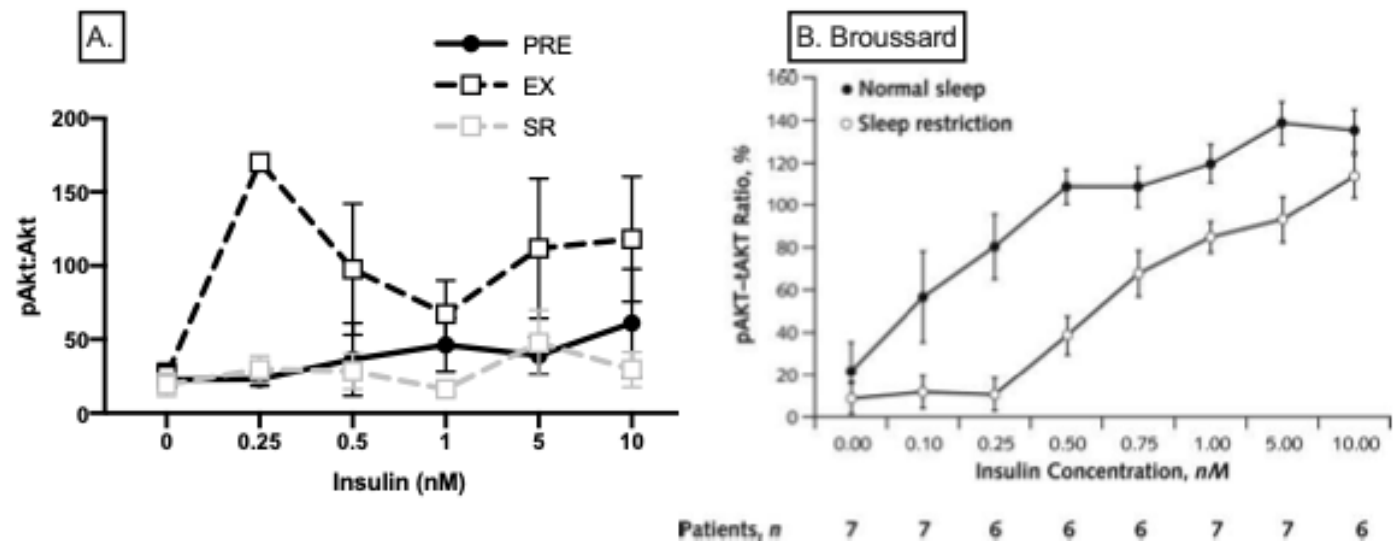

Figure 5.1. Ex vivo adipose tissue insulin stimulation curves for (A) the current study and (B) Broussard et al. (15). The protein content of phosphorylated Akt at Serine 473 (activated) to total Akt protein content ratio was explored in both studies. Data are mean \pm SEM. 


\section{Future Directions}

Collectively, this dissertation suggests that overweight adults undergoing an acute period (five nights) of modest sleep restriction maintain physical activity behaviors and glucose tolerance. Importantly, these findings do not unequivocally rule out metabolic implications of reduced hours of sleep in overweight adults and warrant future research in these areas. The vast majority of previous research on sleep restriction utilizes less than six hours of sleep opportunity and is primarily conducted in healthy males.

Data from this dissertation also demonstrate the powerful impact of the weekend "catch up" sleep on metabolic health and should be considered within research designs as workweek patterns are often five-day / two-day cycles. Despite reduced steps, increased sedentary activity, reduced light PA, and reduced MVPA, HOMA-IR was improved after a two-day period of ad libitum sleep. This insulin resistance data contrasts that of previous work (10) but agrees with others $(11,130)$. Additionally, previous work (8) has shown that ad libitum weekend recovery sleep failed to prevent metabolic dysregulation during a repeating pattern of insufficient sleep. More work is needed to explore if metabolic derangements are prevalent when a repeating pattern of modest sleep restriction is practiced.

Peripheral tissue insulin sensitivity has been indicted by many studies investigating insufficient sleep $(15,16,88)$, but no study to date has yet to combine simultaneous collections of adipose tissue and skeletal muscle. Despite low sample numbers, insulin-stimulated adipose tissue samples appear to have 
increased insulin signaling when exercise is performed during restricted sleep hours compared to baseline and sleep restriction alone (Figure 5.1. A). Since skeletal muscle and adipose tissues are metabolically disrupted with sleep restriction and also known to have beneficial adaptations to exercise, more mechanist studies with the use of exercise as a therapeutic tool to combat sleep restriction metabolic derangements. The combination of tissue samples in concert with stable isotope tracer techniques will provide a robust description of metabolic fluctuations throughout the body.

\section{Acknowledgments}

I would like to acknowledge assistance from Ying Liu for many early morning blood draws, Rebecca Welly for technical expertise in ex vivo adipose tissue handling and processing, Travis Emerson, Ryan Pettit-Mee, and Dr. Nathan Winn for technical assistance, and Drs. Kanaley, Vieira-Potter, Parks, Lastra, and McCrae for their invaluable input in study design and guidance throughout this dissertation study.

\section{Research Support}

This research was supported by Dr. Kanaley through the University of Missouri Research Council Grant and NIH R01 DK101513. 


\section{BIBLIOGRAPHY}

1. Guyon A, Morselli LL, Balbo ML, Tasali E, Leproult R, L'Hermite-Baleriaux M, Van Cauter E, Spiegel K. Effects of insufficient sleep on pituitaryadrenocortical response to crh stimulation in healthy men. Sleep. 2017;40(6).

2. Knutson KL, Van Cauter E, Rathouz PJ, Yan LL, Hulley SB, Liu K, Lauderdale DS. Association between sleep and blood pressure in midlife: The cardia sleep study. Arch Intern Med. 2009;169(11):1055-61.

3. Van Cauter E, Spiegel K, Tasali E, Leproult R. Metabolic consequences of sleep and sleep loss. Sleep Med. 2008;9 Suppl 1:S23-8.

4. Hirshkowitz M, Whiton K, Albert SM, Alessi C, Bruni O, DonCarlos L, Hazen N, Herman J, Katz ES, Kheirandish-Gozal L, Neubauer DN, O'Donnell AE, Ohayon M, Peever J, Rawding R, Sachdeva RC, Setters B, Vitiello MV, Ware JC, Adams Hillard PJ. National sleep foundation's sleep time duration recommendations: Methodology and results summary. Sleep Health. 2015;1(1):40-3.

5. Knutson KL, Van Cauter E. Associations between sleep loss and increased risk of obesity and diabetes. Ann N Y Acad Sci. 2008;1129:287304.

6. Van Cauter E, Blackman JD, Roland D, Spire JP, Refetoff S, Polonsky KS. Modulation of glucose regulation and insulin secretion by circadian rhythmicity and sleep. J Clin Invest. 1991;88(3):934-42.

7. Schmid SM, Hallschmid M, Jauch-Chara K, Wilms B, Benedict C, Lehnert $\mathrm{H}$, Born J, Schultes B. Short-term sleep loss decreases physical activity under free-living conditions but does not increase food intake under timedeprived laboratory conditions in healthy men. Am J Clin Nutr. 2009;90(6):1476-82.

8. Depner CM, Melanson EL, Eckel RH, Snell-Bergeon JK, Perreault L, Bergman BC, Higgins JA, Guerin MK, Stothard ER, Morton SJ, Wright KP, Jr. Ad libitum weekend recovery sleep fails to prevent metabolic dysregulation during a repeating pattern of insufficient sleep and weekend recovery sleep. Curr Biol. 2019;29(6):957-67 e4.

9. Nedeltcheva AV, Kessler L, Imperial J, Penev PD. Exposure to recurrent sleep restriction in the setting of high caloric intake and physical inactivity results in increased insulin resistance and reduced glucose tolerance. $J$ Clin Endocrinol Metab. 2009;94(9):3242-50.

10. Ness KM, Strayer SM, Nahmod NG, Chang AM, Buxton OM, Shearer GC. Two nights of recovery sleep restores the dynamic lipemic response, but not the reduction of insulin sensitivity, induced by five nights of sleep restriction. Am J Physiol Regul Integr Comp Physiol. 2019;316(6):R697R703.

11. Broussard JL, Wroblewski K, Kilkus JM, Tasali E. Two nights of recovery sleep reverses the effects of short-term sleep restriction on diabetes risk. Diabetes Care. 2016;39(3):e40-1. 
12. Broussard JL, Chapotot F, Abraham V, Day A, Delebecque F, Whitmore $\mathrm{HR}$, Tasali E. Sleep restriction increases free fatty acids in healthy men. Diabetologia. 2015;58(4):791-8.

13. Donga $E$, van Dijk M, van Dijk JG, Biermasz NR, Lammers GJ, van Kralingen KW, Corssmit EP, Romijn JA. A single night of partial sleep deprivation induces insulin resistance in multiple metabolic pathways in healthy subjects. J Clin Endocrinol Metab. 2010;95(6):2963-8.

14. Schmid SM, Hallschmid M, Jauch-Chara K, Wilms B, Lehnert H, Born J, Schultes B. Disturbed glucoregulatory response to food intake after moderate sleep restriction. Sleep. 2011;34(3):371-7.

15. Broussard JL, Ehrmann DA, Van Cauter E, Tasali E, Brady MJ. Impaired insulin signaling in human adipocytes after experimental sleep restriction: A randomized, crossover study. Ann Intern Med. 2012;157(8):549-57.

16. Sweeney EL, Jeromson S, Hamilton DL, Brooks NE, Walshe IH. Skeletal muscle insulin signaling and whole-body glucose metabolism following acute sleep restriction in healthy males. Physiol Rep. 2017;5(23).

17. Porter JW, Rowles JL, 3rd, Fletcher JA, Zidon TM, Winn NC, McCabe LT, Park YM, Perfield JW, 2nd, Thyfault JP, Rector RS, Padilla J, Vieira-Potter VJ. Anti-inflammatory effects of exercise training in adipose tissue do not require fgf21. J Endocrinol. 2017;235(2):97-109.

18. Castellani L, Root-Mccaig J, Frendo-Cumbo S, Beaudoin MS, Wright DC. Exercise training protects against an acute inflammatory insult in mouse epididymal adipose tissue. J Appl Physiol (1985). 2014;116(10):1272-80.

19. Zidon TM, Park YM, Welly RJ, Woodford ML, Scroggins RJ, Britton SL, Koch LG, Booth FW, Padilla J, Kanaley JA, Vieira-Potter VJ. Voluntary wheel running improves adipose tissue immunometabolism in ovariectomized low-fit rats. Adipocyte. 2018;7(1):20-34.

20. Brondel L, Romer MA, Nougues PM, Touyarou P, Davenne D. Acute partial sleep deprivation increases food intake in healthy men. Am J Clin Nutr. 2010;91(6):1550-9.

21. VanHelder T, Symons JD, Radomski MW. Effects of sleep deprivation and exercise on glucose tolerance. Aviat Space Environ Med. 1993;64(6):48792.

22. de Souza JFT, Dattilo M, de Mello MT, Tufik S, Antunes HKM. Highintensity interval training attenuates insulin resistance induced by sleep deprivation in healthy males. Front Physiol. 2017;8:992.

23. Lavie CJ, De Schutter A, Parto P, Jahangir E, Kokkinos P, Ortega FB, Arena R, Milani RV. Obesity and prevalence of cardiovascular diseases and prognosis-the obesity paradox updated. Prog Cardiovasc Dis. 2016;58(5):537-47.

24. Reutrakul S, Van Cauter E. Sleep influences on obesity, insulin resistance, and risk of type 2 diabetes. Metabolism. 2018;84:56-66.

25. Cannon CP. Cardiovascular disease and modifiable cardiometabolic risk factors. Clin Cornerstone. 2007;8(3):11-28. 
26. Memar P, Faradji F. A novel multi-class eeg-based sleep stage classification system. IEEE Trans Neural Syst Rehabil Eng.

2018;26(1):84-95.

27. HR Colten, BM Altevogt editors. Sleep disorders and sleep deprivation: An unmet public health problem. Washington (DC)2006.

28. Gais S, Molle M, Helms K, Born J. Learning-dependent increases in sleep spindle density. J Neurosci. 2002;22(15):6830-4.

29. Somers VK, Dyken ME, Mark AL, Abboud FM. Sympathetic-nerve activity during sleep in normal subjects. N Engl J Med. 1993;328(5):303-7.

30. Van Cauter E, Leproult R, Plat L. Age-related changes in slow wave sleep and rem sleep and relationship with growth hormone and cortisol levels in healthy men. JAMA. 2000;284(7):861-8.

31. Herrera CG, Ponomarenko A, Korotkova T, Burdakov D, Adamantidis A. Sleep \& metabolism: The multitasking ability of lateral hypothalamic inhibitory circuitries. Front Neuroendocrinol. 2017;44:27-34.

32. Della Monica C, Johnsen S, Atzori G, Groeger JA, Dijk DJ. Rapid eye movement sleep, sleep continuity and slow wave sleep as predictors of cognition, mood, and subjective sleep quality in healthy men and women, aged 20-84 years. Front Psychiatry. 2018;9:255.

33. Nguyen J, Wright KP, Jr. Influence of weeks of circadian misalignment on leptin levels. Nat Sci Sleep. 2010;2:9-18.

34. Scheer FA, Hilton MF, Mantzoros CS, Shea SA. Adverse metabolic and cardiovascular consequences of circadian misalignment. Proc Natl Acad Sci U S A. 2009;106(11):4453-8.

35. Javeed N, Matveyenko AV. Circadian etiology of type 2 diabetes mellitus. Physiology (Bethesda). 2018;33(2):138-50.

36. Kalsbeek A, Palm IF, La Fleur SE, Scheer FA, Perreau-Lenz S, Ruiter M, Kreier F, Cailotto C, Buijs RM. Scn outputs and the hypothalamic balance of life. J Biol Rhythms. 2006;21(6):458-69.

37. Saini C, Suter DM, Liani A, Gos P, Schibler U. The mammalian circadian timing system: Synchronization of peripheral clocks. Cold Spring Harb Symp Quant Biol. 2011;76:39-47.

38. Partch CL, Green CB, Takahashi JS. Molecular architecture of the mammalian circadian clock. Trends Cell Biol. 2014;24(2):90-9.

39. Tahara Y, Shibata S. Entrainment of the mouse circadian clock: Effects of stress, exercise, and nutrition. Free Radic Biol Med. 2018;119:129-38.

40. Harfmann BD, Schroder EA, Kachman MT, Hodge BA, Zhang X, Esser $K A$. Muscle-specific loss of bmal1 leads to disrupted tissue glucose metabolism and systemic glucose homeostasis. Skelet Muscle. 2016;6:12.

41. McDearmon EL, Patel KN, Ko CH, Walisser JA, Schook AC, Chong JL, Wilsbacher LD, Song EJ, Hong HK, Bradfield CA, Takahashi JS.

Dissecting the functions of the mammalian clock protein bmal1 by tissuespecific rescue in mice. Science. 2006;314(5803):1304-8.

42. Boden G, Chen X, Urbain JL. Evidence for a circadian rhythm of insulin sensitivity in patients with niddm caused by cyclic changes in hepatic glucose production. Diabetes. 1996;45(8):1044-50. 
43. Ando H, Ushijima K, Shimba S, Fujimura A. Daily fasting blood glucose rhythm in male mice: A role of the circadian clock in the liver.

Endocrinology. 2016;157(2):463-9.

44. Lamia KA, Storch KF, Weitz CJ. Physiological significance of a peripheral tissue circadian clock. Proc Natl Acad Sci U S A. 2008;105(39):15172-7.

45. Canaple L, Rambaud J, Dkhissi-Benyahya O, Rayet B, Tan NS, Michalik L, Delaunay F, Wahli W, Laudet V. Reciprocal regulation of brain and muscle arnt-like protein 1 and peroxisome proliferator-activated receptor alpha defines a novel positive feedback loop in the rodent liver circadian clock. Mol Endocrinol. 2006;20(8):1715-27.

46. Zhang EE, Liu Y, Dentin R, Pongsawakul PY, Liu AC, Hirota T, Nusinow DA, Sun X, Landais S, Kodama Y, Brenner DA, Montminy M, Kay SA. Cryptochrome mediates circadian regulation of camp signaling and hepatic gluconeogenesis. Nat Med. 2010;16(10):1152-6.

47. Paschos GK, Ibrahim S, Song WL, Kunieda T, Grant G, Reyes TM, Bradfield CA, Vaughan $\mathrm{CH}$, Eiden M, Masoodi M, Griffin JL, Wang F, Lawson JA, Fitzgerald GA. Obesity in mice with adipocyte-specific deletion of clock component arntl. Nat Med. 2012;18(12):1768-77.

48. Xu H, Li H, Woo SL, Kim SM, Shende VR, Neuendorff N, Guo X, Guo T, Qi T, Pei Y, Zhao Y, Hu X, Zhao J, Chen L, Chen L, Ji JY, Alaniz RC, Earnest DJ, Wu C. Myeloid cell-specific disruption of period1 and period2 exacerbates diet-induced inflammation and insulin resistance. J Biol Chem. 2014;289(23):16374-88.

49. Marcheva B, Ramsey KM, Buhr ED, Kobayashi $\mathrm{Y}$, Su H, Ko CH, Ivanova G, Omura C, Mo S, Vitaterna MH, Lopez JP, Philipson LH, Bradfield CA, Crosby SD, JeBailey L, Wang X, Takahashi JS, Bass J. Disruption of the clock components clock and bmal1 leads to hypoinsulinaemia and diabetes. Nature. 2010;466(7306):627-31.

50. Ferrie JE, Kumari M, Salo P, Singh-Manoux A, Kivimaki M. Sleep epidemiology--a rapidly growing field. Int J Epidemiol. 2011;40(6):1431-7.

51. Knutson KL, Rathouz PJ, Yan LL, Liu K, Lauderdale DS. Intra-individual daily and yearly variability in actigraphically recorded sleep measures: The cardia study. Sleep. 2007;30(6):793-6.

52. Van Den Berg JF, Van Rooij FJ, Vos H, Tulen JH, Hofman A, Miedema HM, Neven AK, Tiemeier H. Disagreement between subjective and actigraphic measures of sleep duration in a population-based study of elderly persons. J Sleep Res. 2008;17(3):295-302.

53. Marino M, Li Y, Rueschman MN, Winkelman JW, Ellenbogen JM, Solet $\mathrm{JM}$, Dulin H, Berkman LF, Buxton OM. Measuring sleep: Accuracy, sensitivity, and specificity of wrist actigraphy compared to polysomnography. Sleep. 2013;36(11):1747-55.

54. Buysse DJ, Reynolds CF, 3rd, Monk TH, Berman SR, Kupfer DJ. The pittsburgh sleep quality index: A new instrument for psychiatric practice and research. Psychiatry Res. 1989;28(2):193-213.

55. Kato T. Development of the sleep quality questionnaire in healthy adults. $J$ Health Psychol. 2014;19(8):977-86. 
56. Johns MW. A new method for measuring daytime sleepiness: The epworth sleepiness scale. Sleep. 1991;14(6):540-5.

57. Hoddes E, Zarcone V, Smythe H, Phillips R, Dement WC. Quantification of sleepiness: A new approach. Psychophysiology. 1973;10(4):431-6.

58. Van de Water AT, Holmes A, Hurley DA. Objective measurements of sleep for non-laboratory settings as alternatives to polysomnography--a systematic review. J Sleep Res. 2011;20(1 Pt 2):183-200.

59. Hirshkowitz M. Polysomnography: Understanding this technology's past might guide future developments. IEEE Pulse. 2014;5(5):26-8.

60. Smith MT, McCrae CS, Cheung J, Martin JL, Harrod CG, Heald JL, Carden KA. Use of actigraphy for the evaluation of sleep disorders and circadian rhythm sleep-wake disorders: An american academy of sleep medicine systematic review, meta-analysis, and grade assessment. J Clin Sleep Med. 2018;14(7):1209-30.

61. Cole RJ, Kripke DF, Gruen W, Mullaney DJ, Gillin JC. Automatic sleep/wake identification from wrist activity. Sleep. 1992;15(5):461-9.

62. Sadeh A, Sharkey KM, Carskadon MA. Activity-based sleep-wake identification: An empirical test of methodological issues. Sleep. 1994;17(3):201-7.

63. Kushida CA, Chang A, Gadkary C, Guilleminault C, Carrillo O, Dement WC. Comparison of actigraphic, polysomnographic, and subjective assessment of sleep parameters in sleep-disordered patients. Sleep Med. 2001;2(5):389-96.

64. Ancoli-Israel S, Cole R, Alessi C, Chambers M, Moorcroft W, Pollak CP. The role of actigraphy in the study of sleep and circadian rhythms. Sleep. 2003;26(3):342-92.

65. Kosmadopoulos A, Sargent C, Darwent D, Zhou X, Roach GD. Alternatives to polysomnography (psg): A validation of wrist actigraphy and a partial-psg system. Behav Res Methods. 2014;46(4):1032-41.

66. Kanady JC, Drummond SP, Mednick SC. Actigraphic assessment of a polysomnographic-recorded nap: A validation study. J Sleep Res. 2011;20(1 Pt 2):214-22.

67. Anothaisintawee T, Reutrakul S, Van Cauter E, Thakkinstian A. Sleep disturbances compared to traditional risk factors for diabetes development: Systematic review and meta-analysis. Sleep Med Rev. 2016;30:11-24.

68. Knutson KL, Spiegel K, Penev P, Van Cauter E. The metabolic consequences of sleep deprivation. Sleep Med Rev. 2007;11(3):163-78.

69. Spiegel K, Leproult R, Van Cauter E. Impact of sleep debt on metabolic and endocrine function. Lancet. 1999;354(9188):1435-9.

70. Buxton OM, Pavlova M, Reid EW, Wang W, Simonson DC, Adler GK. Sleep restriction for 1 week reduces insulin sensitivity in healthy men. Diabetes. 2010;59(9):2126-33.

71. Wang X, Greer J, Porter RR, Kaur K, Youngstedt SD. Short-term moderate sleep restriction decreases insulin sensitivity in young healthy adults. Sleep Health. 2016;2(1):63-8. 
72. Reynolds AC, Dorrian J, Liu PY, Van Dongen HP, Wittert GA, Harmer LJ, Banks S. Impact of five nights of sleep restriction on glucose metabolism, leptin and testosterone in young adult men. PLoS One. 2012;7(7):e41218.

73. Shi SQ, Ansari TS, McGuinness OP, Wasserman DH, Johnson CH. Circadian disruption leads to insulin resistance and obesity. Curr Biol. 2013;23(5):372-81.

74. Turek FW, Joshu C, Kohsaka A, Lin E, Ivanova G, McDearmon E, Laposky A, Losee-Olson S, Easton A, Jensen DR, Eckel RH, Takahashi JS, Bass J. Obesity and metabolic syndrome in circadian clock mutant mice. Science. 2005;308(5724):1043-5.

75. Wilms B, Chamorro R, Hallschmid M, Trost D, Forck N, Schultes B, Molle M, Sayk F, Lehnert H, Schmid SM. Timing modulates the effect of sleep loss on glucose homeostasis. J Clin Endocrinol Metab. 2019;104(7):28018.

76. Schmid SM, Jauch-Chara K, Hallschmid M, Schultes B. Mild sleep restriction acutely reduces plasma glucagon levels in healthy men. J Clin Endocrinol Metab. 2009;94(12):5169-73.

77. Schmid SM, Hallschmid M, Jauch-Chara K, Bandorf N, Born J, Schultes $B$. Sleep loss alters basal metabolic hormone secretion and modulates the dynamic counterregulatory response to hypoglycemia. J Clin Endocrinol Metab. 2007;92(8):3044-51.

78. Goossens $\mathrm{GH}$. The role of adipose tissue dysfunction in the pathogenesis of obesity-related insulin resistance. Physiol Behav. 2008;94(2):206-18.

79. Ness KM, Strayer SM, Nahmod NG, Schade MM, Chang AM, Shearer GC, Buxton OM. Four nights of sleep restriction suppress the postprandial lipemic response and decrease satiety. J Lipid Res. 2019;60(11):1935-45.

80. Bjornholm M, Al-Khalili L, Dicker A, Naslund E, Rossner S, Zierath JR, Arner $\mathrm{P}$. Insulin signal transduction and glucose transport in human adipocytes: Effects of obesity and low calorie diet. Diabetologia. 2002;45(8):1128-35.

81. Kashiwagi A, Verso MA, Andrews J, Vasquez B, Reaven G, Foley JE. In vitro insulin resistance of human adipocytes isolated from subjects with noninsulin-dependent diabetes mellitus. J Clin Invest. 1983;72(4):1246-54.

82. Carrasco-Benso MP, Rivero-Gutierrez B, Lopez-Minguez J, Anzola A, Diez-Noguera A, Madrid JA, Lujan JA, Martinez-Augustin O, Scheer FA, Garaulet M. Human adipose tissue expresses intrinsic circadian rhythm in insulin sensitivity. FASEB J. 2016;30(9):3117-23.

83. Wilms B, Leineweber EM, Molle M, Chamorro R, Pommerenke C, SalinasRiester G, Sina C, Lehnert H, Oster H, Schmid SM. Sleep loss disrupts morning-to-evening differences in human white adipose tissue transcriptome. J Clin Endocrinol Metab. 2019;104(5):1687-96.

84. Shulman Gl. Cellular mechanisms of insulin resistance. J Clin Invest. 2000;106(2):171-6.

85. Saner NJ, Lee MJ, Pitchford NW, Kuang J, Roach GD, Garnham A, Stokes T, Phillips SM, Bishop DJ, Bartlett JD. The effect of sleep 
restriction, with or without high-intensity interval exercise, on myofibrillar protein synthesis in healthy young men. J Physiol. 2020.

86. Nedeltcheva AV, Imperial JG, Penev PD. Effects of sleep restriction on glucose control and insulin secretion during diet-induced weight loss. Obesity (Silver Spring). 2012;20(7):1379-86.

87. Nedeltcheva AV, Kilkus JM, Imperial J, Schoeller DA, Penev PD. Insufficient sleep undermines dietary efforts to reduce adiposity. Ann Intern Med. 2010;153(7):435-41.

88. Rao MN, Neylan TC, Grunfeld C, Mulligan K, Schambelan M, Schwarz JM. Subchronic sleep restriction causes tissue-specific insulin resistance. J Clin Endocrinol Metab. 2015;100(4):1664-71.

89. Irwin MR, Olmstead R, Carroll JE. Sleep disturbance, sleep duration, and inflammation: A systematic review and meta-analysis of cohort studies and experimental sleep deprivation. Biol Psychiatry. 2016;80(1):40-52.

90. Palmblad J, Petrini B, Wasserman J, Akerstedt T. Lymphocyte and granulocyte reactions during sleep deprivation. Psychosom Med. 1979;41(4):273-8.

91. Opp MR. Cytokines and sleep. Sleep Med Rev. 2005;9(5):355-64.

92. Irwin MR, Carrillo C, Olmstead R. Sleep loss activates cellular markers of inflammation: Sex differences. Brain Behav Immun. 2010;24(1):54-7.

93. Bauer J, Hohagen F, Ebert T, Timmer J, Ganter U, Krieger S, Lis S, Postler E, Voderholzer U, Berger M. Interleukin-6 serum levels in healthy persons correspond to the sleep-wake cycle. Clin Investig. 1994;72(4):315.

94. Vgontzas AN, Papanicolaou DA, Bixler EO, Lotsikas A, Zachman K, Kales A, Prolo P, Wong ML, Licinio J, Gold PW, Hermida RC, Mastorakos G, Chrousos GP. Circadian interleukin-6 secretion and quantity and depth of sleep. J Clin Endocrinol Metab. 1999;84(8):2603-7.

95. Vgontzas AN, Zoumakis E, Bixler EO, Lin HM, Follett H, Kales A, Chrousos GP. Adverse effects of modest sleep restriction on sleepiness, performance, and inflammatory cytokines. J Clin Endocrinol Metab. 2004;89(5):2119-26.

96. Redwine L, Hauger RL, Gillin JC, Irwin M. Effects of sleep and sleep deprivation on interleukin-6, growth hormone, cortisol, and melatonin levels in humans. J Clin Endocrinol Metab. 2000;85(10):3597-603.

97. Zielinski MR, Krueger JM. Sleep and innate immunity. Front Biosci (Schol Ed). 2011;3:632-42.

98. Hotamisligil GS, Shargill NS, Spiegelman BM. Adipose expression of tumor necrosis factor-alpha: Direct role in obesity-linked insulin resistance. Science. 1993;259(5091):87-91.

99. Hotamisligil GS, Spiegelman BM. Tumor necrosis factor alpha: A key component of the obesity-diabetes link. Diabetes. 1994;43(11):1271-8.

100. Cavadini G, Petrzilka S, Kohler P, Jud C, Tobler I, Birchler T, Fontana A. Tnf-alpha suppresses the expression of clock genes by interfering with ebox-mediated transcription. Proc Natl Acad Sci U S A. 2007;104(31):12843-8. 
101. Kapas L, Bohnet SG, Traynor TR, Majde JA, Szentirmai E, Magrath P, Taishi P, Krueger JM. Spontaneous and influenza virus-induced sleep are altered in tnf-alpha double-receptor deficient mice. J Appl Physiol (1985). 2008;105(4):1187-98.

102. Kaushal N, Ramesh V, Gozal D. Tnf-alpha and temporal changes in sleep architecture in mice exposed to sleep fragmentation. PLoS One. 2012;7(9):e45610.

103. Chennaoui M, Sauvet F, Drogou C, Van Beers P, Langrume C, Guillard M, Gourby B, Bourrilhon C, Florence G, Gomez-Merino D. Effect of one night of sleep loss on changes in tumor necrosis factor alpha (tnf-alpha) levels in healthy men. Cytokine. 2011;56(2):318-24.

104. Shearer WT, Reuben JM, Mullington JM, Price NJ, Lee BN, Smith EO, Szuba MP, Van Dongen HP, Dinges DF. Soluble tnf-alpha receptor 1 and il-6 plasma levels in humans subjected to the sleep deprivation model of spaceflight. J Allergy Clin Immunol. 2001;107(1):165-70.

105. Ruiz FS, Andersen ML, Martins RC, Zager A, Lopes JD, Tufik S. Immune alterations after selective rapid eye movement or total sleep deprivation in healthy male volunteers. Innate Immun. 2012;18(1):44-54.

106. Hogenkamp PS, Nilsson E, Nilsson VC, Chapman CD, Vogel H, Lundberg LS, Zarei S, Cedernaes J, Rangtell FH, Broman JE, Dickson SL, Brunstrom JM, Benedict C, Schioth HB. Acute sleep deprivation increases portion size and affects food choice in young men.

Psychoneuroendocrinology. 2013;38(9):1668-74.

107. Yang CL, Schnepp J, Tucker RM. Increased hunger, food cravings, food reward, and portion size selection after sleep curtailment in women without obesity. Nutrients. 2019;11(3).

108. Everson CA, Bergmann BM, Rechtschaffen A. Sleep deprivation in the rat: lii. Total sleep deprivation. Sleep. 1989;12(1):13-21.

109. Woods SC, Lotter EC, McKay LD, Porte D, Jr. Chronic intracerebroventricular infusion of insulin reduces food intake and body weight of baboons. Nature. 1979;282(5738):503-5.

110. Sahu A. Leptin signaling in the hypothalamus: Emphasis on energy homeostasis and leptin resistance. Front Neuroendocrinol. 2003;24(4):225-53.

111. Carnell S, Grillot C, Ungredda T, Ellis S, Mehta N, Holst J, Geliebter A. Morning and afternoon appetite and gut hormone responses to meal and stress challenges in obese individuals with and without binge eating disorder. Int J Obes (Lond). 2018;42(4):841-9.

112. Scheer FA, Morris CJ, Shea SA. The internal circadian clock increases hunger and appetite in the evening independent of food intake and other behaviors. Obesity (Silver Spring). 2013;21(3):421-3.

113. Taheri S, Lin L, Austin D, Young T, Mignot E. Short sleep duration is associated with reduced leptin, elevated ghrelin, and increased body mass index. PLoS Med. 2004;1(3):e62.

114. Benedict C, Brooks SJ, O'Daly OG, Almen MS, Morell A, Aberg K, Gingnell M, Schultes B, Hallschmid M, Broman JE, Larsson EM, Schioth 
HB. Acute sleep deprivation enhances the brain's response to hedonic food stimuli: An fmri study. J Clin Endocrinol Metab. 2012;97(3):E443-7.

115. Schmid SM, Hallschmid M, Jauch-Chara K, Born J, Schultes B. A single night of sleep deprivation increases ghrelin levels and feelings of hunger in normal-weight healthy men. J Sleep Res. 2008;17(3):331-4.

116. Spiegel K, Tasali E, Penev P, Van Cauter E. Brief communication: Sleep curtailment in healthy young men is associated with decreased leptin levels, elevated ghrelin levels, and increased hunger and appetite. Ann Intern Med. 2004;141(11):846-50.

117. Schoeller DA, Cella LK, Sinha MK, Caro JF. Entrainment of the diurnal rhythm of plasma leptin to meal timing. J Clin Invest. 1997;100(7):1882-7.

118. Mullington JM, Chan JL, Van Dongen HP, Szuba MP, Samaras J, Price NJ, Meier-Ewert HK, Dinges DF, Mantzoros CS. Sleep loss reduces diurnal rhythm amplitude of leptin in healthy men. $J$ Neuroendocrinol. 2003;15(9):851-4.

119. Spiegel K, Leproult R, L'Hermite-Baleriaux M, Copinschi G, Penev PD, Van Cauter E. Leptin levels are dependent on sleep duration:

Relationships with sympathovagal balance, carbohydrate regulation, cortisol, and thyrotropin. J Clin Endocrinol Metab. 2004;89(11):5762-71.

120. White DP, Weil JV, Zwillich CW. Metabolic rate and breathing during sleep. J Appl Physiol (1985). 1985;59(2):384-91.

121. Bonnet $\mathrm{MH}$, Berry RB, Arand DL. Metabolism during normal, fragmented, and recovery sleep. J Appl Physiol (1985). 1991;71(3):1112-8.

122. Jung CM, Melanson EL, Frydendall EJ, Perreault L, Eckel RH, Wright KP. Energy expenditure during sleep, sleep deprivation and sleep following sleep deprivation in adult humans. J Physiol. 2011;589(Pt 1):235-44.

123. Markwald RR, Melanson EL, Smith MR, Higgins J, Perreault L, Eckel RH, Wright KP, Jr. Impact of insufficient sleep on total daily energy expenditure, food intake, and weight gain. Proc Natl Acad Sci U S A. 2013;110(14):5695-700.

124. Nedeltcheva AV, Kilkus JM, Imperial J, Kasza K, Schoeller DA, Penev PD. Sleep curtailment is accompanied by increased intake of calories from snacks. Am J Clin Nutr. 2009;89(1):126-33.

125. St-Onge MP, Roberts AL, Chen J, Kelleman M, O'Keeffe M, RoyChoudhury A, Jones PJ. Short sleep duration increases energy intakes but does not change energy expenditure in normal-weight individuals. Am J Clin Nutr. 2011;94(2):410-6.

126. Im HJ, Baek SH, Chu MK, Yang KI, Kim WJ, Park SH, Thomas RJ, Yun $\mathrm{CH}$. Association between weekend catch-up sleep and lower body mass: Population-based study. Sleep. 2017;40(7).

127. Kim CW, Choi MK, Im HJ, Kim OH, Lee HJ, Song J, Kang JH, Park KH. Weekend catch-up sleep is associated with decreased risk of being overweight among fifth-grade students with short sleep duration. J Sleep Res. 2012;21(5):546-51.

128. Killick R, Hoyos CM, Melehan KL, Dungan GC, 2nd, Poh J, Liu PY. Metabolic and hormonal effects of 'catch-up' sleep in men with chronic, 
repetitive, lifestyle-driven sleep restriction. Clin Endocrinol (Oxf). 2015;83(4):498-507.

129. Leproult R, Deliens G, Gilson M, Peigneux P. Beneficial impact of sleep extension on fasting insulin sensitivity in adults with habitual sleep restriction. Sleep. 2015;38(5):707-15.

130. Eckel RH, Depner CM, Perreault L, Markwald RR, Smith MR, McHill AW, Higgins J, Melanson EL, Wright KP, Jr. Morning circadian misalignment during short sleep duration impacts insulin sensitivity. Curr Biol. 2015;25(22):3004-10.

131. Balkin TJ, Rupp T, Picchioni D, Wesensten NJ. Sleep loss and sleepiness: Current issues. Chest. 2008;134(3):653-60.

132. Carskadon MA, Dement WC, Mitler MM, Roth T, Westbrook PR, Keenan S. Guidelines for the multiple sleep latency test (mslt): A standard measure of sleepiness. Sleep. 1986;9(4):519-24.

133. Couyoumdjian A, Sdoia S, Tempesta D, Curcio G, Rastellini E, L DEG, Ferrara M. The effects of sleep and sleep deprivation on task-switching performance. J Sleep Res. 2010;19(1 Pt 1):64-70.

134. Curcio G, Ferrara M, De Gennaro L. Sleep loss, learning capacity and academic performance. Sleep Med Rev. 2006;10(5):323-37.

135. Durmer JS, Dinges DF. Neurocognitive consequences of sleep deprivation. Semin Neurol. 2005;25(1):117-29.

136. Ballesio A, Cerolini S, Ferlazzo F, Cellini N, Lombardo C. The effects of one night of partial sleep deprivation on executive functions in individuals reporting chronic insomnia and good sleepers. J Behav Ther Exp Psychiatry. 2018;60:42-5.

137. Cain SW, Silva EJ, Chang AM, Ronda JM, Duffy JF. One night of sleep deprivation affects reaction time, but not interference or facilitation in a stroop task. Brain Cogn. 2011;76(1):37-42.

138. Banich MT, Milham MP, Atchley R, Cohen NJ, Webb A, Wszalek T, Kramer AF, Liang ZP, Wright A, Shenker J, Magin R. Fmri studies of stroop tasks reveal unique roles of anterior and posterior brain systems in attentional selection. J Cogn Neurosci. 2000;12(6):988-1000.

139. Tassi $P$, Bonnefond A, Engasser O, Hoeft A, Eschenlauer R, Muzet A. Eeg spectral power and cognitive performance during sleep inertia: The effect of normal sleep duration and partial sleep deprivation. Physiol Behav. 2006;87(1):177-84.

140. Kato K, Iwamoto K, Kawano N, Noda Y, Ozaki N, Noda A. Differential effects of physical activity and sleep duration on cognitive function in young adults. J Sport Health Sci. 2018;7(2):227-36.

141. Prather AA, Bogdan R, Hariri AR. Impact of sleep quality on amygdala reactivity, negative affect, and perceived stress. Psychosom Med. 2013;75(4):350-8.

142. Mooy JM, de Vries H, Grootenhuis PA, Bouter LM, Heine RJ. Major stressful life events in relation to prevalence of undetected type 2 diabetes: The hoorn study. Diabetes Care. 2000;23(2):197-201. 
143. Garber CE, Blissmer B, Deschenes MR, Franklin BA, Lamonte MJ, Lee IM, Nieman DC, Swain DP, American College of Sports M. American college of sports medicine position stand. Quantity and quality of exercise for developing and maintaining cardiorespiratory, musculoskeletal, and neuromotor fitness in apparently healthy adults: Guidance for prescribing exercise. Med Sci Sports Exerc. 2011;43(7):1334-59.

144. Church TS, Thomas DM, Tudor-Locke C, Katzmarzyk PT, Earnest CP, Rodarte RQ, Martin CK, Blair SN, Bouchard C. Trends over 5 decades in u.S. Occupation-related physical activity and their associations with obesity. PLoS One. 2011;6(5):e19657.

145. Fogelholm M, Kukkonen-Harjula K. Does physical activity prevent weight gain--a systematic review. Obes Rev. 2000;1(2):95-111.

146. Kokkinos P. Physical activity, health benefits, and mortality risk. ISRN Cardiol. 2012;2012:718789.

147. Piercy KL, Troiano RP, Ballard RM, Carlson SA, Fulton JE, Galuska DA, George SM, Olson RD. The physical activity guidelines for americans. JAMA. 2018;320(19):2020-8.

148. McAuley PA, Kokkinos PF, Oliveira RB, Emerson BT, Myers JN. Obesity paradox and cardiorespiratory fitness in 12,417 male veterans aged 40 to 70 years. Mayo Clin Proc. 2010;85(2):115-21.

149. Montoye HJ, Washburn R, Servais S, Ertl A, Webster JG, Nagle FJ. Estimation of energy expenditure by a portable accelerometer. Med Sci Sports Exerc. 1983;15(5):403-7.

150. Troiano RP, Pettee Gabriel KK, Welk GJ, Owen N, Sternfeld B. Reported physical activity and sedentary behavior: Why do you ask? J Phys Act Health. 2012;9 Suppl 1:S68-75.

151. Matthews CE, Berrigan D, Fischer B, Gomersall SR, Hillreiner A, Kim Y, Leitzmann MF, Saint-Maurice P, Olds TS, Welk GJ. Use of previous-day recalls of physical activity and sedentary behavior in epidemiologic studies: Results from four instruments. BMC Public Health. 2019;19(Suppl 2):478.

152. Matthews CE, Moore SC, George SM, Sampson J, Bowles HR. Improving self-reports of active and sedentary behaviors in large epidemiologic studies. Exercise and sport sciences reviews. 2012;40(3):118-26.

153. Hagstromer M, Ainsworth BE, Oja P, Sjostrom M. Comparison of a subjective and an objective measure of physical activity in a population sample. J Phys Act Health. 2010;7(4):541-50.

154. Dyrstad SM, Hansen BH, Holme IM, Anderssen SA. Comparison of selfreported versus accelerometer-measured physical activity. Med Sci Sports Exerc. 2014;46(1):99-106.

155. Schoeller DA, van Santen E. Measurement of energy expenditure in humans by doubly labeled water method. J Appl Physiol Respir Environ Exerc Physiol. 1982;53(4):955-9.

156. Schoeller DA. Measurement of energy expenditure in free-living humans by using doubly labeled water. J Nutr. 1988;118(11):1278-89. 
157. Troiano RP, Berrigan D, Dodd KW, Masse LC, Tilert T, McDowell M. Physical activity in the united states measured by accelerometer. Med Sci Sports Exerc. 2008;40(1):181-8.

158. Aadland E, Ylvisaker E. Reliability of objectively measured sedentary time and physical activity in adults. PLoS One. 2015;10(7):e0133296.

159. Tudor-Locke C, Camhi SM, Troiano RP. A catalog of rules, variables, and definitions applied to accelerometer data in the national health and nutrition examination survey, 2003-2006. Prev Chronic Dis. 2012;9:E113.

160. Tudor-Locke C, Barreira TV, Schuna JM, Jr. Comparison of step outputs for waist and wrist accelerometer attachment sites. Med Sci Sports Exerc. 2015;47(4):839-42.

161. Kerr J, Marinac CR, Ellis K, Godbole S, Hipp A, Glanz K, Mitchell J, Laden $F$, James P, Berrigan D. Comparison of accelerometry methods for estimating physical activity. Med Sci Sports Exerc. 2017;49(3):617-24.

162. Kamada M, Shiroma EJ, Harris TB, Lee IM. Comparison of physical activity assessed using hip- and wrist-worn accelerometers. Gait Posture. 2016;44:23-8.

163. Staudenmayer J, He S, Hickey A, Sasaki J, Freedson P. Methods to estimate aspects of physical activity and sedentary behavior from highfrequency wrist accelerometer measurements. J Appl Physiol (1985). 2015;119(4):396-403.

164. Welk G. Physical activity assessments for health-related research. Champaign, IL: Human Kinetics; 2002, x, 269 p. p.

165. Rosenberger ME, Haskell WL, Albinali F, Mota S, Nawyn J, Intille S. Estimating activity and sedentary behavior from an accelerometer on the hip or wrist. Med Sci Sports Exerc. 2013;45(5):964-75.

166. Bassett DR, Jr., Rowlands A, Trost SG. Calibration and validation of wearable monitors. Med Sci Sports Exerc. 2012;44(1 Suppl 1):S32-8.

167. Ellis K, Kerr J, Godbole S, Staudenmayer J, Lanckriet G. Hip and wrist accelerometer algorithms for free-living behavior classification. Med Sci Sports Exerc. 2016;48(5):933-40.

168. Hildebrand M, VT VANH, Hansen BH, Ekelund U. Age group comparability of raw accelerometer output from wrist- and hip-worn monitors. Med Sci Sports Exerc. 2014;46(9):1816-24.

169. Warren TY, Barry V, Hooker SP, Sui X, Church TS, Blair SN. Sedentary behaviors increase risk of cardiovascular disease mortality in men. Med Sci Sports Exerc. 2010;42(5):879-85.

170. Patterson R, McNamara E, Tainio M, de Sa TH, Smith AD, Sharp SJ, Edwards P, Woodcock J, Brage S, Wijndaele K. Sedentary behaviour and risk of all-cause, cardiovascular and cancer mortality, and incident type 2 diabetes: A systematic review and dose response meta-analysis. Eur $J$ Epidemiol. 2018;33(9):811-29.

171. Booth FW, Roberts CK, Thyfault JP, Ruegsegger GN, Toedebusch RG. Role of inactivity in chronic diseases: Evolutionary insight and pathophysiological mechanisms. Physiol Rev. 2017;97(4):1351-402. 
172. Pate RR, O'Neill JR, Lobelo F. The evolving definition of "sedentary". Exercise and sport sciences reviews. 2008;36(4):173-8.

173. Booth FW, Roberts CK, Laye MJ. Lack of exercise is a major cause of chronic diseases. Compr Physiol. 2012;2(2):1143-211.

174. Bergouignan A, Rudwill F, Simon C, Blanc S. Physical inactivity as the culprit of metabolic inflexibility: Evidence from bed-rest studies. $J$ Appl Physiol (1985). 2011;111(4):1201-10.

175. Olsen RH, Krogh-Madsen R, Thomsen C, Booth FW, Pedersen BK. Metabolic responses to reduced daily steps in healthy nonexercising men. JAMA. 2008;299(11):1261-3.

176. Krogh-Madsen R, Thyfault JP, Broholm C, Mortensen $\mathrm{OH}$, Olsen $\mathrm{RH}$, Mounier R, Plomgaard P, van Hall G, Booth FW, Pedersen BK. A 2-wk reduction of ambulatory activity attenuates peripheral insulin sensitivity. $J$ Appl Physiol (1985). 2010;108(5):1034-40.

177. Mikus CR, Oberlin DJ, Libla JL, Taylor AM, Booth FW, Thyfault JP. Lowering physical activity impairs glycemic control in healthy volunteers. Med Sci Sports Exerc. 2012;44(2):225-31.

178. Winn NC, Pettit-Mee R, Walsh LK, Restaino RM, Ready ST, Padilla J, Kanaley JA. Metabolic implications of diet and energy intake during physical inactivity. Med Sci Sports Exerc. 2019;51(5):995-1005.

179. Stephens BR, Granados K, Zderic TW, Hamilton MT, Braun B. Effects of 1 day of inactivity on insulin action in healthy men and women: Interaction with energy intake. Metabolism. 2011;60(7):941-9.

180. Dunstan DW, Kingwell BA, Larsen R, Healy GN, Cerin E, Hamilton MT, Shaw JE, Bertovic DA, Zimmet PZ, Salmon J, Owen N. Breaking up prolonged sitting reduces postprandial glucose and insulin responses. Diabetes Care. 2012;35(5):976-83.

181. Larsen RN, Kingwell BA, Robinson C, Hammond L, Cerin E, Shaw JE, Healy GN, Hamilton MT, Owen N, Dunstan DW. Breaking up of prolonged sitting over three days sustains, but does not enhance, lowering of postprandial plasma glucose and insulin in overweight and obese adults. Clin Sci (Lond). 2015;129(2):117-27.

182. Pulsford RM, Blackwell J, Hillsdon M, Kos K. Intermittent walking, but not standing, improves postprandial insulin and glucose relative to sustained sitting: A randomised cross-over study in inactive middle-aged men. J Sci Med Sport. 2017;20(3):278-83.

183. Bailey DP, Locke CD. Breaking up prolonged sitting with light-intensity walking improves postprandial glycemia, but breaking up sitting with standing does not. J Sci Med Sport. 2015;18(3):294-8.

184. Benatti FB, Ried-Larsen M. The effects of breaking up prolonged sitting time: A review of experimental studies. Med Sci Sports Exerc. 2015;47(10):2053-61.

185. Morishima T, Restaino RM, Walsh LK, Kanaley JA, Padilla J. Prior exercise and standing as strategies to circumvent sitting-induced leg endothelial dysfunction. Clin Sci (Lond). 2017;131(11):1045-53. 
186. Warburton DER, Bredin SSD. Health benefits of physical activity: A systematic review of current systematic reviews. Curr Opin Cardiol. 2017;32(5):541-56.

187. Bouchard C, Blair SN, Katzmarzyk PT. Less sitting, more physical activity, or higher fitness? Mayo Clin Proc. 2015;90(11):1533-40.

188. Bjornholm M, Kawano Y, Lehtihet M, Zierath JR. Insulin receptor substrate-1 phosphorylation and phosphatidylinositol 3-kinase activity in skeletal muscle from niddm subjects after in vivo insulin stimulation. Diabetes. 1997;46(3):524-7.

189. Goodyear LJ, Giorgino F, Sherman LA, Carey J, Smith RJ, Dohm GL. Insulin receptor phosphorylation, insulin receptor substrate-1 phosphorylation, and phosphatidylinositol 3-kinase activity are decreased in intact skeletal muscle strips from obese subjects. J Clin Invest. 1995;95(5):2195-204.

190. Zierath JR, He L, Guma A, Odegoard Wahlstrom E, Klip A, WallbergHenriksson $\mathrm{H}$. Insulin action on glucose transport and plasma membrane glut4 content in skeletal muscle from patients with niddm. Diabetologia. 1996;39(10):1180-9.

191. Kennedy JW, Hirshman MF, Gervino EV, Ocel JV, Forse RA, Hoenig SJ, Aronson D, Goodyear LJ, Horton ES. Acute exercise induces glut4 translocation in skeletal muscle of normal human subjects and subjects with type 2 diabetes. Diabetes. 1999;48(5):1192-7.

192. Mikines KJ, Sonne B, Farrell PA, Tronier B, Galbo H. Effect of physical exercise on sensitivity and responsiveness to insulin in humans. $A m \mathrm{~J}$ Physiol. 1988;254(3 Pt 1):E248-59.

193. Hawley JA, Houmard JA. Introduction-preventing insulin resistance through exercise: A cellular approach. Med Sci Sports Exerc. 2004;36(7):1187-90.

194. Roberts CK, Little JP, Thyfault JP. Modification of insulin sensitivity and glycemic control by activity and exercise. Med Sci Sports Exerc. 2013;45(10):1868-77.

195. Rynders CA, Weltman JY, Jiang B, Breton M, Patrie J, Barrett EJ, Weltman A. Effects of exercise intensity on postprandial improvement in glucose disposal and insulin sensitivity in prediabetic adults. J Clin Endocrinol Metab. 2014;99(1):220-8.

196. Newsom SA, Everett AC, Hinko A, Horowitz JF. A single session of lowintensity exercise is sufficient to enhance insulin sensitivity into the next day in obese adults. Diabetes Care. 2013;36(9):2516-22 .

197. Houmard JA, Tanner CJ, Slentz CA, Duscha BD, McCartney JS, Kraus WE. Effect of the volume and intensity of exercise training on insulin sensitivity. J Appl Physiol (1985). 2004;96(1):101-6.

198. Ross R, Dagnone D, Jones PJ, Smith H, Paddags A, Hudson R, Janssen I. Reduction in obesity and related comorbid conditions after diet-induced weight loss or exercise-induced weight loss in men. A randomized, controlled trial. Ann Intern Med. 2000;133(2):92-103. 
199. Martin WH, 3rd. Effects of acute and chronic exercise on fat metabolism. Exercise and sport sciences reviews. 1996;24:203-31.

200. Martins AR, Nachbar RT, Gorjao R, Vinolo MA, Festuccia WT, Lambertucci RH, Cury-Boaventura MF, Silveira LR, Curi R, Hirabara SM. Mechanisms underlying skeletal muscle insulin resistance induced by fatty acids: Importance of the mitochondrial function. Lipids Health Dis. 2012;11:30.

201. Craig BW, Hammons GT, Garthwaite SM, Jarett L, Holloszy JO. Adaptation of fat cells to exercise: Response of glucose uptake and oxidation to insulin. J Appl Physiol Respir Environ Exerc Physiol. 1981;51(6):1500-6.

202. Higa TS, Spinola AV, Fonseca-Alaniz MH, Evangelista FS. Remodeling of white adipose tissue metabolism by physical training prevents insulin resistance. Life Sci. 2014;103(1):41-8.

203. Welly RJ, Liu TW, Zidon TM, Rowles JL, 3rd, Park YM, Smith TN, Swanson KS, Padilla J, Vieira-Potter VJ. Comparison of diet vs. Exercise on metabolic function \& gut microbiota in obese rats. Med Sci Sports Exerc. 2016;48(9):1688-98.

204. Stanford KI, Middelbeek RJ, Townsend KL, Lee MY, Takahashi H, So K, Hitchcox KM, Markan KR, Hellbach K, Hirshman MF, Tseng YH, Goodyear LJ. A novel role for subcutaneous adipose tissue in exerciseinduced improvements in glucose homeostasis. Diabetes. 2015;64(6):2002-14.

205. Despres JP, Bouchard C, Savard R, Tremblay A, Marcotte M, Theriault G. The effect of a 20 -week endurance training program on adipose-tissue morphology and lipolysis in men and women. Metabolism. 1984;33(3):235-9.

206. You T, Murphy KM, Lyles MF, Demons JL, Lenchik L, Nicklas BJ. Addition of aerobic exercise to dietary weight loss preferentially reduces abdominal adipocyte size. Int J Obes (Lond). 2006;30(8):1211-6.

207. Ronn T, Volkov P, Tornberg A, Elgzyri T, Hansson O, Eriksson KF, Groop L, Ling C. Extensive changes in the transcriptional profile of human adipose tissue including genes involved in oxidative phosphorylation after a 6-month exercise intervention. Acta Physiol (Oxf). 2014;211(1):188-200.

208. Fabre O, Ingerslev LR, Garde C, Donkin I, Simar D, Barres R. Exercise training alters the genomic response to acute exercise in human adipose tissue. Epigenomics. 2018;10(8):1033-50.

209. Tajiri E, Yoshimura E, Hatamoto Y, Tanaka H, Shimoda S. Effect of sleep curtailment on dietary behavior and physical activity: A randomized crossover trial. Physiol Behav. 2018;184:60-7.

210. Bromley LE, Booth JN, 3rd, Kilkus JM, Imperial JG, Penev PD. Sleep restriction decreases the physical activity of adults at risk for type 2 diabetes. Sleep. 2012;35(7):977-84.

211. Wilms B, Kuhr M, Chamorro R, Klinsmann N, Spyra D, Molle M, Kalscheuer H, Schultes B, Lehnert H, Schmid SM. Chronobiological 
aspects of sleep restriction modulate subsequent spontaneous physical activity. Physiol Behav. 2020;215:112795.

212. Sweeney EL, Peart DJ, Kyza I, Harkes T, Ellis JG, Walshe IH. Impaired insulin profiles following a single night of sleep restriction: The impact of acute sprint interval exercise. Int J Sport Nutr Exerc Metab. 2019:1-6.

213. Stoet G. Psytoolkit: A software package for programming psychological experiments using linux. Behav Res Methods. 2010;42(4):1096-104.

214. Stoet G. Psytoolkit:A novel web-based method for running online questionnaires and reaction-time experiments. Teaching of Psychology. 2017;44(1):24-31.

215. Matsuda M, DeFronzo RA. Insulin sensitivity indices obtained from oral glucose tolerance testing: Comparison with the euglycemic insulin clamp. Diabetes Care. 1999;22(9):1462-70.

216. Gastaldelli A, Harrison SA, Belfort-Aguilar R, Hardies LJ, Balas B, Schenker S, Cusi K. Importance of changes in adipose tissue insulin resistance to histological response during thiazolidinedione treatment of patients with nonalcoholic steatohepatitis. Hepatology. 2009;50(4):108793.

217. Steil GM, Hwu CM, Janowski R, Hariri F, Jinagouda S, Darwin C, Tadros $\mathrm{S}$, Rebrin K, Saad MF. Evaluation of insulin sensitivity and beta-cell function indexes obtained from minimal model analysis of a meal tolerance test. Diabetes. 2004;53(5):1201-7.

218. Rossen J, Buman MP, Johansson UB, Yngve A, Ainsworth B, Brismar K, Hagstromer M. Reallocating bouted sedentary time to non-bouted sedentary time, light activity and moderate-vigorous physical activity in adults with prediabetes and type 2 diabetes. PLoS One. 2017;12(7):e0181053.

219. Garcia-Hermoso A, Saavedra JM, Ramirez-Velez R, Ekelund U, Del PozoCruz B. Reallocating sedentary time to moderate-to-vigorous physical activity but not to light-intensity physical activity is effective to reduce adiposity among youths: A systematic review and meta-analysis. Obes Rev. 2017;18(9):1088-95.

220. Grgic J, Dumuid D, Bengoechea EG, Shrestha N, Bauman A, Olds T, Pedisic Z. Health outcomes associated with reallocations of time between sleep, sedentary behaviour, and physical activity: A systematic scoping review of isotemporal substitution studies. Int J Behav Nutr Phys Act. 2018;15(1):69.

221. Mekary RA, Willett WC, Hu FB, Ding EL. Isotemporal substitution paradigm for physical activity epidemiology and weight change. Am J Epidemiol. 2009;170(4):519-27.

222. Bosy-Westphal A, Hinrichs S, Jauch-Chara K, Hitze B, Later W, Wilms B, Settler U, Peters A, Kiosz D, Muller MJ. Influence of partial sleep deprivation on energy balance and insulin sensitivity in healthy women. Obes Facts. 2008;1(5):266-73. 
223. Al Khatib HK, Harding SV, Darzi J, Pot GK. The effects of partial sleep deprivation on energy balance: A systematic review and meta-analysis. Eur J Clin Nutr. 2017;71(5):614-24.

224. Goodyear LJ, Kahn BB. Exercise, glucose transport, and insulin sensitivity. Annu Rev Med. 1998;49:235-61.

225. Hawley JA. Exercise as a therapeutic intervention for the prevention and treatment of insulin resistance. Diabetes Metab Res Rev. 2004;20(5):38393.

226. Sears B, Perry M. The role of fatty acids in insulin resistance. Lipids Health Dis. 2015;14:121.

227. Shechter A, Rising R, Wolfe S, Albu JB, St-Onge MP. Postprandial thermogenesis and substrate oxidation are unaffected by sleep restriction. Int J Obes (Lond). 2014;38(9):1153-8.

228. Hibi M, Kubota C, Mizuno T, Aritake S, Mitsui Y, Katashima M, Uchida S. Effect of shortened sleep on energy expenditure, core body temperature, and appetite: A human randomised crossover trial. Sci Rep. 2017;7:39640.

229. Wright KP, Jr., Drake AL, Frey DJ, Fleshner M, Desouza CA, Gronfier C, Czeisler CA. Influence of sleep deprivation and circadian misalignment on cortisol, inflammatory markers, and cytokine balance. Brain Behav Immun. 2015;47:24-34.

230. Haack M, Sanchez E, Mullington JM. Elevated inflammatory markers in response to prolonged sleep restriction are associated with increased pain experience in healthy volunteers. Sleep. 2007;30(9):1145-52.

231. van Leeuwen WM, Lehto $M$, Karisola $P$, Lindholm $H$, Luukkonen $R$, Sallinen M, Harma M, Porkka-Heiskanen T, Alenius H. Sleep restriction increases the risk of developing cardiovascular diseases by augmenting proinflammatory responses through il-17 and crp. PLOS One. 2009;4(2):e4589.

232. Sharma A, Madaan V, Petty FD. Exercise for mental health. Prim Care Companion J Clin Psychiatry. 2006;8(2):106.

233. Belenky G, Wesensten NJ, Thorne DR, Thomas ML, Sing HC, Redmond DP, Russo MB, Balkin TJ. Patterns of performance degradation and restoration during sleep restriction and subsequent recovery: A sleep dose-response study. J Sleep Res. 2003;12(1):1-12.

234. Shechter A, Varin F, Boivin DB. Circadian variation of sleep during the follicular and luteal phases of the menstrual cycle. Sleep. 2010;33(5):64756. 


\section{Appendix i}

\section{CONSENT Form TO PARTICIPATE IN A RESEARCH STUdY}

Researcher's Name(s): Jill Kanaley, $\mathrm{PhD}$

Project Number: 2011452

Version \#: 3, November 26, 2018

Project Title: Sleep, Exercise and Insulin Sensitivity

INTRODUCTION

You are being asked to participate in a research study. This research is being conducted to gain a greater understanding how sleep loss may impact physical activity levels and metabolic health. When you are invited to participate in research, you have the right to be informed about the study procedures so that you can decide whether you want to consent to participation. If this form may contain words that you do not know, please ask the researcher to explain any words or information that you do not understand.

You have the right to know what you will be asked to do so that you can decide whether or not to be in the study. Your participation is voluntary. You do not have to be in the study if you do not want to. You may refuse to be in the study and nothing will happen. If you do not want to continue to be in the study, you may stop at any time without penalty or loss of benefits to which you are otherwise entitled.

This research is funded by the MU Department of Nutrition and Exercise Physiology.

\section{WHY IS THIS STUDY BEING DONE?}

Insufficient or disrupted sleep and circadian misalignment have been linked with obesity and are now potential targets to combat obesity. Sleep related issues have become more important as people have been able to work, socialize, and use electronic devices outside of daylight hours. This has shortened sleep which has been associated with increased incidence of obesity and diabetes as well as increased overall sedentary time. Sleeping only $4 \mathrm{~h}$ a night or less for repeated nights has been shown to cause glucose insensitivity. To date, little is known about how we change our physical activity/exercise patterns due to shortened sleep and what happens when we recover our loss of sleep.

\section{HOW MANY PEOPLE WILL BE IN THE STUDY?}

About 20 people will take part in this study at the University of Missouri-Columbia.

You are being asked to take part in this study because you sleep 7-9 h per night, have a BMI of 25-40 $\mathrm{kg} / \mathrm{m} 2$ and are within the ages of $21-40$ years.

\section{WHAT AM I BEING ASKED TO DO?}

This study will involve a screening, some initial testing to make sure you qualify, and completing 2 twoweek study protocols which will be a few weeks apart. One study protocol will involve monitoring your own sleep patterns for one week, followed by a second week where you will be asked to shorten your sleep by $2 \mathrm{hr}$ for 5 nights and then will be followed for 2 nights of ad libitum sleep. During this 2 week 
period, we will ask you to come in for a meal tolerance test at the end of week one, after 5 days of shortened sleep and after 2 days of ad libitum sleep. This 2 week period will be repeated but will include $40 \mathrm{~min}$ of treadmill/walking or running at a moderate intensity ( $65 \% \mathrm{VO} 2 \mathrm{max})$. These study periods will be conducted in a random order.

To monitor physical activity and sleep you will wear an activity monitor (actigraph- worn on the hip) and sleep monitor (actiwatch - worn on the wrist) for 2 weeks. All of your sleep will be done at your own home.

Meal tolerance test: Glucose tolerance will be assessed after 7 days of normal habits, after 5 days of sleep deprivation, and after 2 days of ad libitum sleep, totaling 6 glucose tolerance tests throughout the entirety of the study

This study will be conducted at the MU Physical Activity and Wellness (MUPAW) center in Gwynn Hall and in McKee Gymnasium.

Visit 1: Screening: The screening and testing will take place in MUPAW in Gwynn Hall (Rm 018) and will take $\sim 30 \mathrm{~min}$. During the screening, we will go over this informed consent form and answer any questions you may have. Once the consent form is signed, we will measure your height, weight, waist circumference, and blood pressure. In addition, you will complete questionnaire such as health history, sleep, physical activity, dietary record, depression/anxiety and morningness questionnaire. A DXA scan will also be recorded. You will also perform a maximal peak aerobic capacity test $\left(\mathrm{VO}_{2} \mathrm{max}\right)$.

We ask you to wear a pulse oximeter on your wrist for one night while you sleep. It is a clip that is worn on your finger and watch that collects the data.

Aerobic Capacity: You will perform a maximal peak oxygen consumption test (VO2peak) on a treadmill. Prior to starting the test, electrodes will be placed on your chest and abdomen to monitor heart rate activity during the test. A mask will be fitted securely to your face, covering the nose and mouth, and connected to a metabolic cart through a flexible hose in order to measure the amount of oxygen consumed and carbon dioxide expelled. Heart rate and blood pressure readings will be taken periodically during the test. The test will begin with 2 minutes of moderate walking $(3.5 \mathrm{mph})$ with no resistance. Next, the speed and incline of the treadmill (or resistance on the cycle ergometer) will be increased every 2 minutes until you reach volitional exhaustion. Following the exercise test, you will perform an active cool-down and be monitored for 5-10 minutes until $\mathrm{HR}$ and $\mathrm{BP}$ parameters have returned to near baseline.

Body Composition: A DEXA scan will also be conducted $(10 \mathrm{~min})$. (Women only will be asked if it possibility that they are pregnant. If they say yes, a home pregnancy test prior to the DXA scan will be done).

Visit 2: Subjects will collect physical activity monitor (actigraph) and sleep monitor (actiwatch) along with surveys to fill out each day about dietary consumption, sleep habits and physical activity, lasting for 14 days.

Accelerometer: This measures how much physical activity you engage in and how much time that you are inactive. The accelerometer is small (about the size of a large rubber eraser) and is worn on a belt around your waist. 
Actiwatch: This measures your sleep habits and is worn on the wrist and looks like a watch.

Visit 3-5: Meal tolerance test: You will arrive at MUPAW at $~ 7 \mathrm{AM}$, after completing at least a 10 hour fast, abstain from caffeine for $>10$ hours and alcohol for 24 hours prior to arriving. An IV catheter will be placed in the antecubital vein of a forearm vein. A mixed meal tolerance test will consist of a commercially available shake (similar to Ensure -16 ounces) that will be consumed within 10 minutes. Blood samples $(\sim 5 \mathrm{~mL})$ will be over a $3 \mathrm{~h}$ period following ingestion.

You will be instructed to rest quietly for the period during blood sampling. You will also be required to complete visual analog scales (VAS) for appetite measures at baseline, and at 30-minute intervals thereafter during the tests. This will be done on a handheld device. VAS scales consist of a $10 \mathrm{~cm}$ line where individuals subjectively rate measures of a sensation (i.e. hunger, satiety), and has been correlated with physiological markers.

Visit 6: Repeat of Visit 2.

Visit 7-9: Repeat of Visit 3-5. During these visits you will also be asked to come to McKee Gymnasium to exercise for 45 minutes for 5 days. A mask will be used to monitor oxygen consumption for 10 minutes at the start of the session to ensure appropriate work load.

\section{Optional Fat Biopsies}

Fat is a tissue that is now being recognized as not just an inert tissue but responding to stresses placed on the body and possibly changing metabolism. We are interested in establishing if fat tissue responds to the sleep deprivation stress that we are inducing by altering inflammation and metabolism.

You have the option to participate in this part of the study. We would take a fat biopsy from the fat just beneath the skin in the abdominal region. This would involve numbing the skin, and inserting a large needle into this fat depot to collect the fat. We would like to do this on visits 3,4 and 7 . It would lengthen the visit by about a $1 / 2 \mathrm{hr}$, and we will compensate you for participating in this additional part of the study.

\section{HOW LONG WILL I BE IN THE STUDY?}

This study will take approximately 5 weeks to complete, depending on scheduling. You can stop participating at any time without penalty.

\section{WHAT ARE THE BENEFITS OF BEING IN THE STUDY?}

Your will benefit from participating in the proposed study by learning more about the potential impact of restricting sleep on metabolic health. You will learn about your body composition, aerobic fitness and about your habitual physical activity level. In addition, you may benefit from the exercise sessions as it is designed to improve your health.

\section{WHAT ARE THE RISKS OF BEING IN THE STUDY?}

The risks to you for participating in this study are:

1. The DXA scan may make you slightly uncomfortable because you have to hold very still. This research study involves exposure to radiation and the amount you will receive is equal to the radiation that most Americans receive in about 2 days from background radiation, such as naturally occurring radioactivity in

MU IRB: CONSENT
HS IRB USE ONLY

Approval Date: December 12, 2018

Expiration Date: June 13, 2019
PAGE 3 of 7 
the soil and air. The risk from radiation exposures of this magnitude is too small to be measured directly and is considered to be very low when compared with other everyday risks. Also, we will verbally ask you if you could be pregnant. If you think you could be we will ask you to take a urine pregnancy test so that we can confirm whether you are or not.

2. Blood sampling may cause fainting and some discomfort and/or bruising at the site on your arm where the blood was taken. Rarely an infection occurs at the blood drawing site. There is also a risk of a blood clot forming in your vein and a risk of developing anemia. A nurse or trained technician will use sterile technique to place the catheter.

3. Reproductive risks: The effects of these tests on the female or male reproductive systems or on a developing fetus are unknown but could cause harm. For this reason, it is necessary to avoid getting pregnant while you are a subject in this study. You must also inform Dr. Kanaley immediately if you or you/your partner becomes pregnant. If you have any questions about the reproductive issues or about preventing pregnancy, please discuss them with Dr. Kanaley or your doctor.

4. Exercise testing/training: The risks associated with the exercise test and exercise on the study night include: increased blood pressure, and heart arrhythmias (abnormal heart beat). There is a very small risk of a heart attack during the exercise test or training, and the exercise is supervised by trained technicians. Exercise may cause skeletal muscle soreness or shin soreness. This is not permanent and will resolve within a few days.

5. Mixed Meal Tolerance Test: The risks of the tolerance test are minimal. This is a commercially available product meal replacement shake. Some people do not like the flavor of the shake although we try to provide various flavors.

6. Fat Biopsy - optional: The risks associated with fat biopsies are minimal as they are performed under sterile procedures. It is possible there will be bruising, which may be large and the bruise should subside like any other bruise. A lump may occur due to a collection of blood under the skin. It may take several weeks to be reabsorbed by the body. Occasionally dips at the fat biopsy sites may occur later, and massaging the fat biopsy site should help this to return to normal faster. There is a slight risk of infection if the biopsy site is not well cared for. After the numbing medicine wears off the area may become tender and this pain/discomfort may last about $24-48 \mathrm{hr}$.

\section{WHAT ARE THE COSTS OF BEING IN THE STUDY?}

There is no cost to you.

\section{WHAT OTHER OPTIONS ARE THERE?}

Instead of being in this study, you have these options:

An alternative is to not be in this research study.

You also have the option of not participating in this study and will not be penalized for your decision.

\section{CONFIDENTIALITY}

MU IRB: CONSENT

HS IRB USE ONLY

Approval Date: December 12, 2018

Expiration Date: June 13, 2019

PAGE 4 of 7 
Information produced by this study will be stored in the investigator's file and identified by a code number only. The code key connecting your name to specific information about you will be kept in a separate, secure location. Information contained in your records may not be given to anyone unaffiliated with the study in a form that could identify you without your written consent, except as required by law. If the investigator conducting this study is not your primary or regular doctor, she must obtain your permission before contacting your regular doctor for information about your past medical history or to inform them that you are in this trial.

It is possible that your research record, including sensitive information and/or identifying information, may be inspected and/or copied by the study sponsor (and/or its agent), federal or state government agencies, or hospital accrediting agencies, in the course of carrying out their duties. If your record is inspected or copied by the study sponsor (and/or its agents), or by any of these agencies, the University of Missouri will use reasonable efforts to protect your privacy and the confidentiality of your medical information.

The results of this study may be published in a medical book or journal or used for teaching purposes. However, your name or other identifying information will not be used in any publication or teaching materials without your specific permission.

\section{WILL I BE COMPENSATED FOR PARTICIPATING IN THE STUDY?}

You will be compensated $\$ 350$ upon completion of the study. If you do not complete the whole study you will receive $\$ 50$ for completing the initial screening, $\$ 125$ completing one condition of the study. If you fail to qualify after the screening because you do not sleep $7-9 \mathrm{hr}$ then you will receive only the $\$ 50$.

Optional fat biopsy: Subjects who opt to have the fat biopsies done will receive an additional $\$ 150$ (\$50/biopsy).

\section{WHAT IF I AM INJURED?}

It is not the policy of the University of Missouri to compensate human subjects in the event the research results in injury. The University of Missouri, in fulfilling its public responsibility, has provided medical, professional and general liability insurance coverage for any injury in the event such injury is caused by the negligence of the University of Missouri, its faculty and staff. The University of Missouri also provides, within the limitations of the laws of the State of Missouri, facilities and medical attention to subjects who suffer injuries while participating in the research projects of the University of Missouri. In the event you have suffered injury as the result of participation in this research program, you are to contact the Risk Management Officer, telephone number (573) 882-1181, at the Health Sciences Center, who can review the matter and provide further information. This statement is not to be construed as an admission of liability.

\section{WHAT ARE MY RIGHTS AS A PARTICIPANT?}

Participation in this study is voluntary. You do not have to participate in this study.

You will also be informed of any new information discovered during the course of this study that might influence your health, welfare, or willingness to be in this study.

WHO DO I CONTACT IF I HAVE QUESTIONS, CONCERNS, OR COMPLAINTS?

MU IRB: CONSENT
HS IRB USE ONLY

Approval Date: December 12, 2018

Expiration Date: June 13, 2019 
Please contact Jill Kanaley (573-882-2519) if you have questions about the research. Additionally, you may ask questions, voice concerns or complaints to the research team.

\section{WHOM DO I CALL IF I HAVE QUESTIONS OR PROBLEMS?}

If you have any questions regarding your rights as a participant in this research and/or concerns about the study, or if you feel under any pressure to enroll or to continue to participate in this study, you may contact the University of Missouri Campus Institutional Review Board (which is a group of people who review the research studies to protect participants' rights) at (573) $882-9585$ or umcresearchcirb@missouri.edu.

You may ask more questions about the study at any time. For questions about the study or a researchrelated injury, contact Jill Kanaley at 573-882-2519

A copy of this Informed Consent form will be given to you before you participate in the research.

Are you participating in any other research projects? Yes No

We will be storing your blood samples. If we should want to measure something in your blood not listed above (e.g. glucose, insulin, etc), we would like permission to go ahead and use your samples. Usually these measurements are to look at other hormone concentrations.

Please check below if we can keep your samples to measure other hormones. YES NO

I authorize the University of Missouri- Dept. of Nutrition and Exercise Physiology to keep this information and any information gained from my participation in their studies in a database so that they may contact me regarding future studies. YES NO

Fat Biopsies: We will be storing your fat samples. If we should want to measure something in your fat other than inflammatory markers, histology or metabolic markers, etc, we would like permission to go ahead and use your samples. Usually these measurements are to look at new markers that become available.

Please check below if we can keep your samples to measure other hormones. YES NO

\section{SIGNATURES}

I have read this consent form and my questions have been answered. My signature below means that I do want to be in the study. I know that I can remove myself from the study at any time without any problems.

\section{Subject}

Legal Guardian/Advocate/Witness (if required)*
Date

Date 


\section{$\overline{\text { Additional Signature (if required) (identify relationship to subject)* }} \quad \overline{\text { Date }}$}

\section{Optional Fat Biopsy}

I am agreeing to the additional portion of the study to have 3 fat biopsies. All my questions have been answered. My signature below indicates that I do want to also have the fat biopsies, knowing that I decline from participating in this part of the study at any time without any problems.

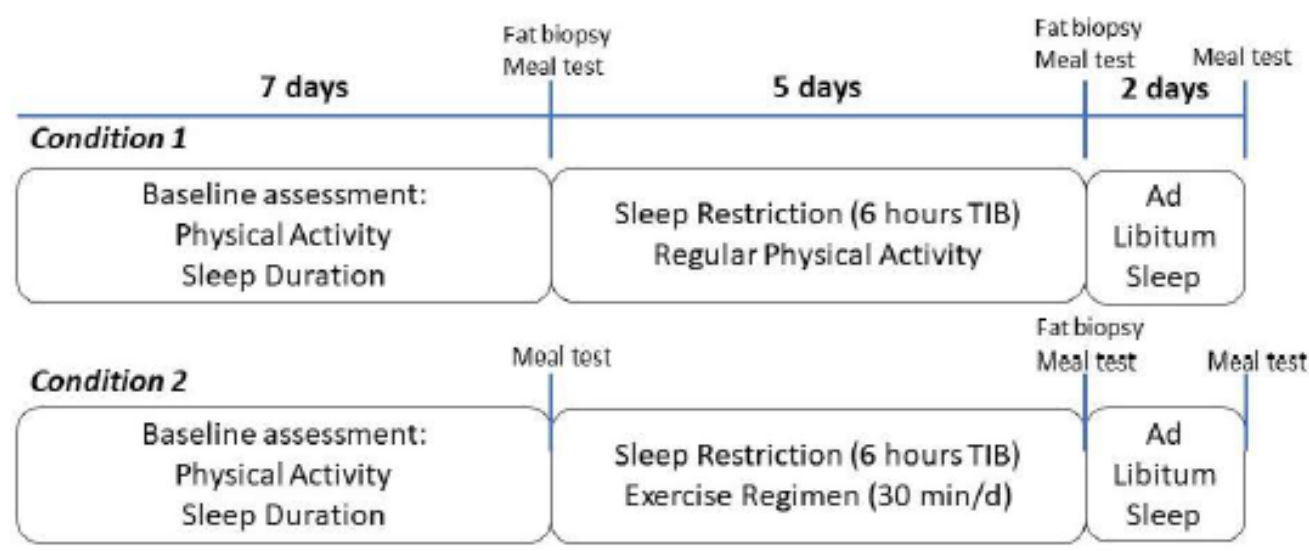




\section{Sleep, Exercise, and Insulin Sensitivity}

\section{Screening}

Screening ID:

Study ID:

Gender

Age:

D.O.B.:

Height:

Waist Circumference:

Medications:

Questionnaires: Berlin: NO

Qualify? YES NO

PSQl:

Date:

Consent signed?

BMI:

(cm)

Weight: ( $\mathrm{kg})$

Hip Circumference: (cm)

Notes:

Berlin: Low Risk (0-1 category scores "positive"

High Risk (2-3 categories score "positive")

PSQI: $\geq 5$ indicates a "poor" sleeper

ESS: 0-5 Lower Normal Daytime Sleepiness

6-10 Higher Normal Daytime Sleepiness

13-15 Moderate Excessive Daytime Sleepiness

11-12 Mild Excessive Daytime Sleepiness

16-24 Severe Excessive Daytime Sleepiness

DEXA

\%Fat: (\%)

Fat: (kg)

Lean: (kg)

Bone Density:

Ambulatory $\mathrm{O2}$ sensor to take home:

Events per hour:

(must be $<15$ events/hour) 
Flow for SLEEP study (No biopsy protocol)

- 630 am warm up metabolic cart for RMR

- Thaw and fill blood collection tubes (purple top) with $20 \mathrm{uL}$ DPPIV inhibitor and $20 \mathrm{uL}$ Aprotinin (210 lab, Kanaley -80C)

- Keep on ice

- 7 am subject arrival

○ RMR

- 20 minutes to equilibrate, 15 minutes of data collection (11.2 on flow)

○ IV insertion

- 8 am (after RMR) pre blood samples $(-10,0)$ collected

○ $1 \mathrm{~mL}$ waste collection

○ $2.5 \mathrm{mLs}$

- YSI glucose analysis

- Cholestec lipid panel from time 0 draw

- Only for PRE visit of 1 st condition

- Consumption of 2 ensure shakes (located in $18 \mathrm{C}$ fridge or MUNCH walk in fridge)

- Encourage 10 minutes to finish drinks

- $2.5 \mathrm{mLs}$ of blood collected each draw

- Spin - plasma aliquots (2)

- After 60 minute blood draw

- Cognitive function testing, laptop -- PsyToolkit

- 2 practice tests and 1 recording test for each test (task switching, stroop, n-back)

- After 3rd round record information displayed and press space bar and select save data

- Ignore mean response time and error rate lines

- If blood draw disrupts testing, repeat testing

- DASS42 questionnaire on paper

- Remind subject of sleeping schedule for time till next blood draw session

- Sleep restriction period (M-F) - Normal waking hours, late to bed

- 6 hours of time in bed is expectation

- Weekend period - ad libitum

- No restrictions on time in bed 
Flow for SLEEP study (+ biopsy protocol)

- 530 am warm up metabolic cart for RMR

- Thaw and fill blood collection tubes (purple top) with 20 uL DPPIV inhibitor and $20 \mathrm{uL}$ Aprotinin (210 lab, Kanaley -80C)

- Keep on ice

- 6 am subject arrival

○ RMR

- 20 minutes to equilibrate, 15 minutes of data collection (11.2 on flow)

- IV insertion

- 7 am Adipose Tissue Biopsy

○ Clean

- Kanaley supplies

- Ice bag and bandages

- Pre blood samples $(-10,0)$ collected

- $1 \mathrm{~mL}$ waste collection

○ $2.5 \mathrm{mLs}$

- YSI glucose analysis

- Cholestec lipid panel from time 0 draw

- Only for PRE visit of 1 st condition

- Consumption of 2 ensure shakes (located in $18 \mathrm{C}$ fridge or $\mathrm{MUNCH}$ walk in fridge)

- Encourage 10 minutes to finish drinks

- $2.5 \mathrm{mLs}$ of blood collected each draw

- Spin - plasma aliquots (2)

- After 60 minute blood draw

- Cognitive function testing, laptop -- PsyToolkit

- 2 practice tests and 1 recording test for each test (task switching, stroop, n-back)

- After 3rd round record information displayed and press space bar and select save data

- Ignore mean response time and error rate lines

- If blood draw disrupts testing, repeat testing

- DASS42 questionnaire on paper

- Remind subject of sleeping schedule for time till next blood draw session

- Sleep restriction period (M-F) - Normal waking hours, late to bed

- 6 hours of time in bed is expectation

- Weekend period - ad libitum

- No restrictions on time in bed 
This Diary is designed to gather information about your night of sleep, and the activity the takes place prior to that night of sleep. You will fill the top portion out before going to bed, and the bottom portion when you wake up in the morning.

Please remember to press the event marker on your Actiwatch (by holding the side button for 3 seconds) when you get into bed at night and when you get out of bed in the morning.

Evening: Please fill this section out right before you go to bed on

I had alcoholic drinks today.

I had caffeine drinks today.

I completed the following exercise today:

\begin{tabular}{|c|c|c|}
\hline Type & Duration & Description \\
\hline & & \\
\hline & & \\
\hline & & \\
\hline
\end{tabular}

If you removed the watch:

\begin{tabular}{|c|c|c|}
\hline Time OFF & Time ON & Reason \\
\hline & & \\
\hline & & \\
\hline
\end{tabular}

Medications (amount and time) taken today:

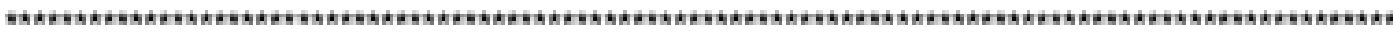

Next Morning: Please fill this section out the morning of

I napped for minutes yesterday.

I napped imes yesterday.

I went to bed last night at AM/PM

It took me

I woke up minutes to fall asleep.

I was awake for times last night.

My final wake up time was I got out of bed at minutes in the middle of the night.

I would rate my quality of sleep last night as

1. Very poor

2. Poor

3. Fair

4. Good

5. Excellent 


\section{Sleep, Exercise, and Insulin Sensitivity}

Participant ID\#:

Date:

Visit: NoEX/EX Pre / Post / Post Ad-lib

Weight:

(kg) Height:

(cm)

Blood Pressure:

1 Pulse:

REE: Start Time:

Saved file as:

Adipose Tissue Biopsy:

Histology:

Insulin stimulation:

$\begin{array}{llllll}0 & 0.1 & 0.5 & 1 & 5 & 10 \\ 0 & 10 & & & & \end{array}$

Isoproterenol stimulation:

\# Frozen samples:

\# of biopsies taken:

Mixed Meal Test

Time

Blood Glucose (mg/dL)

$-10$

$\longrightarrow$

${ }^{5}$

10

15

30

45

60

90

120

150

180

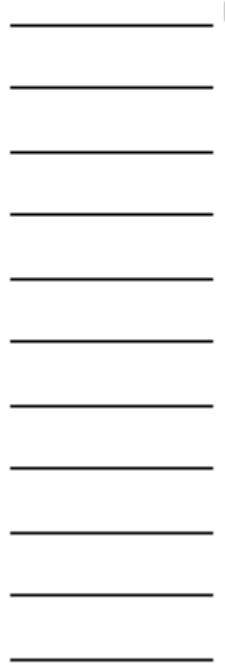

Cholestech Lipid Panel: pre to

TG

Cholesterol

Drink start time:
HDL

LDL

non $H D L$ 


\section{Sleep, Exercise, and Insulin Sensitivity}

\section{Questionnaires}

DASS42:

Stroop

1. Stroop Effect (I-C):

2. Congruent:

3. Incongruent:

4. Mean Response time:

5. Error Rate:

$\mathrm{N}$-Back

1. Error count in missing 3 -back items:

2. Wrongly reporting there was an 3 back item:

3. Mean Response time:

4. Error Rate:

Task Switching

1. RTs in single-task blocks:

2. RTs in mixed block, task-repeat trials:

3. RTs in mixed block, task=switch trials:

4. Task switch cost in RTs:

5. Mean Response Time:

6. Error Rate: 


\section{Appendix ii}

Exercise Physiology

Phone: 740-285-7685

Doctoral Candidate

University of Missouri

Email: jaywayneporter@gmail.com

Doctoral candidate aspiring to develop and execute meaningful and impactful health and wellness oriented scientific research.

Experienced human physiology researcher with strong communication, organizational, and laboratory skills.

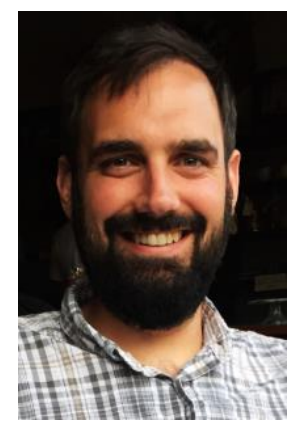

\section{EDUCATION}

2015-2020

$2013-2015$

Ph.D. Exercise Physiology, University of Missouri, Columbia, MO

- Doctoral Committee: Jill A. Kanaley, PhD (mentor/chair); Elizabeth J. Parks, PhD; Victoria J. Vieira-Potter, PhD; Guido Lastra-Gonzalez, MD; Christina S. McCrae, PhD

- Dissertation: Sleep, Exercise, and Insulin Sensitivity

2013-2015 M.S. Exercise and Nutrition Sciences, Montana State
University, Bozeman, MT
○ Mentor: Mary P. Miles PhD
O Additional completion of Verification Statement for the
Didactic Program in Dietetics

$2007-2011 \quad$ B.S. Nutrition and Community Health, The Ohio State University, Columbus, $\mathrm{OH}$

- Minor in Exercise Science

\section{RESEARCH INTERESTS}

- Exercise endocrinology and metabolism as related to obesity and type 2 diabetes.

- Adipose tissue inflammation and metabolism.

- Metabolic implications to reduced hours of sleep.

\section{CLINICAL TRIAL PROJECTS}

- Sleep, exercise, and insulin sensitivity: NCT03556410

- Dissertation Project; Examine the effects of a modest workweek sleep restriction pattern on physical activity and insulin sensitivity, and capacity of exercise to ameliorate metabolic implications of reduced sleep.

- Adipose tissue inflammation in individuals undergoing bariatric surgery: NCT03419273

- Determine the effects of menopause on adipose tissue depot-specific immunometabolic characteristics and examine immunometabolic sex differences in adipose tissue.

- Lowering impaired fasting glucose with exercise (LIFE): NCT03019510; NIH R01 DK101513 
- Determine the effects of exercise at different times of day on endogenous glucose production in relation to the Dawn Phenomenon.

- Diet Composition and Physical Inactivity on Insulin Sensitivity and $\beta$-cell Function: NCT03013764

- Determine the extent to which short-term high protein (HP) feeding may protect against the metabolic perturbations of physical inactivity (i.e. PPG, hyperinsulinemia, and insulin sensitivity).

- Metabolic Implications of Diet and Energy Intake during Physical Inactivity. Winn NC, Pettit-Mee R, Walsh LK, Restaino RM, Ready ST, Padilla J, Kanaley JA. Med Sci Sports Exerc. 2019 May;51(5):995-1005. doi: 10.1249/MSS.0000000000001892. PMID:30694977

- Low Intensity Physical Activity During Sitting on Glycemic Control and Vascular Function in Obese Individuals: NCT03419754

- Evaluate whether increased blood flow during sitting via low intensity physical activity (fidgeting) prevents the impairment in vascular function and poorer glycemic control associated with prolonged sitting.

- Sugar-sweetened beverages decrease benefits of exercise in overweight adults: NCT03576703

- Determine if exercise has an inflammatory lowering effect the day after exercise when caloric intake is matched with and without SSBs.

\title{
GRADUATE ASSISTANTSHIPS
}

\section{Graduate Research Assistant}

University of Missouri

PI: Jill Kanaley, PhD

R01 NIDDK: Dawn Phenomena: Lowering Impaired Fasting Glucose with Exercise (LIFE).

Clinical Trials NCT number: NCT03019510

Montana State University

PI: Mary P Miles, PhD

Nutrition Research Laboratory

NIH CTR-IN - Mountain West Research Consortium: Sugar-sweetened beverages decrease benefits of exercise in overweight adults. NCT03576703

$\mathrm{NIH}$ - MT INBRE: Identification of adiposity-based differences in postexercise metabolic responses to optimize health benefits.

\author{
Graduate Teaching Assistant \\ University of Missouri \\ NEP 4850 - Physiology of Exercise - Terese Zidon / Jill Kanaley, PhD \\ Spring 2016 \\ Laboratory instructor \\ NEP 4200/7200 - Sports Performance and Conditioning - James Mann,


Spring 2016

Online Lectures: Cardiovascular \& Respiratory Physiology;

Adaptations to Aerobic Training; Bioenergetics - Energy Systems and Substrate Metabolism; Skeletal Muscle Physiology.

Montana State University

Kinesiology 105 - Foundations of Exercise Science - Milica McDowell, DPT Fall '14 and Spring '15 Semesters

Lecture instruction

\section{SCHOLARSHIPS and AWARDS}

2019 - Doctoral Student Investigator Award

New England American College of Sports Medicine (NEACSM)

Conference

Project: Modest sleep restriction, exercise, and insulin sensitivity.

2019 - Mabel Campbell/Campbell-Harrison Scholarship

College of Human Environmental Sciences, University of Missouri

2019 - James L. McGregor Scholarship in Health and Exercise Sciences

Nutrition and Exercise Physiology, College of Human Environmental

Sciences, University of Missouri

2019 - Research Recognition Award

Endocrinology \& Metabolism Section, Experimental Biology

Project: Age, sex, and depot differences in adipose tissue from obese subjects.

2019 - Professional Presentation Travel Award

Graduate School, University of Missouri

2018 - Edward J. O’Brien Scholarship

Nutrition and Exercise Physiology, College of Human Environmental

Sciences, University of Missouri

Exhibiting leadership and having made contributions to the Exercise Physiology Program.

2016 - 9th Annual Course on Isotope Tracers in Metabolic Research: Principles and Practice of Kinetic Analysis

National Institute of Health/National Mouse Metabolic Phenotyping Centers

2015 - Marion K. and Vernon W. Piper Distinguished Doctoral Fellowship University of Missouri - College of Human Environmental Sciences

2014 - Travel Scholarship

Montana State University - Graduate School / College of Education, Health, and Human Development 


\section{GRANT SUPPORT}

2018 - University of Missouri Research Council Grant

Sleep Restriction and Physical Activity, PI: Jill Kanaley, PhD $\$ 10,000$

2015 - University of Missouri - Corporate Advisory Board Research Grant Department of Nutrition and Exercise Physiology Jay Porter; Jill Kanaley, PhD; Victoria Vieira-Potter, PhD Project: Anti-inflammatory effects of exercise training in adipose tissue do not require FGF21. $\$ 4,000$

\section{PUBLICATIONS}

1. Anti-inflammatory effects of exercise training in adipose tissue do not require FGF21. Porter JW, Rowles JL 3rd, Fletcher JA, Zidon TM, Winn NC, McCabe LT, Park YM, Perfield JW 2nd, Thyfault JP, Rector RS, Padilla J, Vieira-Potter VJ. J Endocrinol. 2017 Nov;235(2):97-109. doi: 10.1530/JOE-17-0190. Epub 2017 Aug 1. PMID: 28765264

2. Concentric and eccentric exercise, glycemic responses to a postexercise meal, and inflammation in women with high versus low waist circumference. Miles MP, Horrigan LC, Jay SE, Brown KM, Porter JW, Steward AN. Appl Physiol Nutr Metab. 2016 Dec;41(12):1262-1270. Epub 2016 Aug 24. PMID: 27841026

Manuscripts in Accepted:

- Age, sex, and depot-specific differences in adipose tissue estrogen receptors in individuals with obesity. Porter JW, Welly R, Spencer N, Pitt J, Vieira-Potter VJ, Kanaley JA.

Manuscripts in progress:

- Modest workweek sleep restriction does not influence steps, physical activity intensity, or insulin sensitivity in overweight adults. Jay W Porter, Ryan J Pettit-Mee, Travis Emerson, Cristina S McCrae, Guido Lastra, Victoria J.Vieira-Potter, Elizabeth J. Parks, Jill A Kanaley

- Post meal hypoglycemia with and without exercise in non-obese and obese individuals. Porter JW, Pettit-Mee RJ, Ready ST, Winn NC, Chockalingam A, Lastra Gonzalez G, Kanaley JA

\section{PRESENTATIONS}

Modest sleep restriction, exercise, and insulin sensitivity. Porter, JW., Pettit-Mee, RJ., Barnas, JL., Emerson, T., Kanaley, JA. New England chapter for American College of Sports Medicine (NEACSM) conference. ${ }^{* *}$ Oral presentation Doctoral Student Investigator Award 
Post meal hypoglycemia with and without exercise in non-obese and obese individuals. Porter, J.W., Pettit-Mee, R., Ready, S., Winn, N.C., Chockalingam, A., Gonzalez, G.L. and Kanaley, J.A..: Medicine \& Science in Sports \& Exercise, 51(6), pp.139-140. ${ }^{\star \star}$ Thematic poster session - Hormones and Obesity

Age, sex, and depot differences in adipose tissue from obese subjects. Jay W Porter, Rebecca Welly, Nicole Spencer, James Pitt, Victoria J Vieira-Potter, and Jill A Kanaley. The FASEB Journal 2019 33:1_supplement, 752.5-752.5 ** 2019 Research Recognition Award - Endocrinology \& Metabolism Section, Experimental Biology

Exercise normalizes dysfunctional adipose tissue phenotype in FGF21-null mice. Jay Porter, Joe L. Rowles III, Justin A. Fletcher, Terese M. Zidon, Nathan C. Winn, Leighton McCabe, Young Min Park, James W. Perfield, John P. Thyfault, R. Scott Rector, Jaume Padilla, Victoria J. Vieira-Potter. Medicine \& Science in Sports \& Exercise. 49(5S):1028, May 2017.

Role of estrogen receptor alpha in protective effects of soy in adipose tissue following ovariectomy. McCabe LT, Zidon TM, Welly RJ, Porter JW, Winn NC, Stricklin OE, Gastecki ML, Lubahn DB, Padilla J, Vieira-Potter VJ. The FASEB Journal 2017 31:1_supplement, 646.39-646.39

Exercise, inflammation, and sugar consumption in adults with normal versus impaired fasting glucose tolerance. Jay W. Porter, Andrea N. Steward, John T. Halvorson, John G. Seifert, Sarah Bronsky, Ashley E. Connors, Mary P. Miles. Medicine \& Science in Sports \& Exercise. 48(5S):486-487, May 2016.

${ }^{* *}$ Thematic poster session - Nutrition, Physical Activity, and Chronic Disease

Effect of hypertriglyceridemia, sugar ingestion, and exercise on substrate metabolism in overweight and obese individuals. Steward, Andrea N.; Porter, Jay W.; Halvorson, John T.; Connors, Ashley E.; Bronsky, Sarah; Seifert, John G.; Miles, Mary P. Medicine \& Science in Sports \& Exercise. 48(5S):523, May 2016.

Metabolic flexibility and substrate utilization following exercise in hypertriglyceridemic versus normal triglyceridemic individuals. Halvorson, John T.; Steward, Andrea N.; Porter, Jay W.; Bronsky, Sarah; Connors, Ashley E.; Seifert, John G.; Miles, Mary P. Medicine \& Science in Sports \& Exercise. 48(5S):385, May 2016.

Exercise induced inflammation changes influenced by body composition and waist circumference. Jay W. Porter, Andrea N. Steward, Laura C. Horrigan, Karen M. Brown, Sara E. Jay, Mary P. Miles. Medicine \& Science in Sports \& Exercise. 47(5S):891, May 2015.

Downhill walking versus running as exercise models to study inflammation in women. Steward, Andrea N.; Porter, Jay W.; Horrigan, Laura C.; Brown, Karen 
M.; Jay, Sara; Miller, Colleen P.; McNulty, Katherine AM; Miles, Mary P. Medicine \& Science in Sports \& Exercise. 47(5S):888-889, May 2015.

Influence of recommended recovery meal on insulin indices in women of varying body fat percentages. Horrigan, Laura C.; Jay, Sara E.; Brown, Karen M.; Porter, Jay W.; Steward, Andrea N.; Miles, Mary P. Medicine \& Science in Sports \& Exercise. 46(5S):306, May 2014.

Body composition and inflammation responses to concentrically and eccentrically biased exercise. Brown, Karen M.; Horrigan, Laura C.; Jay, Sara E.; Steward, Andrea N.; Porter, Jay W.; Miles, Mary P. Medicine \& Science in Sports \& Exercise. 46(5S):920, May 2014.

Glycemic response to recovery meal differs following concentric and eccentric exercise bouts. Jay, Sara E.; Brown, Karen M.; Horrigan, Laura C.; Steward, Andrea N.; Porter, Jay W.; Miles, Mary P. Medicine \& Science in Sports \& Exercise. 46(5S):360, May 2014.

\section{PEER REVIEWER}

- Invited: Medicine and Science in Sports and Exercise

- Co Reviewer Jill A. Kanaley, PhD: European Journal of Nutrition

\section{SKILLS}

Laboratory: Assays/ELISA: colorimetric, fluorometric, single and multiplex approaches; Stable isotope tracers for metabolic research; Gas Chromatography - Mass Spectrometry; Western Blot; RT-PCR; Formalin fixed, paraffin imbedded Histological Analysis; Thin Layer Chromatography; Yellow Springs Instrument (YSI) Glucose / Lactate Analyzer; Tissue processing: human and animal, fresh, frozen and fixed; hormone/drug tissue stimulation protocols

Human: Stress Testing: 12 lead EKG; Respiratory Exchange: Indirect calorimetry, Exercise response; Body Composition: Dual-energy X-Ray Absorptiometry, BOD POD; Oral Glucose / Mixed Meal Tolerance Testing; Blood drawing via butterfly needle and catheters; Research Meal Prep - Recipe design, cooking, and packaging

Computer: Office; iWork; G Suite; Statistical Software - SPSS, GraphPad Prism, $\mathrm{R}, \mathrm{G}^{\star}$ Power, Excel StatPlus

\section{PROFESSIONAL AFFILIATIONS}

2013 - Present 2016 - Present 2018 - Present
American College of Sports Medicine (ACSM) American Society of Nutrition (ASN) American Physiologic Society (APS) 


\section{PROFESSIONAL DEVELOPMENT}

Isotope Tracers in Metabolic Research

November, 2016

9th Annual Course on Isotope Tracers in Metabolic Research: Principles and Practice of Kinetic Analysis

National Institute of Health/National Mouse Metabolic Phenotyping

Centers

Vanderbilt University

\section{Grad Writers Academy}

Oct. 8th, 2016

Nominated by Director of Graduate Studies and Adviser.

\section{PUBLIC OUTREACH}

Exercise is Medicine, various MIZZOU education and outreach events Exercise Education, Diabetes Month, Capital Regional Medical Center, Jeff City, MO (11/16/17)

Radio Friends with Paul Pepper, Exercising with Diabetes (aired 12/12/17)

\section{CERTIFICATIONS}

CPR and First Aid (2006 - Present)

\section{PREVIOUS WORK EXPERIENCE}

Nutrition Specialist - King Soopers, Longmont/Boulder, CO

October, 2011 - July, 2013

Assisted customers with their health and wellness goals via natural and organic supplements through nutrition information, counseling, and guidance.

Communicated with vendors and sales representatives, and monitored and controlled inventory ordering and receiving. Provided gluten-free diet tours and information sessions throughout Colorado. 
Jay Wayne Porter was born in Portsmouth, $\mathrm{OH}, 1989$ to Kenneth and Lynn Porter. After graduate from Piketon High School in 2007, Jay enrolled at The Ohio State University in Columbus, $\mathrm{OH}$. He earned a Bachelor of Science degree in Nutrition and Community Health with a minor in Exercise Science. After undergrad, Jay moved to Boulder, CO, and worked as a Nutrition Specialist for King Soopers. In the Fall of 2013, Jay entered graduate school at Montana State University, where he earned a Master of Science degree in Exercise and Nutrition Sciences with mentorship from Dr. Mary P. Miles. In the Fall of 2015, Jay entered graduate school at the University of Missouri, where he earned a Doctor of Philosophy degree in Exercise Physiology under the mentorship of Dr. Jill A. Kanaley. Jay plans to pursue a career in research with a focus on obesity and type 2 diabetes. 